\title{
(ब)

AUTARQUIA ASSOCIADA À UNIVERSIDADE DE SÃO PAULO

Determinação de contaminantes inorgânicos em pescados consumidos em São Paulo como contribuição à garantia da segurança alimentar

BRUNO TAPPIZ

Dissertação apresentada como parte dos requisitos para obtenção do Grau de Mestre em Ciências na Área de Tecnologia Nuclear - Aplicações

Orientador:

Prof. Dr. Edson Gonçalves Moreira

São Paulo

2019 
INSTITUTO DE PESQUISAS ENERGÉTICAS E NUCLEARES

Autarquia associada à Universidade de São Paulo

Determinação de contaminantes inorgânicos em pescados consumidos em São Paulo como contribuição à garantia da segurança alimentar

BRUNO TAPPIZ

Dissertação apresentada como parte dos requisitos para obtenção do Grau de Mestre em Ciências na Área de Tecnologia Nuclear - Aplicações

Orientador:

Prof. Dr. Edson Gonçalves Moreira 
Fonte de Financiamento: CNPq (Processo 130043/2017-6) e FAPESP (Processo 2015/10774-9 e Processo 2009/01452-7)

Autorizo a reprodução e divulgação total ou parcial deste trabalho, para fins de estudo e pesquisa, desde que citada a fonte

Como citar:

TAPPIZ, B. Determinação de contaminantes inorgânicos em pescados consumidos em São Paulo como contribuição à garantia da segurança alimentar. 2019.

105 p. Dissertação (Mestrado em Tecnologia Nuclear), Instituto de Pesquisas Energéticas e Nucleares, IPEN-CNEN/SP, São Paulo. Disponível em: (data de consulta no formato: $\mathrm{dd} / \mathrm{mm} / \mathrm{aaaa}$ )

Ficha catalográfica elaborada pelo Sistema de geração automática da Biblioteca IPEN/USP, com os dados fornecidos pelo(a) autor(a)

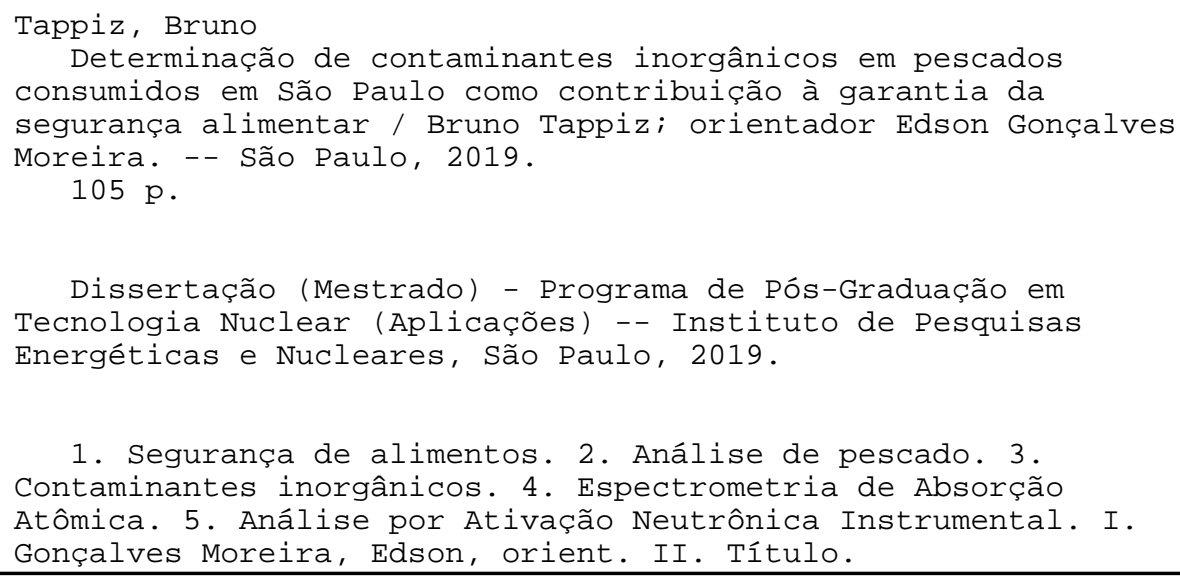


Dedico este trabalho à minha mãe Agueda, irmão Márcio e tia Marta. 


\section{Agradecimentos}

Primeiramente gostaria de agradecer ao meu núcleo familiar. Tenho certeza que sem o apoio e a credibilidade por parte deles, esta jornada teria sido muito mais difícil.

Gostaria de cumprimentar de forma muito cordial o meu orientador, Dr. Edson Gonçalves Moreira, por este tempo em que trabalhamos juntos. Além de por todos os ensinamentos que, naturalmente ocorrem durante o mestrado, teve para comigo sempre uma abordagem muito respeitosa, paciente e humanizada na relação aluno-professor. Terei sempre comigo esses bons momentos vividos nessa incrível experiência de vida. Obrigado por ser este grande amigo!

À Tatyane por aceitar ter alguém do seu lado com uma rotina relativamente incomum, sempre me respeitando, apoiando e acreditando neste projeto, sendo paciente nos momentos mais difíceis. Te agradeço todos os dias.

Aos meus colegas de trabalho do Centro do Reator de Pesquisas (CERPq) e também aos professores deste departamento. O CERPq é esse lugar incrível de trabalhar, e esse mérito é de vocês.

À Carolina, amiga de longa data da graduação. Foi muito legal trilhar no meio acadêmico do seu lado.

À Nicole, então colega da mesa ao lado, que com certeza será amizade de uma vida.

À Carolina Theophilo por toda ajuda prestada especialmente no laboratório de Espectrometria de Absorção Atômica.

Ao Instituto de Pesquisas Energéticas e Nucleares (IPEN - CNEN/SP) que tornou possível a execução do presente trabalho.

Ao Conselho Nacional de Desenvolvimento Tecnológico e Científico (CNPq processo 130043/2017-6) pelo apoio financeiro via a bolsa de mestrado concedida.

À Fundação de Amparo à Pesquisa do Estado de São Paulo (FAPESP processos 2015/10774-9 e 2009/01452-7) pelo fomento à presente pesquisa. 
À todos que participaram deste trabalho diretamente e indiretamente. Karen Campos Fabiano, Dra. Ana Paula de Souza Lima, Dr. Edson Gonçalves Moreira, Dra. Marina Beatriz Agostini Vasconcellos. Com certeza, sem a contribuição de todos vocês, esse trabalho estaria sendo apresentado de forma completamente diferente. 


\section{RESUMO}

TAPPIZ, B. Determinação de contaminantes inorgânicos em pescados consumidos em São Paulo como contribuição à garantia da segurança alimentar. 2019, 105 p. Dissertação (Mestrado em Tecnologia Nuclear) Instituto de Pesquisas Energéticas e Nucleares - IPEN CNEN/SP. São Paulo.

O consumo do pescado é importante para a saúde humana pelo fato desse alimento ser fonte de proteína de alta qualidade, vitaminas, nutrientes essenciais e dois ácidos poli-insaturados ômega-3. Entretanto, o pescado também pode apresentar risco à saúde humana se estiver contaminado por substâncias tóxicas. Visando avaliar o teor de elementos essenciais e tóxicos, foram utilizado as técnicas de Análise por Ativação Neutrônica e Espectrometria de Absorção Atômica na determinação dos elementos As, Br, $\mathrm{Cd}, \mathrm{Cl}, \mathrm{Co}, \mathrm{Cr}, \mathrm{Cs}, \mathrm{Fe}, \mathrm{Hg}, \mathrm{K}, \mathrm{Mg}, \mathrm{Mn}, \mathrm{Na}, \mathrm{Pb}, \mathrm{Rb}$, Sb, Se e Zn nos tecidos comestíveis (filés) de seis pescados dentre os mais consumidos na cidade de São Paulo: corvina Micropogonias furnieri (Desmarest, 1823); pescada - Cynoscion leiarchus (Cuvier, 1830); robalo - Centropomus undecimalis (Bloch, 1792); sardinha - Sardinella brasiliensis (Steindachner, 1879); anchova - Pomatomus saltatrix (Linnaeus, 1766) e tainha - Mugil liza (Valenciennes, 1836). Para validar os métodos analíticos utilizados em relação à exatidão, foram utilizados o índice z e o valor de HorRat em materiais de referência certificados analisados sob as mesmas condições das amostras. Os elementos $\mathrm{Br}, \mathrm{K}$ e $\mathrm{Na}$ foram determinados por duas modalidades de irradiação e o teste-t de Student foi utilizado para verificar se havia ou não diferença significativa entre as técnicas. Na determinação dos elementos essenciais e potencialmente tóxicos, foi possível a construção de banco de dados para os elementos $\mathrm{Br}, \mathrm{Cl}, \mathrm{Co}, \mathrm{Cs}, \mathrm{Fe}, \mathrm{K}, \mathrm{Mg}, \mathrm{Mn}, \mathrm{Na}, \mathrm{Rb}$, Se e $\mathrm{Zn}$ para potenciais futuras discussões. Para avaliar se havia ou não risco à segurança alimentar, foram comparado os teores de $\mathrm{As}, \mathrm{Cd}, \mathrm{Hg}$ e $\mathrm{Pb}$ com a legislação vigente no Brasil e com valores internacionais. Em relação à segurança alimentar, para os contaminantes $\mathrm{Cd}$ e $\mathrm{Pb}$ foram obtidos teores abaixo de todos os limites técnicos usados neste trabalho. Para As, a maior parte deve estar na forma orgânica, portanto, a determinação de $\mathrm{Hg}$ se mostrou determinante. De forma geral, não haveria perigo no consumo da sardinha, pescada, tainha, corvina e robalo, enquanto que para a anchova foi inconclusivo.

Palavras-chave: Segurança de alimentos, análise de pescado, contaminantes inorgânicos, Espectrometria de Absorção Atômica, Análise por Ativação Neutrônica Instrumental. 


\begin{abstract}
TAPPIZ, B. Determination of inorganic contaminants in fish consumed at São Paulo city as a contribution for assuring food safety. 2019, 105 p. Dissertação (Mestrado em Tecnologia Nuclear) Instituto de Pesquisas Energéticas e Nucleares - IPEN - CNEN/SP. São Paulo.
\end{abstract}

Fish consumption is important for human health because this food is a source of high-quality protein, vitamins, essential nutrients and two kinds of omega-3 polyunsaturated acids. However, fish consumption may present risk to human health if contaminated by toxic substances. With the aim of evaluating the content of essential and toxic elements, the techniques of Instrumental Neutron Activation Analysis and Atomic Absorption Spectrometry were used to determine $\mathrm{As}, \mathrm{Br}, \mathrm{Cd}, \mathrm{Cl}, \mathrm{Co}, \mathrm{Cr}, \mathrm{Cs}, \mathrm{Fe}, \mathrm{Hg}, \mathrm{K}, \mathrm{Mg}, \mathrm{Mn}, \mathrm{Na}$, $\mathrm{Pb}, \mathrm{Rb}, \mathrm{Sb}$, Se and $\mathrm{Zn}$ in the edible tissues (fillet) of six of the most consumed fishes at São Paulo city: whitemouth croaker - Micropogonias furnieri (Desmarest, 1823), smooth weakfish - Cynoscion leiarchus (Cuvier, 1830), common snook - Centropomus undecimalis (Bloch, 1792), Brazilian sardine - Sardinella brasiliensis (Steindachner, 1879), bluefish Pomatomus saltatrix (Linnaeus, 1766) and lebranche mullet - Mugil liza (Valenciennes, 1836). To validate the analytical methods for accuracy, $z$-score and HorRat values were applied to certified reference materials analyzed under the same conditions of samples. The elements $\mathrm{Br}, \mathrm{K}$ and $\mathrm{Na}$ were determined by two irradiation modalities, and the Student's ttest was used to verify whether there were significant differences between the modalities. In the analysis of essential and potentially toxic elements, it was possible to create a database for $\mathrm{Br}, \mathrm{Cl}, \mathrm{Co}, \mathrm{Cs}, \mathrm{Fe}, \mathrm{K}, \mathrm{Mg}, \mathrm{Mn}, \mathrm{Na}, \mathrm{Rb}, \mathrm{Se}$ and $\mathrm{Zn}$ for potential future discussions. In order to assess food safety risks, the levels of $\mathrm{As}, \mathrm{Cd}, \mathrm{Hg}$ and $\mathrm{Pb}$ were compared with the Brazilian's law and international values. Regarding food safety, $\mathrm{Cd}$ and $\mathrm{Pb}$ contents were bellow all technical limits used in this study. As for As, most part of this element may be in organic form, therefore the $\mathrm{Hg}$ analysis was determinant. In general, there would be no risk in the consumption of Brazilian sardine, smooth weakfish, lebranche mullet, whitemouth croaker and common snook, while for bluefish it was inconclusive.

Key words: Food safety, fish analysis, inorganic contaminants, Atomic Absorption Spectrometry, Instrumental Neutron Activation Analysis. 


\section{LISTA DE TABELAS}

Tabela 1 - Consumo do pescado em algumas capitais brasileiras ................................... 17

Tabela 2 - Principais espécies de pescado comercializado no CEAGESP em 2009 ........... 18

Tabela 3 - Legislação brasileira e outras que estabelecem valores máximos de elementos

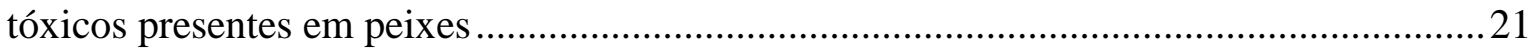

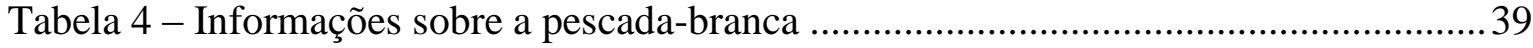

Tabela 5 - Informações sobre os hábitos alimentares dos pescados .................................. 40

Tabela 6 - Medições biométricas (valores médios \pm desvio padrão, $n=10$, valores mínimos e máximos entre parênteses) e R, relação da massa do peixe inteiro pelo tecido comestível

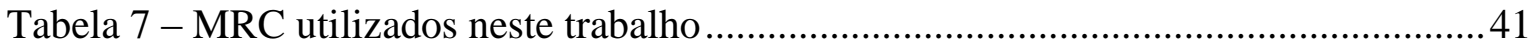

Tabela 8 - Volumes utilizados pelas pipetas automáticas .................................................. 43

Tabela 9 - Valores de média, desvio padrão relativo (DPR) e erro relativo (ER) $(n=12) 43$

Tabela 10 - Valores de média, DPR e ER do volume do balão volumétrico $(n=11) \ldots \ldots . . .44$

Tabela 11 - Cálculo das massas dos elementos nos padrões pipetados ............................... 45

Tabela 12 - Parâmetros dos radionuclídeos utilizados na INAA de curta duração...............46

Tabela 13 - Parâmetros dos radionuclídeos utilizados na INAA de longa duração ............. 48

Tabela $14-\mathrm{L}_{\mathrm{D}}$ e $\mathrm{L}_{\mathrm{Q}}$ dos pescados analisados na INAA de curta duração (massa da

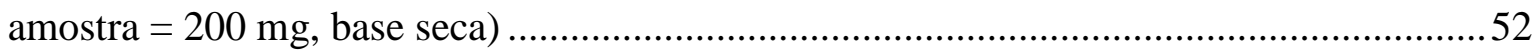

Tabela 15 - $\mathrm{L}_{\mathrm{D}}$ e $\mathrm{L}_{\mathrm{Q}}$ dos pescados analisados na INAA de longa duração (massa da

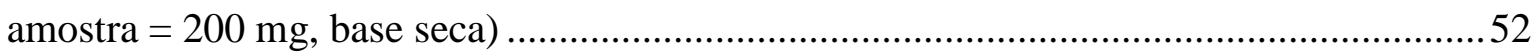

Tabela $16-\mathrm{L}_{\mathrm{D}}$ e $\mathrm{L}_{\mathrm{Q}}$ dos pescados analisados na AAS (massa da amostra $=350 \mathrm{mg}$, volume

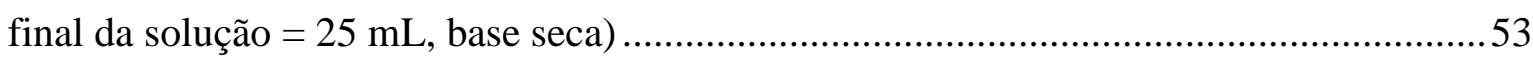

Tabela 17 - Fontes de incertezas utilizadas e sua conversão para forma de incerteza padrão

Tabela 18 - Incerteza expandida obtida para os elementos determinados por irradiação de curta duração

Tabela 19 - Incerteza expandida obtida para os elementos determinados por irradiação de longa duração.....

Tabela 20 - Fontes de incertezas utilizadas em AAS e sua conversão em incerteza padrão

Tabela 21 - Incerteza expandida obtida para elementos determinados por AAS 61 
Tabela 22 - Fração mássica obtida por INAA (média \pm incerteza expandida, $k=2$, base seca, $n=4$ ) e os valores certificado dos materiais de referência

Tabela 23 - Fração mássica obtida por INAA (media \pm incerteza expandida; $k=2$; base seca, $n=3$ ) e os valores certificados dos materiais de referência

Tabela 24 - Fração mássica obtida por INAA (media \pm incerteza expandida; $k=2$; base seca, $n=3$ ) e os valores certificados dos materiais de referência

Tabela 25 - Fração mássica obtida por AAS (média $\pm \mathrm{U}$; base seca, $n=3, k=2$ ) e os valores certificados dos materiais certificados

Tabela 26 - Valores de HorRat para os MRC analisados por irradiação de curta duração. 68 Tabela 27 - Valores de HorRat para os MRC analisados por irradiação de longa duração 69

Tabela 28 - Valores de HorRat para os MRC analisados em CV e ET AAS 70

Tabela 29 - Premissas e teste-t de Student entre os elementos Br, Na e K (valor de $p$ ) ..... 72

Tabela 30 - Compilação dos indicadores de qualidade, U e LQ 73

Tabela 31 - Fração mássica dos elementos determinados na base úmida (média \pm desvio padrão e intervalo entre parênteses)

Tabela 32 - Comparação dos elementos tóxicos em relação aos encontrados na literatura, base úmida, valores apresentados juntamente com desvio padrão ...................................... 76

Tabela 33 - Síntese dos resultados para verificação de risco para segurança alimentar ..... 87

Tabela 34 - Informações sobre o pescado sardinha .......................................................... 101

Tabela 35 - Informações sobre o pescado corvina ............................................................ 101

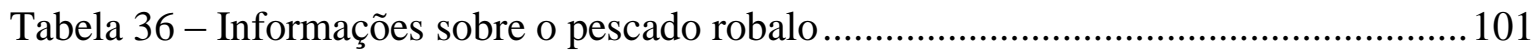

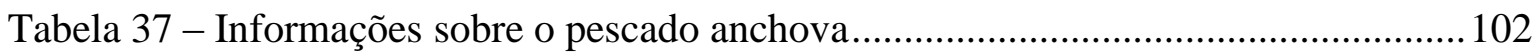

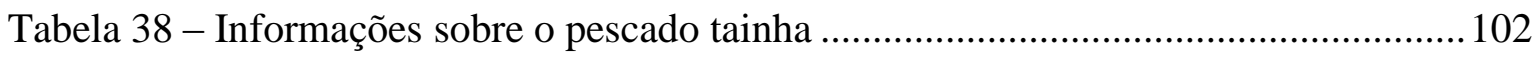

Tabela 39 - Determinação do teor de umidade residual da tainha .................................... 103

Tabela 40 - Determinação do teor de umidade residual do robalo ................................... 103

Tabela 41 - Determinação do teor de umidade da anchova ................................................ 103

Tabela 42 - Determinação do teor de umidade da pescada-branca ..................................... 104

Tabela 43 - Determinação do teor de umidade da sardinha ............................................... 104

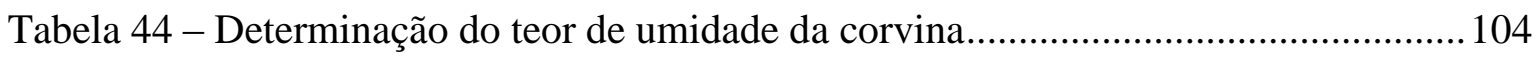

Tabela 45 - Determinação do teor de umidade dos MRC ................................................ 105 


\section{LISTA DE FIGURAS}

Figura 1 - Amostra sendo pesada no invólucro de polietileno em balança analítica

Figura 2 - Papéis de filtro cortados e sustentados por baquetas de vidro, de forma a se pipetar as soluções padrão

Figura 3 - Preparação do conjunto para irradiação de curta duração

Figura 4 - Preparação do conjunto para irradiação de longa duração

Figura 5 - Fluxograma do procedimento de diluição a partir da solução concentrada para obtenção das soluções da curva de calibração para $\mathrm{Hg}$

Figura 6 - Fluxograma do procedimento de diluição a partir da solução concentrada para obtenção das soluções da curva de calibração para $\mathrm{Cd}$

Figura 7 - Fluxograma do procedimento de diluição a partir da solução concentrada para obtenção das soluções da curva de calibração para $\mathrm{Pb}$ .51

Figura 8 - Diagrama de Ishikawa para o método de INAA .54

Figura 9 - Contribuições das incertezas padrão na INAA de curta duração ........................57

Figura 10 - Contribuições das incertezas padrão na INAA de longa duração .....................58

Figura 11 - Diagrama de Ishikawa com as incertezas de entrada usadas para AAS ...........59

Figura 12 - Contribuições das incertezas padrão na AAS

Figura 13 - Valores do índice z em forma gráfica para os MRC utilizados na irradiação de curta duração

Figura 14 - Valores do índice z em forma gráfica para os MRC utilizados na irradiação de longa duração..... 66

Figura 15 - Valores de índice z obtidos para os MRC por AAS...... 68

Figura 16 - Representação gráfica dos valores de HorRat para os MRC analisados por irradiação de curta duração

Figura 17 - Representação gráfica dos valores de HorRat para os MRC analisados na irradiação de longa duração .

Figura 18 - Representação gráfica dos valores de HorRat para os MRC analisados por CV e ET AAS.

Figura 19 - Comparação dos espécimes de pescada (P) e sardinha (S) com o limite legal de As

Figura 20 - Comparação dos espécimes de robalo (R) e anchova (A) com o limite legal de As 79 
Figura 21 - Comparação dos espécimes de corvina (C) e tainha (T) com limites legais de As 80

Figura 22 - Comparação dos espécimes de pescada (P) e corvina (C) com os limites legais de $\mathrm{Hg}$

Figura 23 - Comparação dos espécimes da sardinha (S) e tainha (T) com os limites legais de $\mathrm{Hg}$ 82

Figura 24 - Comparação dos espécimes do robalo (R) e anchova (A) com os limites legais de $\mathrm{Hg}$. 82

Figura 25 - Comparação dos espécimes da pescada $(\mathrm{P})$ com os limites técnicos para $\mathrm{Pb}$.. 84 Figura 26 - Comparação dos espécimes de pescada (P) e robalo (R) com os limites legais de $\mathrm{Cd}$. 85

Figura 27 - Comparação dos espécimes de sardinha (S) e tainha (T) com os limites legais de Cd. 86 


\section{LISTA DE ABREVIATURAS E SIGLAS}

AAS - Espectrometria de Absorção Atômica;

CEAGESP - Companhia de Entrepostos e Armazéns Gerais de São Paulo;

CNEN - Comissão Nacional de Energia Nuclear;

CONSEA - Conselho Nacional de Segurança Alimentar;

CV AAS - Espectrometria de Absorção Atômica por Geração de Vapor Frio;

DHA - Acido docosaexaenoico;

DPR - Desvio padrão relativo

EFSA - European Food Safety Authority;

EIRA - Elemento de Irradiação Refrigerado a Água;

EPA - Ácido eicosapentaenoico;

ER - Erro relativo;

EtHg - Eetilmercúrio;

ET AAS - Espectrometria de Absorção Atômica com Atomização Eletrotérmica;

EUA - Estados Unidos da América;

FAO - Organização das Nações Unidas para a Alimentação e Agricultura;

FDA - Food and Drug Administration;

FSANZ - Food Standard Australia New Zealand;

IAEA - Agência Internacional de Energia Atômica;

ICP AES - Espectrometria de Emissão Atômica com Plasma Acoplado Indutivamente;

ICP OES - Espectrometria de Emissão Óptica com Plasma Acoplado Indutivamente;

INAA - Análise por Ativação Neutrônica Instrumental;

INMETRO - Instituto Nacional de Metrologia, Qualidade e Tecnologia; 
IPEN - Instituto de Pesquisas Energéticas e Nucleares;

LAN - Laboratório de Ativação Neutrônica;

$\mathrm{L}_{\mathrm{D}}$ - Limite de detecção;

$\mathrm{L}_{\mathrm{Q}}$ - Limite de quantificação;

MeHg - Metilmercúrio;

MERCOSUL - Mercado Comum do Sul;

MIP OES - Espectrometria de Emissão Óptica com Plasma Induzido por Micro-ondas;

MRC - Material de referência certificado;

NIST - National Institute of Standard and Technology;

NRCC - National Research Council Canada;

POP - Poluente orgânico persistente;

SR-TXRF - Fluorescência de Raios X Total com Radiação de Sincrotron;

UE - União Europeia. 


\section{SUMÁRIO}

1 INTRODUÇÃ

1.10 consumo do pescado - dos benefícios aos riscos ........................................................... 16

1.2 Contaminantes inorgânicos em organismos aquáticos e sua ingestão pelo homem ............ 19

1.3 A importância da determinação de contaminantes inorgânicos em organismosaquáticos: segurança alimentar................................................................................................................................................ 20

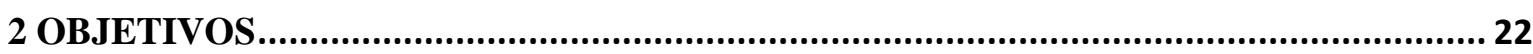

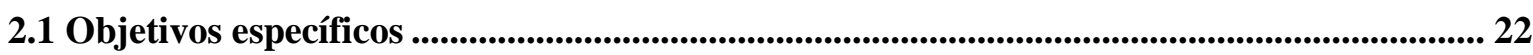

3 REVISÃO DA LITERATURA DE CONTAMINANTES EM PESCADOS ....................... 23

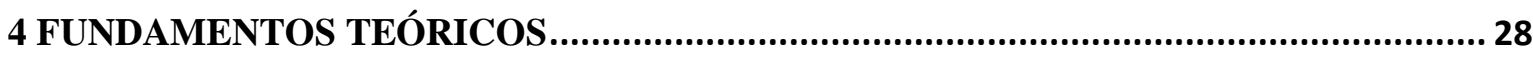

4.1 Análise por Ativação Neutrônica Instrumental (INAA) ............................................................... 28

4.1.1 O modelo matemático da análise por ativação neutrônica ...................................................... 29

4.2 Espectrometria de Absorção Atômica (AAS) ................................................................................. 31

4.2.1 Espectrometria de Absorção Atômica com Atomização Eletrotérmica (ET AAS) ....31

4.2.2 Espectrometria de Absorção Atômica por Geração de Vapor Frio (CV AAS) ........... 32

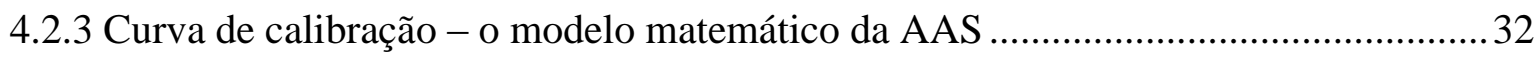

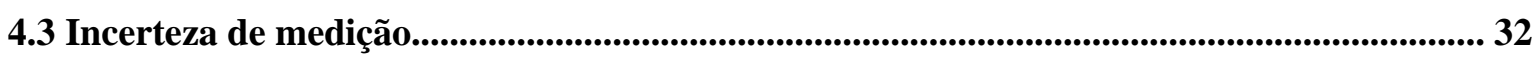

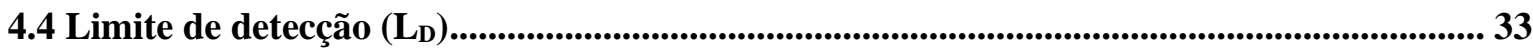

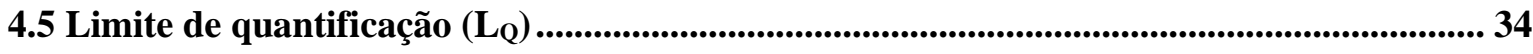

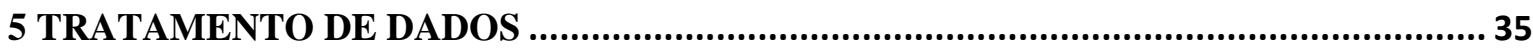

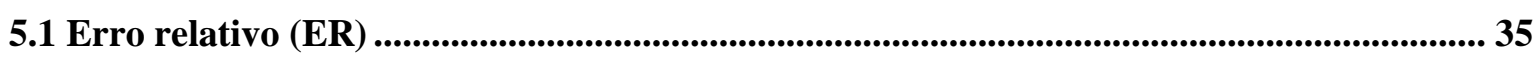

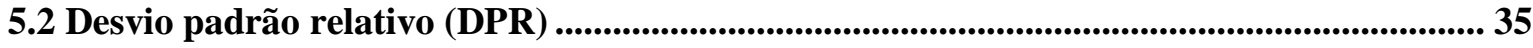

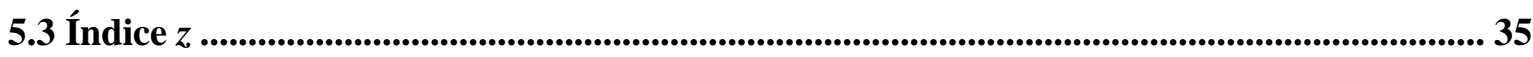

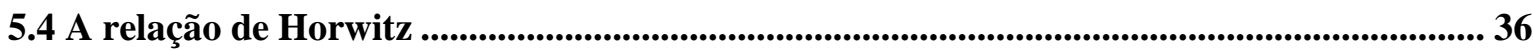

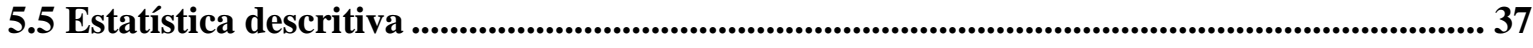

5.6 Teste de hipóteses .................................................................................................................................................. 37

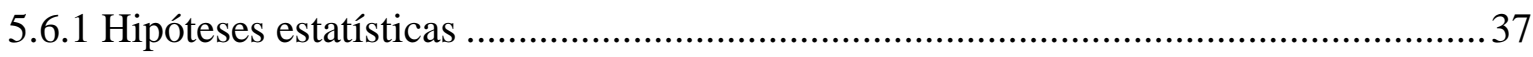

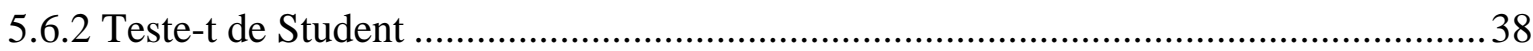

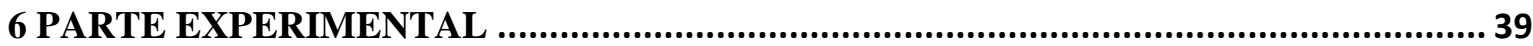




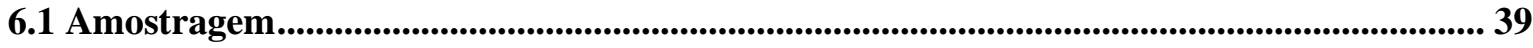

6.2 Determinação do teor de umidade........................................................................................................ 40

6.3 Preparação das amostras e padrões para irradiação ......................................... 41

6.3.1 Confecção dos invólucros de polietileno para o armazenamento das amostras e padrões

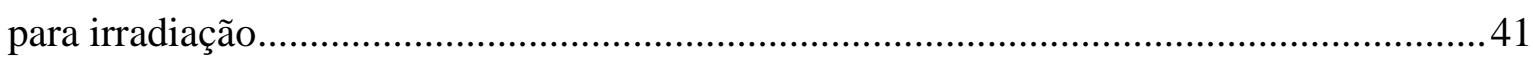

6.3.2 Pesagem das amostras de pescado e dos materiais de referência certificados ......................... 42

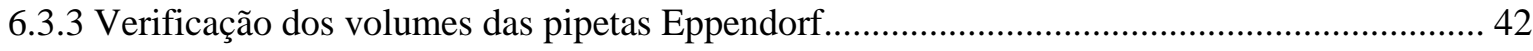

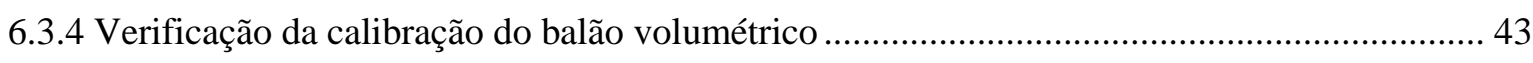

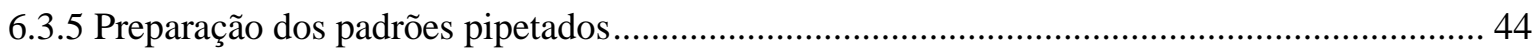

6.4 Irradiação e medição das radiações induzidas ............................................................................... 45

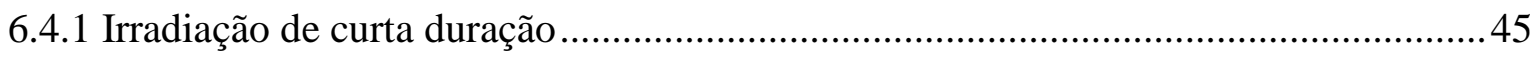

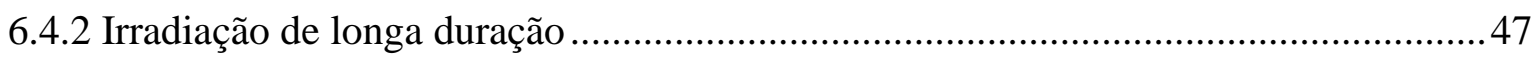

6.5 Espectrometria de Absorção Atômica (AAS) .................................................................................. 49

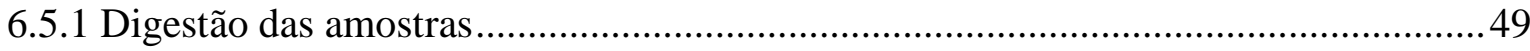

6.5.2 Espectrometria de Absorção Atômica por Geração de Vapor Frio (CV AAS) ...........49

6.5.3 Espectrometria de Absorção Atômica com Atomização Eletrotérmica (ET AAS) ....50

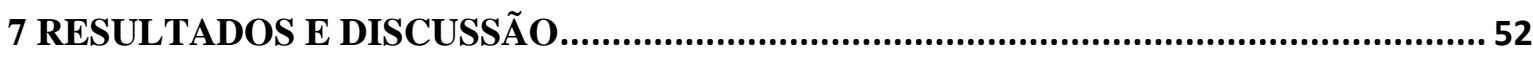

7.1 Limites de detecção $\left(L_{D}\right)$ e quantificação $\left(L_{Q}\right)$ das técnicas analíticas utilizadas ................ 52

7.1.1 Análise por Ativação Neutrônica Instrumental ......................................................52

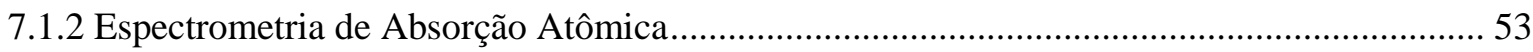

7.2 Cálculo da incerteza de medição.............................................................................................................. 53

7.2.1 Análise por Ativação Neutrônica............................................................................ 53

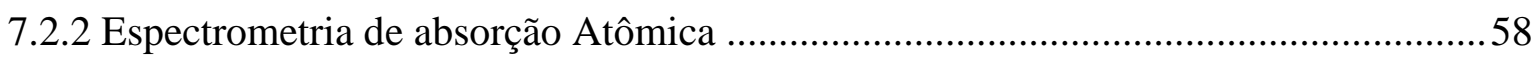

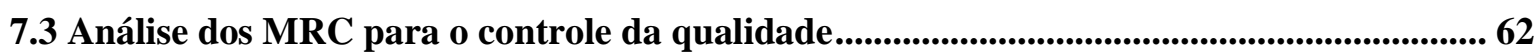

7.3.1 Índice $\mathrm{z}$

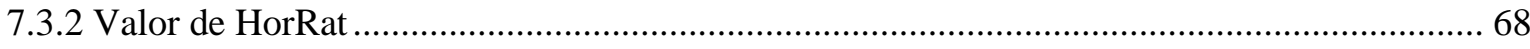

7.4 Análise dos pescados ................................................................................................................................. 71

7.4.1 Comparação entre irradiações de curta e longa duração.............................................71

7.4.2 Caracterização elementar dos tecidos comestíveis dos pescados ..............................73 
7.5 Comparação dos teores de contaminantes com as legislações................................................... 78

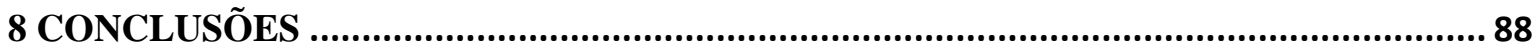

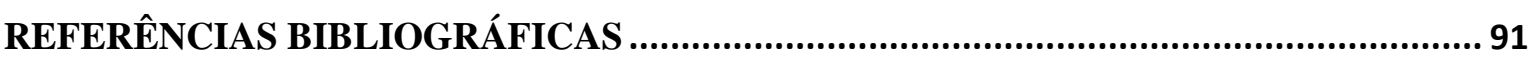

APÊNDICE A - Informações sobre a amostragem dos pescados ....................................... 101

APÊNDICE B - Teores de umidade das amostras e MRC.................................................. 103 


\section{INTRODUÇÃO}

\subsection{O consumo do pescado - dos benefícios aos riscos}

Pescado é definido como peixes, crustáceos, moluscos, anfíbios, répteis, equinodermos e outros animais aquáticos utilizados na alimentação humana (BRASIL, 2017). Alimento por sua vez é toda substância de fonte animal, vegetal, mineral, incluindo bebida, destinada a ser ingerida pelo homem e fornecer elementos necessários ao seu desenvolvimento e manutenção (EVANGELISTA, 2000; BRASIL, 1965).

No que diz respeito ao papel que desenvolve no organismo, basta destacar que o alimento é imprescindível a todos os seres viventes e formas de vida. Esta virtude lhe é dada pelo seu conteúdo de elementos nutrientes, capazes de repor as substâncias orgânicas que lhes correspondem, gastas com as atividades do organismo. Constituem, pois, os alimentos, os materiais a que recorre o organismo, para fabricar seus tecidos e obter energia propulsora dos processos biológicos. A principal característica dos alimentos é sua importância ante a dimensão da função que exerce na manutenção orgânica do indivíduo, em todas as fases e períodos etários que atravesse (EVANGELISTA, 2000).

Referente ao pescado, sobretudo no que se refere aos peixes, seu consumo apresenta muitos benefícios para a saúde humana (ZMOZINSKI et al., 2015) como a grande quantidade de proteína de alta qualidade, vitaminas, nutrientes essenciais e dois tipos de ácido graxos poli-insaturados ômega-3: o ácido eicosapentaenoico (EPA) e o ácido docosaexaenoico (DHA). O pescado ainda é responsável por 17\% do consumo de proteína de origem animal e $6 \%$ do consumo de proteínas por humanos (DOMINGO et al., 2007).

Mesmo com todos os benefícios do pescado, apenas em 2013 estima-se que o brasileiro alcançou a média mínima de consumo de pescado recomendado pela Organização Mundial da Saúde, de 12 quilos por habitante por ano (PORTAL BRASIL, 2013). Em relação à frequência do consumo, a Associação Americana do Coração recomenda duas porções por semana (DOMINGO, 2016; AMERICAN HEART ASSOCIATION, 2017). 
Ao se mencionar as qualidades nutricionais do pescado e o acesso da população ao mesmo, se faz necessária a definição de segurança alimentar. A segurança alimentar, termo em inglês traduzido por food security é definida, segundo a Organização das Nações Unidas para a Alimentação e Agricultura (FAO, 2002) como situação que existe quando todas as pessoas, em todos os tempos, possuem acesso físico, econômico e social a uma alimentação suficiente, segura e nutritiva, que atenda às necessidades dietéticas e preferências alimentares para uma vida ativa e saudável.

No Brasil, o tema é tratado pelo Conselho Nacional de Segurança Alimentar (CONSEA), que define segurança alimentar como: realização do direito de todos ao acesso regular e permanente de alimentos de qualidade, sem comprometer o acesso a outras necessidades essenciais, tendo como base práticas alimentares promotoras de saúde que respeitem a diversidade cultural, econômica e socialmente sustentáveis (BRASIL, 2006).

Culturalmente, o consumo do pescado apresenta panorama bastante distinto nas diferentes regiões do país, e o acesso a esse alimento se dá basicamente por meio de supermercados, mercados municipais, feiras e restaurantes (FAO, 2005). A Tabela 1 traz algumas informações sobre essa temática.

Tabela 1 - Consumo do pescado em algumas capitais brasileiras

\begin{tabular}{ccccccc}
\hline Mercado & Recife & Maceió & Aracaju & Brasília & Rio de Janeiro & São Paulo \\
\hline Consumo total (t) & 28.872 & 12.685 & 7.760 & 23.201 & 167.124 & 249.087 \\
$\begin{array}{c}\text { Consumo per capita } \\
(\mathrm{kg} / \text { habitante ano) }\end{array}$ & 8,05 & 12,8 & 16,8 & 12,8 & 16,4 & 15,3 \\
\hline
\end{tabular}
Fonte: FAO, 2005.

Em relação ao consumo total, a cidade de São Paulo é a maior consumidora de pescado do Brasil, e integrando a região metropolita, é responsável pela importação dos principais produtos do setor (NEIVA et al., 2010). Uma das principais formas de distribuição do pescado na capital paulista é via a Companhia de Entrepostos e Armazéns Gerais de São Paulo (CEAGESP), tendo como as espécies mais vendidas em 2009: sardinha, pescada, corvina, cavalinha, tilápia, bacalhau seco, atum e tainha. Maiores informações são apresentadas na Tabela 2 (NEIVA et al., 2010). 
Tabela 2 - Principais espécies de pescado comercializado no CEAGESP em 2009

\begin{tabular}{ccc}
\hline \multicolumn{3}{c}{ Pescado } \\
\hline Ordem & Produto & Toneladas \\
\hline $1^{0}$ & Sardinha (Sardinella $s p$ ) & 6.719 \\
$2^{0}$ & Pescada (Cynoscion $s p$ ) & 6.579 \\
$3^{0}$ & Salmão (Salmo Salar) & 2.993 \\
$4^{0}$ & Corvina (Micropogonias $s p$ ) & 2.804 \\
$5^{0}$ & Cação (Prionace $s p$ ) & 2.529 \\
$6^{0}$ & Mistura (várias espécies) & 2.248 \\
$7^{0}$ & Cavalinha (Scomber $s p)$ & 1.759 \\
$8^{0}$ & Tilápia (Oreochromis $s p)$ & 1.586 \\
$9^{0}$ & Bacalhau seco (Gadus morhua) & 1.539 \\
$10^{0}$ & Atum (Thunnus $s p$ ) & 1.423 \\
$11^{0}$ & Tainha (Mugil $s p$ ) & 1.391 \\
\hline
\end{tabular}

Fonte: NEIVA et al., 2010.

O volume de pescado consumido é muito importante, tanto para a economia quanto para a saúde do consumidor, devido ao grande potencial nutricional, como citado anteriormente. Entretanto, o pescado também pode ser produto de alto risco se estiver contaminado por substâncias tóxicas. Desta forma, é necessário, do ponto de vista higiênico e sanitário, que exista monitoramento de toda a cadeia produtiva do pescado, possibilitando que se possa identificar e manter sob controle eventuais pontos de contaminação (MANTOVANI, 2005).

Ao relacionar potenciais riscos à alimentos, outra definição, desta vez sanitária, é necessária. A segurança alimentar (ou segurança de alimentos), food safety em inglês, é definida pela FAO por: todos os perigos, crônicos ou agudos, que podem tornar os produtos de gênero alimentício prejudiciais para a saúde do consumidor. As preocupações sobre os riscos dos produtos alimentícios são geralmente pautadas em: perigos microbiológicos, resíduos de pesticidas, uso indevido de aditivos alimentares e contaminantes químicos, incluindo toxinas biológicas (FAO, 2003).

Ressalta-se, portanto, que em português, a palavra segurança alimentar possui duas conotações: segurança alimentar como food security - no sentido quantitativo e food safety - no sentido qualitativo (TALAMINI et al., 2005). O presente trabalho, pautado na determinação de contaminantes inorgânicos, está contextualizado na segunda acepção. 


\subsection{Contaminantes inorgânicos em organismos aquáticos e sua ingestão pelo homem}

Contaminantes são, segundo o Codex Alimentarius (Codex), quaisquer substâncias não intencionalmente adicionadas aos alimentos e que neles estão presentes como resultado de produção, transformação, processamento, preparação, embalagem, acondicionamento, transporte ou como resultado de contaminação ambiental (CODEX, 2018).

Contaminantes inorgânicos ${ }^{1}$, também chamados de metais pesados, referem-se à elementos químicos metálicos que possuem densidade maior do que $4 \mathrm{~g} / \mathrm{cm}^{3}$. Fazem parte desse grupo alguns metais que o organismo necessita em quantidades pequenas, e que podem ser prejudiciais em quantidade excessiva, como $\mathrm{Co}, \mathrm{Cu}, \mathrm{Fe}, \mathrm{Mn}, \mathrm{Mo}, \mathrm{Ni}$, V e $\mathrm{Zn}$, e outros que não possuem nenhum efeito benéfico nos organismos, como o $\mathrm{As}, \mathrm{Cd}, \mathrm{Hg} \mathrm{e} \mathrm{Pb}$, considerados as principais ameaças por serem muito prejudiciais aos animais e plantas (MUNIR et al., 2016).

A toxicidade dos contaminantes inorgânicos pode ser explicada de algumas maneiras. Quando ionizados, esses compostos podem facilmente reagir com substâncias biogênicas, como proteína e ácido nucléico, apresentando influências significativas na estrutura tridimensional das proteínas. Os elementos tóxicos podem também competir e substituir outros elementos essenciais necessários no centro da vitalidade das metaloenzimas (JIN et al., 2012).

Os contaminantes inorgânicos presentes no ambiente aquático se originam de fontes naturais e antropogênicas (CORRALES et al., 2016). Esses elementos possuem persistência no meio-ambiente (GU et al., 2015), ou seja, não são eliminados pelas instalações de saneamento ou pela capacidade de autopurificação da natureza (JIN et al., 2012).

Os contaminantes inorgânicos são inertes e se depositam nos sedimentos, esses por sua vez fornecem habitat e alimento para peixes e bentos, podendo haver assim bioacumulação e biomagnificação dos contaminantes presentes no corpo d’água e no

\footnotetext{
${ }^{1}$ Optou-se por utilizar o termo contaminantes inorgânicos ao invés de metais pesados, pois o termo "pesado" faz menção direta à massa, o que pode induzir o leitor à confusão, uma vez que a massa atômica dos ditos metais pesados variam bastante entre si. Além do mais, outro elemento considerado tóxico e muito importante é o As, que é ametal. Desta forma, o termo contaminantes inorgânicos abrange os elementos dessa categoria de forma mais satisfatória do que metais pesados na visão do autor.
} 
sedimento para os organismos por meio de suas relações alimentares (YI et al., 2017; CORRALES et al., 2016).

Seres humanos, por sua vez, podem ingerir estes pescados potencialmente contaminados. Segundo MORGANO et al (2011), a principal fonte de exposição em relação aos contaminantes inorgânicos decorre do consumo do alimento, sobretudo de pescados, e por este motivo, estudos do acúmulo de elementos tóxicos em peixes são amplamente realizados para garantia da segurança alimentar (GU et al., 2015).

\subsection{A importância da determinação de contaminantes inorgânicos em organismos aquáticos: segurança alimentar}

Os níveis dos contaminantes nos pescados são particularmente importantes porque apresentam potencial risco à saúde daqueles que os consomem (TÜRKMEN et al., 2009) e, por este motivo, a legislação brasileira que estabelece teores máximos desses contaminantes nos pescados diz que seus níveis deverão ser os mais baixos possíveis, devendo prevenir-se a contaminação do alimento na fonte; aplicando-se a tecnologia mais apropriada na produção, manipulação, armazenamento, processamento e envase, de forma a evitar que um alimento contaminado seja comercializado ou consumido (BRASIL, 2013).

A justificativa para imposição destes teores se dá pela necessidade de manter o conteúdo de contaminantes em níveis toxicológicos aceitáveis, visando proteger a saúde pública. Sobre o pescado, o conteúdo máximo refere-se aos peixes e aos produtos de pesca a serem consumidos eviscerados, sem cabeça e sem tórax, quando for o caso. Se o pescado está destinado a ser consumido por inteiro, o conteúdo máximo está destinado ao peixe inteiro (BRASIL, 2013). Tais dados da legislação brasileira e de outros países para valores máximos de elementos tóxicos podem ser encontrados na Tabela 3. 
Tabela 3 - Legislação brasileira e outras que estabelecem valores máximos de elementos tóxicos presentes em peixes

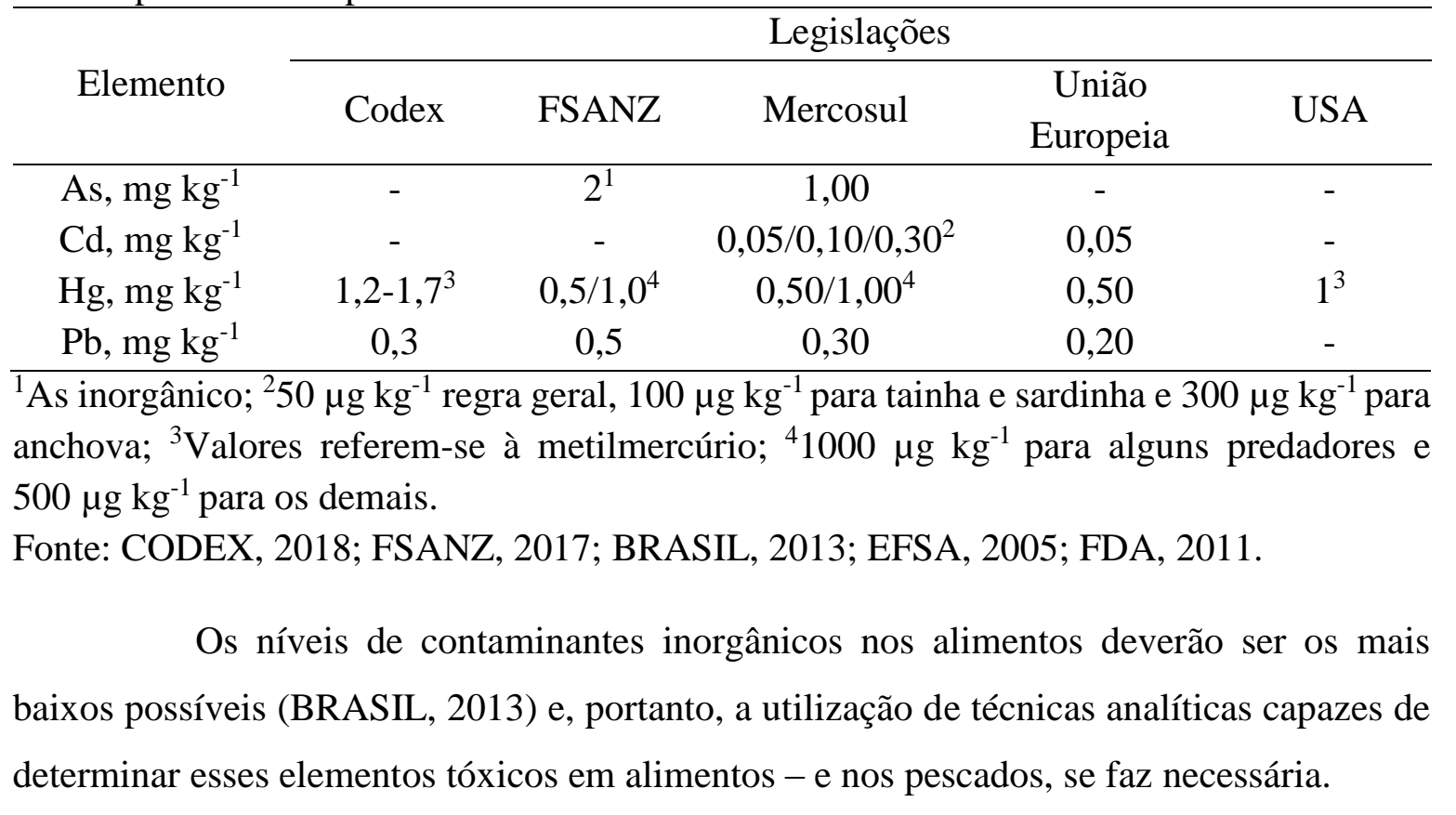




\section{OBJETIVOS}

Baseado no descrito anteriormente, este projeto de mestrado teve como objetivo analisar a fração mássica de elementos tóxicos e potencialmente tóxicos no tecido comestível (filé) de alguns dos pescados mais consumidos no município de São Paulo: corvina Micropogonias furnieri (Desmarest, 1823); pescada-branca - Cynoscion leiarchus (Cuvier, 1830); robalo - Centropomus undecimalis (Bloch, 1792); sardinha-verdadeira - Sardinella brasiliensis (Steindachner, 1879); anchova Pomatomus saltatrix (Linnaeus, 1766); e tainha - Mugil liza (Valenciennes, 1836); como contribuição a garantia da segurança alimentar. As nuances do objetivo principal são listadas abaixo.

\subsection{Objetivos específicos}

- Validação dos métodos utilizados em relação à exatidão por meio da análise de materiais de referência certificados (MRC);

- Determinação dos elementos potencialmente tóxicos $\mathrm{Br}, \mathrm{Cl}, \mathrm{Co}, \mathrm{Cr}, \mathrm{Cs}, \mathrm{Fe}$, $\mathrm{K}, \mathrm{Mg}, \mathrm{Mn}, \mathrm{Na}, \mathrm{Rb}, \mathrm{Sb}$, Se e Zn e estritamente tóxico As por INAA, com o intuito da garantia da segurança alimentar para os contaminantes inorgânicos, e de construção de banco de dados para os demais elementos, possibilitando futuras discussões;

- Verificar se há diferença significativa para os elementos determinados pelas duas modalidades de INAA (Br, K e Na) por meio de teste-t de Student;

- Determinação dos contaminantes inorgânicos $\mathrm{Cd}, \mathrm{Hg}$ e $\mathrm{Pb}$, sendo $\mathrm{Cd}$ e $\mathrm{Pb}$ por ET AAS e Hg por CV AAS;

- Comparação dos valores de fração mássica dos contaminantes inorgânicos determinados com as legislações do FSANZ, MERCOSUL e União Europeia (UE) e guias CODEX e FDA, por meio de análise descritiva dos dados. 


\section{REVISÃO DA LITERATURA DE CONTAMINANTES EM PESCADOS}

Diversas legislações e outros documentos técnicos no mundo tratam de teores máximos de contaminantes inorgânicos nos alimentos. Em relação ao pescado, o guia americano diz que pesticidas e contaminantes químicos apresentam potencial risco à saúde humana e, por isso, níveis de tolerância são estabelecidos em alguns dos contaminantes mais tóxicos e persistentes que possam existir nesse alimento (FDA, 2011).

A legislação da Austrália e Nova Zelândia diz que os alimentos devem ser adequados e seguros para a alimentação humana e que, neste sentido, limites máximos têm sido estabelecidos quando é observado que contaminantes e toxinas naturais apresentam potencial risco ao consumidor (FSANZ, 2016).

No Brasil, a Portaria que tratava sobre o tema dizia que os níveis máximos de contaminantes eram estabelecidos em alimentos que constituem riscos à saúde humana (BRASIL, 1998). Posteriormente, a Agência Nacional de Vigilância Sanitária (ANVISA), em 2013, emitiu nova Resolução alegando que é necessário atualizar os limites máximos de contaminantes inorgânicos em alimentos e que é essencial manter o conteúdo de contaminantes em níveis toxicológicos aceitáveis, visando proteger a saúde pública (BRASIL, 2013).

Pautado em diversas legislações e outros documentos técnicos, é evidente que os elementos tóxicos são de crescente preocupação global (GU et al., 2015). É neste contexto que este capítulo aborda, e portanto contextualiza, o presente estudo com outros trabalhos presentes na literatura. Foram destacados dez trabalhos que tratam sobre a determinação de contaminantes inorgânicos e também de risco-benefício do consumo, tendo em vista o potencial nutricional do pescado.

Na pesquisa realizada por TERRA et al. (2008) foram analisados os elementos tóxicos $\mathrm{Cu}, \mathrm{Cr}, \mathrm{Pb}$ e $\mathrm{Zn}$ contidos nas gônadas e músculos de três espécies de pescados de diferentes níveis tróficos - Oligosarcus hepsetus (carnívoro), Geophagus brasiliensis (onívoro) e Hypostomus luetkeni (detritívoro), amostrados em 4 áreas do rio de Paraíba do 
Sul. A técnica analítica utilizada para determinação desses contaminantes foi a Fluorescência de Raios X de Reflexão Total com Radiação de Sincrotron (SR-TXRF). Neste trabalho, com exceção do $\mathrm{Cu}$, todos os contaminantes apresentaram nos músculos e/ou gônadas frações mássicas superiores à legislação brasileira. Os autores concluem ainda que a espécie $O$. hepsetus (carnívoro) em geral apresentou maiores teores de contaminantes inorgânicos, e o segmento médio-superior do Rio Paraíba do Sul, região que engloba grandes áreas urbanas apresentou os piores resultados para os contaminantes.

No estudo de YILDIRIM et al. (2009), foi analisada a fração mássica dos elementos tóxicos $\mathrm{Cd}, \mathrm{Cr}, \mathrm{Cu}, \mathrm{Ni}, \mathrm{Pb}$ e $\mathrm{Zn}$ no tecido muscular de 61 amostras de 6 espécies: Sparus auratus, Pomatomus saltatrix, Sarda sarda, Engraulis encrasicholus, Sander lucioperca e Scomber scombrus, por AAS, adquiridos no varejo em Kayseri, Turquia. Para $\mathrm{Cd}, 50 \%$ das amostras excederam a legislação turca, enquanto que para $\mathrm{Pb}$ a taxa foi de 9,8\%. Em relação ao Zn, $18 \%$ das amostras excederam o Codex Turco de alimentos. Nenhuma amostra excedeu a legislação turca para $\mathrm{Cu}$, enquanto $\mathrm{Ni}$ e $\mathrm{Cr}$ não possuem limites estabelecidos pelas autoridades desse país. Os autores concluíram que, com base nos resultados, particularmente os elementos estritamente tóxicos $(\mathrm{Cd}$ e $\mathrm{Pb})$ e os níveis muito elevados de $\mathrm{Zn}$ em algumas espécies de pescado poderiam constituir problema para a saúde pública.

BLOOMINGDALE et al. (2010) fizeram estudo qualitativo sobre o consumo do pescado durante a gravidez. Os autores citam que o benefício do consumo está na ingestão adequada de ácido graxo poli-insaturado ômega-3 durante a gravidez, particularmente do DHA, que é essencial ao neurodesenvolvimento fetal. Em relação ao risco, está na possibilidade da presença do metilmercúrio, uma neurotoxina à qual o cérebro do feto é sensível. Os autores relatam que, após discussão, mulheres grávidas que não consomem pescados com frequência estariam dispostas a consumir mais, se fossem aconselhadas por seus obstetras ou até mesmo por outras fontes, desde que as informações fossem claras e facilmente acessíveis sobre quais tipos de pescados são seguros para comer durante a gravidez.

No estudo conduzido por MORGANO et al. (2011) foi determinado o teor dos contaminantes As, $\mathrm{Cd}$. $\mathrm{Cr}, \mathrm{Hg}$ e $\mathrm{Pb}$ em 240 amostras das espécies pescada (Macrodon ancylodo), tainha (Mugil liza), corvina (Micropogonais furnieri) e sardinha (Sardinella brasiliensis), adquiridas no CEAGESP e analisadas por Espectrometria de Emissão Óptica com Plasma Acoplado Indutivamente (ICP OES). Os autores relataram que, 
baseados nos dados obtidos no estudo, é possível concluir que as espécies analisadas, comercializadas na cidade de São Paulo, apresentaram contaminação por elementos tóxicos. Os autores ressaltaram a necessidade de monitoramento constante de contaminantes no pescado nacional.

Na pesquisa realizada por GÖRÜR et al. (2012) foram analisados os níveis de radiação devido a presença dos radionuclídeos ${ }^{226} \mathrm{Ra},{ }^{232} \mathrm{Th}$ e ${ }^{137} \mathrm{Cs}$ (Espectrometria Gama) e os elementos tóxicos $\mathrm{As}, \mathrm{Cr}, \mathrm{Cu}, \mathrm{Fe}, \mathrm{Mn}, \mathrm{Ni}, \mathrm{Pb}$ e $\mathrm{Zn}$ (Fluorescência de Raios-X por Dispersão de Energia) em 4 espécies de pescados: anchova (Engraulis encrasicholus), truta (Oncorhynchus mykiss), rabilho (Trachurus mediterranus) e badejo (Merlangius merlangus) amostrados na região do Mar Negro da Turquia, local contaminado pelo acidente nuclear de Chernobyl de 1986. Os autores afirmaram que a dose estimada devido ao consumo de pescado não representa ameaça à saúde humana, e que a fração mássica dos elementos tóxicos estavam abaixo da ingestão diária recomendada pelas organizações internacionais.

No estudo de SUBOTIĆ et al. (2013) foram determinados os elementos Al, As, B, Ba, Cd, Co, Cr, Cu, Fe, Hg, Li, Mn, Mo, Ni, Pb, Se, Sr e Zn por ICP OES, em 4 espécies de pescados: zander (Sander lucioperca), siluro (Silurus glanis), donzela (Lota lota) e carpa (Cyprinus carpio) coletados no rio Danúbio, Sérvia. Nesse trabalho, os autores obtiveram dados para os elementos traços e tóxicos abaixo das concentrações máximas aceitáveis, contudo, pelo fato do teor de $\mathrm{Hg}$ ter chegado perto do valor limite, os autores afirmam que o consumo desses pescados poderia ser potencialmente perigoso para o ser humano.

O trabalhado conduzido por PERUGINI et al. (2014) teve como objetivo analisar o teor dos elementos tóxicos $\mathrm{As}, \mathrm{Cd}, \mathrm{Cu}, \mathrm{Hg}, \mathrm{Pb}, \mathrm{Se}$ e $\mathrm{Zn}$ por Espectrometria de Emissão Atômica por Plasma Acoplado Indutivamente (ICP AES) em músculo e osso de 4 espécies de pescado (Mullus barbatus, Merluccius merluccius, Micromesistius poutassou e Scomber scombrus), amostrados no mar Adriático. De forma geral, as concentrações dos elementos foram maiores nos músculos do que nos ossos dos peixes. Em relação aos elementos tóxicos $\mathrm{Cd}, \mathrm{Hg}$ e $\mathrm{Pb}$, esses excederam os limites legais nas espécies analisadas, gerando preocupação com a saúde do consumidor e do meio ambiente.

GU et al. (2015) avaliaram a concentração dos elementos tóxicos $\mathrm{Cd}, \mathrm{Cu}, \mathrm{Cr}, \mathrm{Fe}$, Mn, Ni, Pb e Zn por AAS em 29 espécies de pescados do mar da China Meridional. Com exceção do $\mathrm{Fe}$ e $\mathrm{Mn}$, os elementos tóxicos determinados apresentaram teores menores do que os limites de ingestão diária aceitáveis. Os autores concluíram que, em relação a saúde 
humana, os riscos existentes decorrentes da exposição desses contaminantes por meio do consumo das espécies marinhas analisadas eram insignificantes.

No trabalho de DOMINGO (2016), o autor fez avaliação dos benefícios para saúde versus o risco do consumo regular de peixe e frutos do mar. O autor citou que os principais benefícios do consumo do pescado estão associados ao teor de proteína de alta qualidade, vitaminas e outros nutrientes essenciais. Relacionado aos contaminantes, o autor os separou em dois grupos - inorgânicos, compreendido por $\mathrm{As}, \mathrm{Cd}, \mathrm{Hg}, \mathrm{MeHg}$ e $\mathrm{Pb}$; e orgânicos - constituídos pelos poluentes orgânicos persistentes (POPs), cuja impacto na saúde humana varia de cancerígenos, disruptores endócrinos com efeitos adversos na homeostase central e outros de impactos poucos conhecidos. O autor cita também que, segundo estudos, de 90 a 95\% da exposição de seres humanos aos elementos tóxicos e POPs se dá via alimentação, e que $90 \%$ vem de origem animal, e portanto, atenção especial é necessária para o pescado. $\mathrm{O}$ autor conclui o trabalho refletindo sobre a recomendação da Associação Americana do Coração de consumir pescado duas vezes por semana e que, baseado em seu trabalho e outros da literatura, diverge parcialmente da recomendação.

A pesquisa de MAKEDONSKI et al. (2017) teve como objetivo avaliar os níveis de $\mathrm{As}, \mathrm{Cd}, \mathrm{Cu}, \mathrm{Hg}, \mathrm{Pb}$ e $\mathrm{Zn}$ nas partes comestíveis e guelras das setes espécies búlgaras mais consumidas: espadilha (Sprattus sprattus), carapau (Trachurus mediterrâneos ponticus), sável-do-mar-negro (Alosa pontica), bonito (Sarda sarda), anchova (Pomatomus saltatrix) e tainha (Mugil cephalus). As técnicas utilizadas foram analisador direto de mercúrio para $\mathrm{Hg}$ total e AAS e para os demais elementos. Os autores obtiveram resultados para os elementos tóxicos maiores nas guelras para todos os elementos. Os autores verificaram, comparando com a literatura, que a concentração desses contaminantes diminuiu em comparação ao período de 2004-2006. Por fim, concluíram que não há riscos para a saúde humana devido à exposição pelo consumo dos pescados analisados, uma vez que os resultados obtidos para os elementos determinados estavam em limites aceitáveis para o consumo humano.

No trabalho de RÍOS et al. (2018) foram determinados os elementos tóxicos As, $\mathrm{Cd}, \mathrm{Hg}$ e $\mathrm{Pb}$ por Espectrometria de Emissão Óptica com Plasma Induzido por Micro-ondas (MIP OES) em 96 amostras de robalo (Centropomus undecimalis), aracimbora (Caranx hippos), sororoca (Scomberomorus brasiliensis), aracapuã (Lutjanus purpureus), xarelete (Caranx crysos), pirapema (Megalops atlanticus), ubarana (Elops saurus), mero (Epinephelus itajara), coletados no delta do rio Atrato no Golfo de Urabá, no Caribe 
colombiano. Para os resultados obtidos, todas as espécies excederam os valores máximos permitidos para $\mathrm{Pb}, C$. hippos e $M$. atlanticus excederam para $\mathrm{Hg}$, praticamente nenhuma espécie excedeu para $\mathrm{Cd}$, e para As, em termos de valores médios, nenhuma espécie ultrapassou os valores máximos permitidos. Os autores concluíram que a supervisão dos contaminantes inorgânicos pelas autoridades competentes é recomendada, tanto em áreas contaminadas quanto para espécies comestíveis, sendo que nessa avaliação deveriam estar inclusas avaliações de risco para estimar o potencial impacto desses poluentes na saúde humana.

O termo de segurança alimentar (food safety) foi definido pela FAO em 2003 (FAO, 2003). Desde então, as pesquisas nesta área se intensificaram, o que possibilitou o estabelecimento de legislações e guias técnicos modernos, mencionadas aqui anteriormente visando proteger a saúde do consumidor. Por meio deste Capítulo, torna-se possível verificar a correlação da presente dissertação de mestrado com a literatura, tanto nacional quanto internacionalmente. No Capítulo de resultados e discussão, se utilizará novamente da literatura para comparar os resultados obtidos de fração mássica dos contaminantes com outros trabalhos similares já realizados. 


\section{FUNDAMENTOS TEÓRICOS}

\subsection{Análise por Ativação Neutrônica Instrumental (INAA)}

A ativação com nêutrons é o primeiro estágio no método de INAA. Baseia-se em converter alguns núcleos estáveis em núcleos radioativos, emitindo radiação que pode ser usada para fins analíticos (GREENBERG et al., 2011).

Cada núcleo atômico pode capturar nêutrons durante a irradiação. A reação nuclear resulta, muitas vezes, na mudança da massa nuclear. Imediatamente após a captura, o excesso de energia será emitido na forma de fótons ou partículas. O novo núcleo formado pode ser instável. Núcleos instáveis começam a decair para um núcleo estável por meio de emissão de radiação em um ou mais de um dos seguintes processos: decaimento $\alpha$, decaimento $\beta^{-}$, captura eletrônica, decaimento $\beta^{+}$ou transição interna. Em muitos casos, radiação $\gamma$ e raios-X também serão emitidos (GREENBERG et al., 2011):

Para exemplificar, o resultado da captura de um nêutron pelo núcleo atômico, supondo um núcleo de cobalto, tem-se a Reação 1:

$$
{ }^{59} \mathrm{Co}+{ }^{1} \mathrm{n} \rightarrow{ }^{60} \mathrm{Co}+\gamma \text { prontos }
$$

O núcleo radioativo formado, ${ }^{60} \mathrm{Co}$, decai pela emissão $\beta^{-}$e radiação $\gamma$. A reação pode ser reescrita na sua forma implícita da seguinte forma, descrita na Reação 2:

$$
{ }^{59} \mathrm{Co}(\mathrm{n}, \gamma){ }^{60} \mathrm{Co}
$$

Por fim, para estes radionuclídeos artificiais induzidos, pode-se aplicar a espectrometria de raios $\gamma$, que medirá o número de contagens num dado período de tempo, a partir do qual a taxa de desintegrações e o número de núcleos desintegrantes são calculados. O último número é diretamente proporcional ao número de núcleos do nuclídeo sujeito à reação nuclear e, assim, ao número de núcleos do elemento, que finalmente fornece o seu teor na amostra analisada (GREENBERG et al., 2011). 


\subsubsection{O modelo matemático da análise por ativação neutrônica}

O número de núcleos ativados $N\left(t_{i r}, t_{d}\right)$ presentes no começo da medição é dado pela Equação 3:

$$
N\left(t_{i r}, t_{d}\right)=\frac{R N_{0}}{\lambda}\left(1-e^{-\lambda_{t i r}}\right) e^{-\lambda t_{d}}
$$

e o número de núcleos $\Delta N$ desintegrando-se durante a medição é dado pela Equação 4:

$$
\Delta N\left(t_{i r}, t_{d}, t_{m}\right)=\frac{R N_{0}}{\lambda}\left(1-e^{-\lambda_{t i r}}\right) e^{-\lambda t_{d}}\left(1-e^{-\lambda t_{m}}\right)
$$

em que:

$R=$ taxa de reação;

$N_{0}=$ número de núcleos alvos;

$t_{i r}=$ tempo de irradiação;

$t_{\mathrm{d}}=$ tempo de decaimento ou de espera (tempo entre o fim da irradiação e o começo da medição;

$t_{\mathrm{m}}=$ duração da medição (BODE, 1996);

$\lambda=$ constante de decaimento.

sendo $\lambda$ definido pela Equação 5:

$$
\lambda=\frac{\ln (2)}{t_{1 / 2}}
$$

em que $t_{1 / 2}$ é o tempo de meia vida do radionuclídeo.

Rearranjando o número de núcleos alvos $N_{0}$ segundo a Equação 6: (BODE, 1996;

ZAHN et al., 2015)

$$
N_{0}=\frac{N_{a} \theta m_{a} C_{a}}{M}
$$

em que:

$N_{a}=$ constante de Avogadro;

$\theta=$ abundância isotópica do núcleo alvo $N_{0} ;$ 
$m_{a}=$ massa da amostra;

$C_{a}=$ fração mássica do elemento na amostra;

$M=$ massa molar.

E aplicando a equação simplificada da taxa de reação da Equação 7 (GREENBERG et al., 2011):

$$
R=\Phi_{t h} \sigma_{e f f}
$$

em que:

$\Phi_{\text {th }}=$ o fluxo "convencional" de nêutrons térmicos, para energias até o ponto de corte de Cd; $\sigma_{\text {eff }}=$ a seção de choque efetiva .

$\mathrm{O}$ resultado de uma área líquida $\mathrm{A}$ de um pico num espectro que corresponde a um fóton de energia é expresso pela seguinte fórmula da ativação expressa na Equação 8 (GREENBERG et al., 2011, ZAHN et al., 2015):

$$
A=\Phi_{t h} \sigma_{e f f} \frac{N_{a} \theta m_{a} C_{a}}{M}\left(1-e^{-\lambda_{t i r}}\right) e^{-\lambda t_{d}} \frac{\left(1-e^{-\lambda t_{m}}\right)}{\lambda} I \gamma \varepsilon
$$

sendo:

$I \gamma=$ a abundância de raios gamas (probabilidade de desintegração dos núcleos por emissão de fótons);

$\varepsilon=$ a eficiência do detector para o fotopico (probabilidade de um fóton de dada energia contribuir para o fotopico do espectro).

No método comparativo, a amostra desconhecida é irradiada junto com um padrão contendo a massa conhecida do elemento de interesse. Ambos ficam sob as mesmas condições de irradiação, de tal forma que muitos parâmetros se cancelam - como a seção de choque, o fluxo de nêutrons e o tempo de irradiação. Amostra e padrão ainda possuem as mesmas dimensões de confecção e são medidos na mesma distância do detector, o que por sua vez, cancelam os parâmetros de eficiência do detector para o fotopico e abundância dos raios gamas. Outras constantes físicas, como $N_{\mathrm{a}}, \theta, M$ e $\lambda$ matematicamente se cancelam. Em suma, todos os parâmetros citados acima são eliminados, sobrando apenas parâmetros conhecidos de massa da amostra e do padrão, concentração do elemento de interesse no padrão e a diferença de tempo entre o começo da medição do padrão e da amostra 
(GREENBERG et al., 2011, ZAHN et al., 2015). Quando a razão das equações de atividade da amostra e padrão é feita, têm-se a Equação 9.

$$
\frac{A a}{A p}=\frac{m_{a} C_{a} e^{-\lambda t_{d_{a}}}}{m_{p} C_{p} e^{-\lambda t_{d p}}}
$$

em que os índices a e p, representam, respectivamente, amostra e padrão. Por fim, isolandose a fração mássica do elemento na amostra $\left(\mathrm{C}_{\mathrm{a}}\right)$, tem-se a fórmula final utilizada na INAA pelo método comparativo, descrita na Equação 10:

$$
C_{a}=\frac{A_{a} m_{p} C_{p}}{m_{a} A_{p}} e^{-\lambda\left(t_{d_{p}}-t_{d_{a}}\right)}
$$

Assim, a INAA comparativa permite uma forma de ativação neutrônica mais simplificada, com a utilização de padrão pipetado. As modalidades de irradiação de curta e longa duração serão aplicadas em elementos que possuem, respectivamente, radionuclídeos com baixos e altos tempos de meia vida.

\subsection{Espectrometria de Absorção Atômica (AAS)}

As técnicas espectroscópicas de absorção atômica envolvem a quantificação da energia absorvida pelos átomos no estado fundamental do elemento de interesse a partir de uma fonte de radiação incidente (CIENFUEGOS e VAITSMAN, 2000; HIGSON, 2009).

A quantidade de radiação absorvida é proporcional à quantidade de átomos no estado fundamental, e, portanto, proporcional à concentração da solução que está sendo medida (CIENFUEGOS e VAITSMAN, 2000).

\subsubsection{Espectrometria de Absorção Atômica com Atomização Eletrotérmica (ET AAS)}

Na técnica ET AAS, as amostras são atomizadas em forno de grafite por meio de atomização eletrotérmica (HIGSON, 2009). A amostra depositada no tubo de grafite é submetida, por meio de aquecimento eletrotérmico, à: dessolvatação, pirólise e atomização. Uma vez que os átomos encontram-se no estado fundamental, a radiação emitida pela lâmpada do elemento de interesse pode ser absorvida e a concentração do mesmo na solução determinada (CIENFUEGOS e VAITSMAN, 2000). 


\subsubsection{Espectrometria de Absorção Atômica por Geração de Vapor Frio (CV AAS)}

A técnica de Vapor Frio é aplicada na determinação do elemento Hg devido a suas propriedades físico-químicas, como, por exemplo, sua pressão de vapor. O Hg pode ser facilmente reduzido quimicamente para sua forma metálica e, portanto, essa técnica não carece de atomizador. Após a redução, o Hg é simplesmente transportado para a fase gasosa por um gás de arraste que o levará até a célula de absorção (WELZ e SPERLING, 1999).

\subsubsection{Curva de calibração - o modelo matemático da AAS}

Calibração é a relação entre a concentração do analito e a absorbância (grandeza medida pelo espectrômetro). Essa relação é estabelecida matematicamente em AAS a partir de soluções padrões. A apresentação gráfica da função de calibração é denominada curva de calibração ou curva analítica, onde a concentração do analito é determinada por interpolação (WELZ e SPERLING, 1999).

Em condições ideais de soluções diluídas, devido à Lei de Lambert-Beer, há relação linear entre absorbância e a concentração do analito (WELZ e SPERLING, 1999). Como se trata de função linear, a mesma apresenta a seguinte forma, descrita na Equação 11:

$$
A=m x+c
$$

em que:

$A=$ absorbância;

$x=$ concentração;

$m=$ coeficiente angular da curva analítica;

$c=$ coeficiente linear da curva analítica.

\subsection{Incerteza de medição}

Incerteza de medição é "parâmetro não negativo que caracteriza a dispersão dos valores atribuídos a um mensurando, com base nas informações utilizadas" (INMETRO, 2012, p. 24). Para seu cálculo neste trabalho, foi utilizado o guia Eurachem - Quantificando Incerteza em Medição Analítica (EURACHEM e CITAC, 2012).

Para estimar a incerteza de medição, foram seguidos os quatro passos definidos pelo guia, que são: 
1. Descrição clara do mensurando e sua relação com as grandezas de entrada (modelo matemático);

2. Identificação das fontes de incertezas;

3. Quantificação das componentes de incertezas:

- Definição do tipo de incerteza em A ou B;

- Quantificação das componentes das grandezas de entrada;

- $\quad$ Conversão das incertezas em incerteza padrão;

4. Cálculo da incerteza combinada:

- Cálculo da incerteza padrão combinada;

- $\quad$ Revisão e se necessário, reavaliação de grandes componentes;

- Cálculo da incerteza expandida por meio da aplicação do fator de abrangência adequado.

\subsection{Limite de detecção (LD)}

O limite de detecção é definido como o menor valor de concentração do analito que pode ser detectado pelo método (INMETRO, 2007).

Para o método de INAA utilizado, o cálculo do $\mathrm{L}_{\mathrm{D}}$ foi realizado por meio da Equação 12 (CURRIE, 1999).

$$
L_{D}=3,29 \sigma_{o}
$$

sendo o termo $\sigma_{o}$ descrito na Equação 13 como:

$$
\sigma_{o}=\frac{\sqrt{B G}}{t_{v}}
$$

em que:

$\mathrm{BG}=$ número total de contagens de radiação de fundo para determinado pico analítico;

$t_{\mathrm{v}}=$ tempo em que determinada amostra foi medida.

Já para o cálculo do $\mathrm{L}_{\mathrm{D}}$ para $\mathrm{AAS}$, foi utilizado a Equação 14 (INMETRO, 2007):

$$
L_{D}=\bar{X}+t s
$$

sendo que: 
$\bar{X}$ é a média e s é o desvio padrão dos brancos da amostra;

$t$ é o valor de $t$ de Student, dependente do tamanho na amostra e do nível de confiança.

\subsection{Limite de quantificação $\left(L_{Q}\right)$}

Segundo o INMETRO o limite de quantificação é definido como "a menor concentração do analito que pode ser determinada com nível aceitável de exatidão e precisão" (INMETRO, 2007, p.14).

Para o cálculo do LQ para o método de INAA, foi utilizada a Equação 15 (CURRIE, 1999).

$$
L_{Q}=10 \sigma_{o}
$$

Os resultados obtidos pelas equações 12 e 15 estavam em contagens por segundo (cps) e para sua conversão em fração mássica, os resultados de $L_{D}$ e $L_{Q}$ foram levados à planilha de cálculo de fração mássica, a fim de se obter a conversão de cps em mg kg-1.

Já para o cálculo de $\mathrm{L}_{\mathrm{Q}}$ para o método de AAS, foi utilizada Equação 16 (INMETRO, 2007):

$$
L_{Q}=\bar{X}+10 s
$$




\section{TRATAMENTO DE DADOS}

\subsection{Erro relativo (ER)}

O erro relativo, definido pela Equação 17, possibilita avaliar a exatidão do método (INMETRO, 2011). A exatidão é o grau de concordância entre o valor medido e o valor do mensurando (INMETRO, 2012).

$$
E R=\frac{X_{l a b}-X_{V}}{X_{V}} 100
$$

sendo as variáveis:

$X_{\mathrm{lab}}=$ média aritmética dos valores obtidos;

$X_{\mathrm{V}}=$ valor aceito como verdadeiro (valor certificado do MRC).

\subsection{Desvio padrão relativo (DPR)}

O desvio padrão relativo, definido pelo Equação 18, é um parâmetro normalizado que permite avaliar a precisão do método (INMETRO, 2007). Precisão é o grau de concordância entre valores medidos, obtidos por medições repetidas, sob condições especificadas (INMETRO, 2012).

$$
D P R=\frac{D P}{C M D} 100
$$

em que:

$D P$ é o desvio padrão;

$C M D=$ concentração média determinada.

\section{3 Índice $z$}

$\mathrm{O}$ índice $\mathrm{z}$ avalia a estimativa do erro de um resultado em relação a dado valor alvo, levando-se em consideração o valor de dispersão $\sigma$ assumido (FAPAS, 2002), permitindo avaliar a exatidão da análise. Neste trabalho, optou-se por realizar o cálculo desse 
índice por meio da equação de Horwitz modificada (THOMPSON, 2000) descrita na Equação 19:

$$
z=\frac{\left(x_{\text {calc }}-x\right)}{\sigma}
$$

sendo:

$x$ é o valor certificado;

$x_{\text {calc }}$ é o valor obtido e

$\sigma$ é o valor de dispersão dos dados derivado da equação de Horwitz modificada, que varia de acordo com a ordem de grandeza da concentração de um elemento na forma adimensional, sendo:

$\sigma=0,22 \mathrm{csec}<1,210^{-7}$

$\sigma=0,02 \mathrm{c}^{0,8495}$ se $1,210^{-7} \leq \mathrm{c} \leq 0,138$

$\sigma=0,01 \mathrm{c}^{0,5}$ se c $<0,138$.

O critério para avaliação do índice z é, segundo o INMETRO (2011):

$|z| \leq 2$, resultado satisfatório;

$2<|z| \leq 3$, resultado considerado questionável e;

$|z|>3$, resultado considerado insatisfatório.

O cálculo do índice z será realizado para todos os MRC, analisados nas mesmas condições das amostras, nas técnicas de INAA e AAS.

\subsection{A relação de Horwitz}

A relação de Horwitz, conhecida também como valor de HorRat é um parâmetro normalizado (HORWITZ e ALBERT, 2006), simples e satisfatório para avaliar a aceitabilidade da precisão de um método (WOOD, 1999). A Equação 20 define o Valor de HorRat como (HORWITZ e ALBERT; 2006):

$$
\text { HorRat }=\frac{D P R_{r}}{P D P R_{r}}
$$

sendo: 
$D P R_{r}=$ desvio padrão relativo calculado;

$P D P R_{r}=\mathrm{O}$ valor de Horvitz derivado da equação de Horvitz; $2^{(1-\log \mathrm{C})}$, sendo $\mathrm{C}$ a fração mássica do elemento na forma adimensional.

Se os valores de HorRat forem $\leq 2$, podem-se assumir os resultados como satisfatoriamente reprodutíveis (WOOD, 1999).

O valor de HorRat será calculado para todos os MRC analisados sob as mesmas condições de análise nas técnicas de INAA e AAS.

\subsection{Estatística descritiva}

A estatística descritiva tem como objetivo descrever, analisar e interpretar dados numéricos de uma população ou amostra (FONSECA e MARTINS, 2015).

\subsection{Teste de hipóteses}

\subsubsection{Hipóteses estatísticas}

Hipótese estatística é definida como "uma afirmação sobre uma propriedade ou parâmetro de uma população" (ROCHA e MARTINS, 2015, p.219).

O teste de hipóteses é realizado entre a hipótese nula e a alternativa (ROCHA, 2015). A hipótese nula é a testada, expressando sempre igualdade, enquanto a alternativa é dada por desigualdade (FONSECA, 2015).

Para verificar a existência de diferenças significativas no teste de hipóteses, foi utilizado nível de significância $(\alpha)$ de 0,05 , ou seja, a probabilidade de erro é de $5 \%$ (SPIEGEL e STEPHENS, 2009).

Como critério de aceitação do teste de hipóteses, tem-se o valor de $p$, que é definido como a probabilidade de observância de uma estatística amostral como extrema (ou mais extrema) do que outra observada sob condição de que a hipótese nula é verdadeira. De modo geral, a interpretação do valor de $p$ se dá em função de $\alpha$, caso $p \leq \alpha$, rejeita-se a hipótese nula (SPIEGEL e STEPHENS, 2009). 


\subsubsection{Teste-t de Student}

O teste-t de Student é um ensaio estatístico que avalia se o valor médio de uma amostra independente que segue distribuição normal apresenta ou não diferença significativa com o valor médio da hipótese nula (FENG et al., 2017).

As premissas para realização do teste-t de Student são a normalidade e a homogeneidade de variância (homocedasticidade). Para avaliar a normalidade dos dados, utilizou-se o teste de Shapiro-Wilk com nível de significância de $\alpha=5 \%$. Já para a verificação da homogeneidade de variância, utilizou-se o teste $\mathrm{F}$, também com nível de significância de 5\%. Quando as premissas não forem observadas, há como alternativa o teste estatístico não paramétrico de Mann-Whitney (FONSECA, 2015). Todos os testes estatísticos deste trabalho foram realizados no software Past 3.

O teste-t será utilizado na comparação entre os elementos $\mathrm{Br}$, $\mathrm{Na}$ e $\mathrm{K}$ determinados por ambas as modalidades de INAA, e também para verificar se há diferença de fração mássica dos contaminantes em função do local de origem dos pescados. 


\section{PARTE EXPERIMENTAL}

\subsection{Amostragem}

Dez espécimes das seis espécies, dentre as mais consumidas no município de São Paulo (NEIVA et al., 2010), foram adquiridos em 2009 como parte de projeto apoiado pela Agência Internacional de Energia Atômica (IAEA, 2012). As amostras foram adquiridas na Companhia de Entrepostos e Armazéns Gerais de São Paulo (CEAGESP)².

Optou-se por adquirir os pecados diretamente com o fornecedor, pelo fato de se possuir, assim, melhores informações a respeito da procedência dos mesmos, como local e data da pesca, e, consequentemente eventuais informações associadas. Tais informações para a pescada-branca encontram-se na Tabela 4.

Tabela 4 - Informações sobre a pescada-branca

\begin{tabular}{ccccc}
\hline Nome popular & Peso total $(\mathrm{g})$ & Tamanho $(\mathrm{cm})$ & Local da pesca & Data de coleta \\
\hline Pescada-branca 1 & 176 & 25 & Itajaí-SC & $22 / 10 / 2009$ \\
Pescada-branca 2 & 200 & 25 & Itajaí-SC & $22 / 10 / 2009$ \\
Pescada-branca 3 & 168 & 25 & Itajaí-SC & $22 / 10 / 2009$ \\
Pescada-branca 4 & 156 & 26 & Itajaí-SC & $22 / 10 / 2009$ \\
Pescada-branca 5 & 176 & 26 & Itajaí-SC & $22 / 10 / 2009$ \\
Pescada-branca 6 & 207 & 27 & Itajaí-SC & $22 / 10 / 2009$ \\
Pescada-branca 7 & 219 & 27 & Rio Grande - RS & $30 / 10 / 2009$ \\
Pescada-branca 8 & 217 & 27 & Rio Grande - RS & $30 / 10 / 2009$ \\
Pescada-branca 9 & 240 & 28 & Rio Grande - RS & $30 / 10 / 2009$ \\
Pescada-branca 10 & 217 & 27 & Rio Grande - RS & $30 / 10 / 2009$ \\
\hline
\end{tabular}

Fonte: autor da dissertação.

Informações sobre os demais pescados (sardinha, corvina, robalo, anchova e tainha) encontram-se no Apêndice A.

\footnotetext{
2 Ressalta-se que as amostras foram adquiridas, preparadas, e algumas analisadas antes do início deste trabalho de mestrado. Isso resultou na publicação de FABIANO et al., (2016). Quando estes dados forem apresentados e/ou utilizados neste trabalho, serão dados os devidos créditos.
} 
Outro parâmetro importante referente à amostragem é a diferença dos hábitos alimentares das espécies analisadas. Essas informações estão contidas na Tabela 5.

Tabela 5 - Informações sobre os hábitos alimentares dos pescados

\begin{tabular}{clc}
\hline Espécie & \multicolumn{1}{c}{ Alimentação } & Referência \\
\hline M. furnieri (corvina) & Crustáceos, moluscos e peixes & FROESE \& PAULY, \\
C. leiarchus (pescada-branca) & Anelídeos, crustáceos e peixes & CLAUZET et al., 2005 \\
C. undecimalis (robalo) & Peixes e crustáceos & FROESE \& PAULY, \\
S. brasiliensis (sardinha) & Zooplâncton e copépodes & 2018 \\
P. saltatrix (anchova) & Peixes, crustáceos e cefalópodes & FROESE \& PAULY, \\
M. liza (tainha) & Detritos orgânicos e algas & FROESE \& PAULY, \\
& & 2018 \\
\hline
\end{tabular}

Fonte: autor da dissertação.

Os pescados foram transportados do entreposto comercial até o Laboratório de Ativação Neutrônica (LAN) em caixas isotérmicas entre camadas de gelo. Na Tabela 6 são descritas as características biométricas dos pescados assim como a relação da massa do peixe inteiro e tecidos musculares usualmente comestíveis.

Tabela 6 - Medições biométricas (valores médios \pm desvio padrão, $n=10$, valores mínimos e máximos entre parênteses) e R, relação da massa do peixe inteiro pelo tecido comestível

\begin{tabular}{ccccc}
\hline Espécies & Comprimento $(\mathrm{cm})$ & $\begin{array}{c}\text { Massa do peixe inteiro } \\
(\mathrm{g})\end{array}$ & $\begin{array}{c}\text { Massa comestível - filé } \\
(\mathrm{g})\end{array}$ & $\mathrm{R}$ \\
\hline Corvina $^{1}$ & $44 \pm 4(39-52)$ & $1005 \pm 322(661-1542)$ & $296 \pm 88(166-437)$ & $0,30 \pm 0,04$ \\
Pescada $^{1}$ & $26 \pm 1(25-28)$ & $200 \pm 27(156-240)$ & $81 \pm 14(55-99)$ & $0,41 \pm 0,03$ \\
Robalo $^{1}$ & $46 \pm 12(35-66)$ & $974 \pm 692(353-2139)$ & $408 \pm 281(158-928)$ & $0,43 \pm 0,02$ \\
Sardinha $^{1}$ & $18 \pm 1(17-20)$ & $85 \pm 21(61-118)$ & $36 \pm 9(18-50)$ & $0,43 \pm 0,06$ \\
Anchova $^{2}$ & $58 \pm 14(45-78)$ & $2320 \pm 1769(890-4472)$ & $375 \pm 112(239-573)$ & $0,38 \pm 0,08$ \\
Tainha $^{2}$ & $48 \pm 1(46-51)$ & $986 \pm 110(816-1206)$ & $846 \pm 713(250-1750)$ & $0,34 \pm 0,05$ \\
\hline
\end{tabular}

Fonte: ${ }^{1}$ FABIANO e col. 2016; ${ }^{2}$ autor da dissertação.

O procedimento para o preparo das amostras consistiu em lavá-las com água purificada (Milli-Q), liofilizar os tecidos comestíveis dos peixes em liofilizador de bancada, com posterior moagem em liquidificador adaptado com pás de titânio. O material moído então foi peneirado, homogeneizado e armazenado em frascos descontaminados.

\subsection{Determinação do teor de umidade}

Para atribuir valores de frações mássicas na base úmida para os pescados analisados, além de levar em consideração a perda de água durante o processo preparação da amostra (liofilização), é necessária também a determinação do teor de umidade residual dos pescados, que ficam armazenados em freezers antes das análises. 
Para esta determinação, foram pesados aproximadamente $0,5 \mathrm{~g}$ de cada espécime em pesa filtro na balança analítica (Shimadzu AUW 220D), o pesa filtro foi levado para estufa com ventilação mecânica (Visomes Plus) a $85^{\circ} \mathrm{C}$ e deixado por 24 horas. Após esse período, o mesmo foi retirado da estufa, e levado para o dessecador até esse retornar à temperatura ambiente. Por fim, procedeu-se com nova pesagem para determinar a massa seca. Procedimento similar foi feito para os MRC, com a diferença de que foram utilizadas as temperaturas solicitadas nos certificados dos mesmos. Na Tabela 7 estão especificados os MRC utilizados neste trabalho. Os teores de umidade das amostras e MRC determinados encontram-se no Apêndice B.

Tabela 7 - MRC utilizados neste trabalho

\begin{tabular}{cc}
\hline Identificação do MRC & Referência \\
\hline IPEN TM-1 tecido de mexilhão & MOREIRA et al., 2018 \\
MRC MODAS-3 tecido de peixe & LGC, 2015 \\
IPEN MRC Micropogonias furnieri & Comunicação pessoal $^{3}$ \\
NIST SRM 2976 tecido de mexilhão & NIST, 2018 \\
NIST SRM 1566b tecido de ostra & NIST, 2018 \\
NRCC DORM-4 proteína de peixe & NRCC, 2017 \\
NRCC DOLT-3 fígado de cação & NRCC, 2002 \\
\hline
\end{tabular}

Fonte: autor da dissertação.

\subsection{Preparação das amostras e padrões para irradiação}

\subsubsection{Confecção dos invólucros de polietileno para o armazenamento das amostras e padrões para irradiação}

Para desmineralizar o polietileno utilizado, evitando interferências químicas antes da irradiação, o mesmo foi colocado em ácido nítrico diluído (10\% v/v - Merck) por 24 horas, lavado com água Mili-Q e, em seguida, deixado para secar em capela de fluxo laminar. Depois, o polímero foi dobrado de forma apropriada e em seguida selado em seladora (Registron) com auxílio de folha de celofane. A folha de celofane possui ponto de fusão maior do que a do polietileno, o que permite selar o material armazenador sem o fundir. Obteve-se no final do processo invólucros de dimensões de aproximadamente $1,5 \mathrm{~cm}$ por $1,5 \mathrm{~cm}$.

\footnotetext{
${ }^{3} \mathrm{O}$ documento oficial de caracterização desse MRC não foi publicado até o momento em que esta dissertação foi escrita, mas será: Final Report: Arcal Project RLA/2/2014.
} 


\subsubsection{Pesagem das amostras de pescado e dos materiais de referência certificados}

Cerca de $200 \mathrm{mg}$ dos espécimes das seis espécies de pescado foram pesadas em balança analítica com o auxílio de espátulas, diretamente no invólucro de polietileno anteriormente preparado. As amostras pesadas permaneceram na geladeira até o momento da irradiação. Procedimento semelhante foi realizado para a pesagem dos MRC, com a ressalva da massa, que foi de $150 \mathrm{mg}$. A Figura 1 ilustra a pesagem de uma amostra. As mesmas amostras e MRC utilizados para irradiação curta foram utilizados para irradiação longa, após esperado o devido decaimento radioativo.

Figura 1 - Amostra sendo pesada no invólucro de polietileno em balança analítica

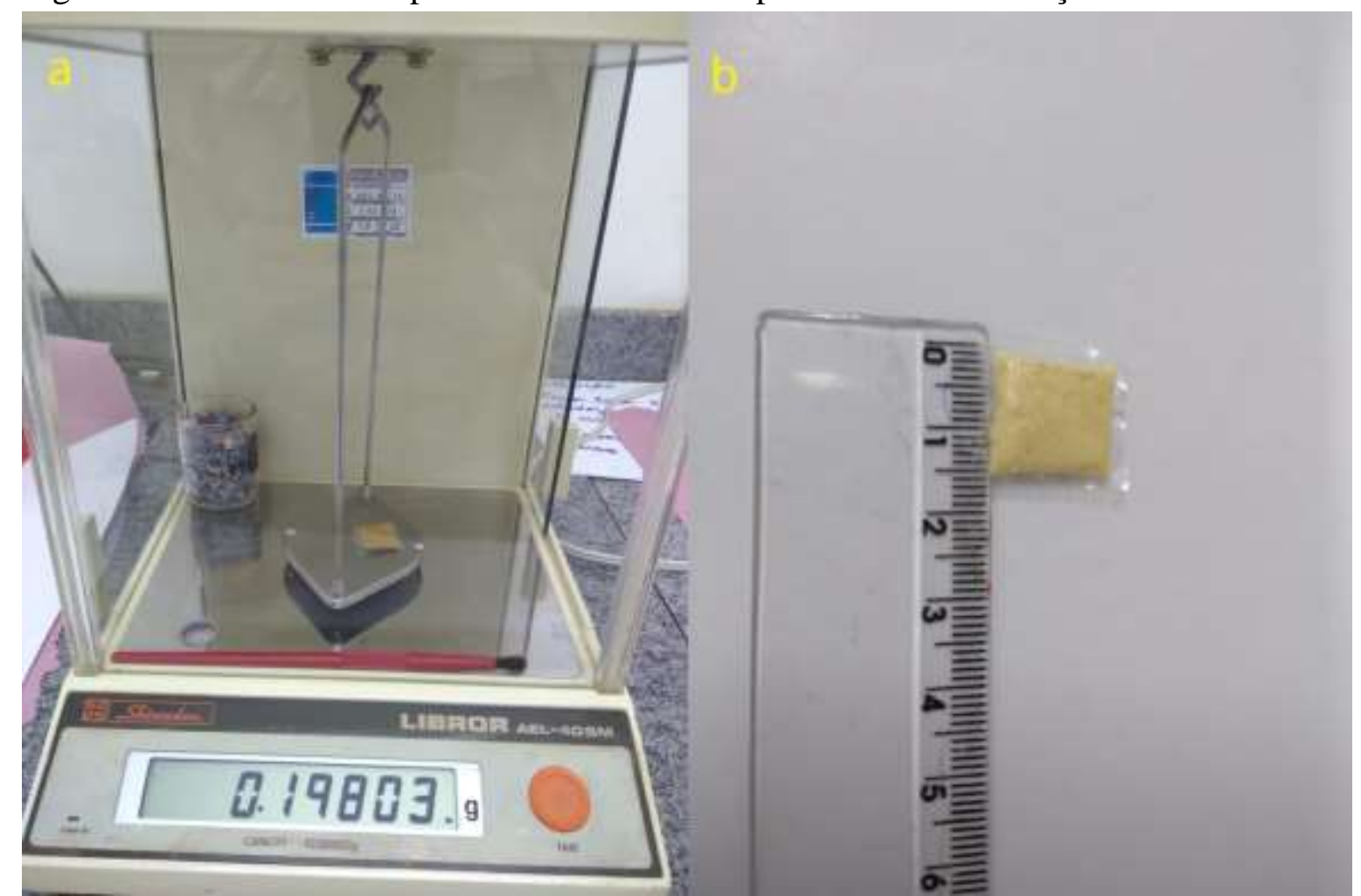

a) aproximadamente $200 \mathrm{mg}$ de amostra sendo pesada; b) amostra já pesada. Fonte: autor da dissertação.

\subsubsection{Verificação dos volumes das pipetas Eppendorf}

Visando determinar o volume exato da solução padrão que seria pipetado na preparação dos padrões pipetados realizou-se a verificação dos volumes das pipetas automáticas nos volumes utilizados (Tabela 8). 
Tabela 8 - Volumes utilizados pelas pipetas automáticas

\begin{tabular}{ccc}
\hline Volumes utilizados, $\mu \mathrm{L}$ & Pipeta $10-100 \mu \mathrm{L}$ & Pipeta $100-1000 \mu \mathrm{L}$ \\
\hline 25 & $\mathrm{x}$ & - \\
50 & $\mathrm{x}$ & - \\
100 & $\mathrm{x}$ & - \\
500 & - & $\mathrm{x}$ \\
1000 & - & $\mathrm{x}$ \\
\hline
\end{tabular}

Fonte: autor da dissertação.

O procedimento foi realizado da seguinte maneira: um béquer de $10 \mathrm{~mL}$ foi pesado em balança analítica, a mesma foi tarada e, se pipetou água nos respectivos volumes com anotação das massas de água. Com o valor da temperatura da água medido por meio de termômetro (Hg Brasil), e sabendo-se o valor da densidade da água por meio do Chemical Engineer's Handbook (PERRY, 1941), foi possível determinar o volume exato de água pipetado. Para cada volume, o procedimento foi repetido 12 vezes. Posteriormente, foi calculado a média, desvio padrão relativo (DPR) e erro relativo (ER). Tais dados encontramse na Tabela 9.

Tabela 9 - Valores de média, desvio padrão relativo (DPR) e erro relativo (ER) $(n=12)$

\begin{tabular}{cccccc}
\hline Volume nominal & 25 & 50 & 100 & 500 & 1000 \\
\hline Média $\mu \mathrm{L}$ & $24,67 \pm 0,89$ & $49,59 \pm 0,62$ & $99,33 \pm 0,97$ & $492,67 \pm 0,85$ & $984,8 \pm 5,7$ \\
DPR $(\%)$ & 0,54 & 0,16 & 0,37 & 0,25 & 0,28 \\
ER $(\%)$ & 1,3 & 0,82 & 0,67 & 1,5 & 1,5 \\
\hline
\end{tabular}

Incerteza apresentada é incerteza expandida, calculada usando-se o fator de abrangência $k=2$, que fornece nível de confiança de aproximadamente $95 \%$. Fonte: autor da dissertação.

Com valores de DPR $<1 \%$ e de $\mathrm{ER} \leq 1,5 \%$, os resultados obtidos na determinação dos volumes utilizados das pipetas automáticas foram considerados satisfatórios.

\subsubsection{Verificação da calibração do balão volumétrico}

Em alguns casos, antes de pipetar a solução elementar no papel de filtro, foi necessário diluir a mesma, visando diminuir a concentração de elementos onde há, por exemplo, nuclídeos alvo com seção de choque elevada e que poderiam ativar muito. $\mathrm{O}$ balão volumétrico utilizado é calibrado, e o valor de seu volume utilizado nos cálculos de concentração é o que consta no certificado de calibração. Entretanto, com o intuito de verificar o volume do balão, procedimento semelhante à calibração das pipetas foi adotado. O balão volumétrico de $10 \mathrm{~mL}$ foi colocado na balança e a mesma foi tarada. Avolumou-se 
de água até o menisco, obtendo-se então, a massa de água no balão. Sabendo a temperatura da água, medida por meio de termômetro, e verificando o valor da densidade para essa temperatura por meio do Chemical Engineer's Handbook (PERRY, 1941), foi possível calcular o volume de água no balão. Repetiu-se esse procedimento 11 vezes, o que possibilitou o cálculo da média, DRP e ER do volume do balão, que se encontram na Tabela 10. Obteve-se o valor para o volume do balão, via verificação do volume, menos preciso do que o valor do certificado, entretanto, o valor verificado foi satisfatório em relação ao valor certificado numa análise descritiva dos dados.

Tabela 10 - Valores de média, DPR e ER do volume do balão volumétrico $(n=11)$

\begin{tabular}{ccc}
\hline & Volume verificado & Volume certificado \\
\hline Média $(\mathrm{mL})$ & $10,02 \pm 0,01$ & $10,002 \pm 0,008$ \\
DPR $(\%)$ & 0,050 & - \\
ER $(\%)$ & $-0,17$ & $-0,02$ \\
\hline
\end{tabular}

Incerteza apresentada é incerteza expandida, calculada usando-se o fator de abrangência $k=2$, que fornece nível de confiança de aproximadamente $95 \%$. Fonte: autor da dissertação.

\subsubsection{Preparação dos padrões pipetados}

A preparação dos padrões pipetados foi realizada pipetando soluções padrão elementares (Spex CertiPrep) em papéis de filtro (Whatman $\mathrm{N}^{\circ} 40$ ) devidamente cortados, como ilustra a Figura 2, por meio de pipetas Eppendorf.

Figura 2 - Papéis de filtro cortados e sustentados por baquetas de vidro, de forma a se pipetar as soluções padrão

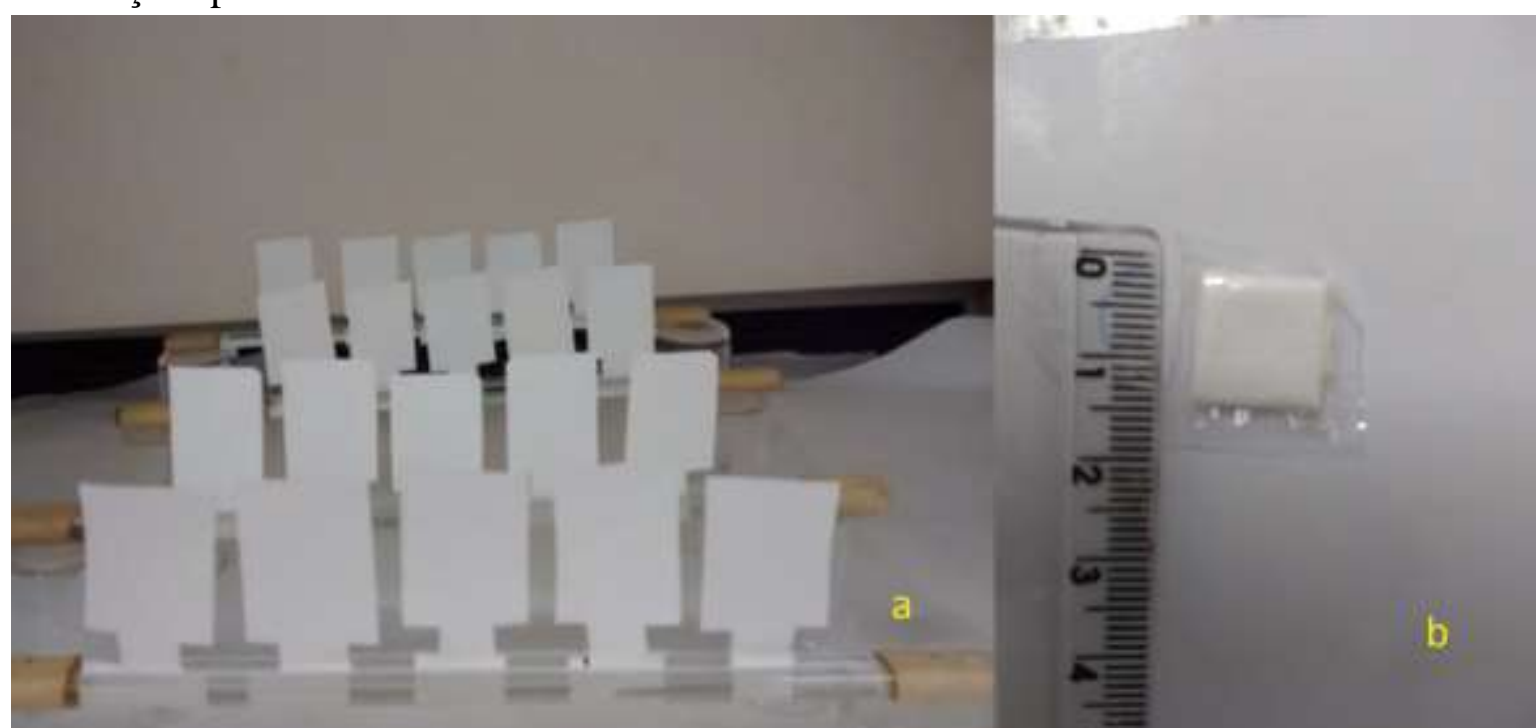

a) papéis de filtro cortados e organizados antes de ser pipetado a solução padrão; b) padrão pipetado devidamente preparado. Fonte: autor da dissertação. 
Posteriormente, os papéis de filtro foram dobrados com auxílio de pinças forradas com Parafilm, evitando contato direto entre a pinça e o padrão. Depois de dobrados, os padrões foram colocados cuidadosamente dentro de invólucros de polietileno e selados.

Sabendo-se os valores exatos dos volumes pipetados, se houve ou não diluição e a concentração da solução padrão, foi possível calcular as massas dos elementos nos padrões pipetados. Tais valores de massas se encontram na Tabela 11.

Tabela 11 - Cálculo das massas dos elementos nos padrões pipetados

\begin{tabular}{ccccccc}
\hline Padrão & Elemento & $\begin{array}{c}\text { Concentração } \\
\text { da solução } \\
\text { padrão } \\
\left(\mu \mathrm{g} \mathrm{mL} \mathrm{mL}^{-1}\right)\end{array}$ & $\begin{array}{c}\text { Volume } \\
\text { pipetador } \\
(\mu \mathrm{L})\end{array}$ & $\begin{array}{c}\text { Volume do } \\
\text { balão }(\mathrm{mL})\end{array}$ & $\begin{array}{c}\text { Volume do } \\
\text { pipetador } \\
(\mu \mathrm{L})\end{array}$ & $\begin{array}{c}\text { Massa do } \\
\text { elemento no } \\
\text { padrão }(\mu \mathrm{g})\end{array}$ \\
\hline $\mathrm{CB}$ & $\mathrm{Br}$ & $999 \pm 3$ & $984,8 \pm 5,7$ & $10,002 \pm 0,008$ & $49,59 \pm 0,62$ & $4,878 \pm 0,087$ \\
& $\mathrm{Cl}$ & $10000 \pm 100$ & - & - & $24,67 \pm 0,89$ & $247 \pm 11$ \\
$\mathrm{Mg}$ & $\mathrm{Mg}$ & $9997 \pm 50$ & - & - & $99,33 \pm 0,97$ & $993 \pm 12$ \\
$\mathrm{NKM}$ & $\mathrm{Na}$ & $9994 \pm 50$ & $3939 \pm 23$ & $10,002 \pm 0,008$ & $49,59 \pm 0,62$ & $195,2 \pm 3,4$ \\
& $\mathrm{~K}$ & $10018 \pm 50$ & - & - & $99,33 \pm 0,97$ & $995 \pm 12$ \\
& $\mathrm{Mn}$ & $1004 \pm 2$ & $984,8 \pm 5,7$ & $10,002 \pm 0,008$ & $49,59 \pm 0,62$ & $4,902 \pm 0,087$ \\
$\mathrm{FC}$ & $\mathrm{Cs}$ & $1002 \pm 5$ & $49,59 \pm 0,62$ & $10,002 \pm 0,008$ & $49,59 \pm 0,62$ & $0,1226 \pm 0,0062$ \\
& $\mathrm{Fe}$ & $10008 \pm 30$ & - & - & $49,59 \pm 0,62$ & $496,3 \pm 8,2$ \\
$\mathrm{ME}$ & $\mathrm{As}$ & $1001 \pm 3$ & $984,8 \pm 5,7$ & $10,002 \pm 0,008$ & $24,67 \pm 0,89$ & $2,43 \pm 0,11$ \\
& $\mathrm{Co}$ & $1002 \pm 3$ & $984,8 \pm 5,7$ & $10,002 \pm 0,008$ & $24,67 \pm 0,89$ & $2,43 \pm 0,11$ \\
& $\mathrm{Cr}$ & $1005 \pm 3$ & $1970 \pm 11$ & $10,002 \pm 0,008$ & $24,67 \pm 0,89$ & $4,89 \pm 0,22$ \\
& $\mathrm{Rb}$ & $999 \pm 3$ & $2954 \pm 17$ & $10,002 \pm 0,008$ & $24,67 \pm 0,89$ & $7,29 \pm 0,33$ \\
& $\mathrm{Sb}$ & $1001 \pm 3$ & $49,59 \pm 0,62$ & $10,002 \pm 0,008$ & $24,67 \pm 0,89$ & $0,1224 \pm 0,0067$ \\
& $\mathrm{Se}$ & $10004 \pm 30$ & $99,33 \pm 0,97$ & $10,002 \pm 0,008$ & $24,67 \pm 0,89$ & $2,45 \pm 0,11$ \\
& $\mathrm{Zn}$ & $10011 \pm 30$ & $984,8 \pm 5,7$ & $10,002 \pm 0,008$ & $24,67 \pm 0,89$ & $24,34 \pm 0,60$ \\
\hline
\end{tabular}

Incerteza apresentada é incerteza expandida, calculada usando-se o fator de abrangência $k=2$, que fornece nível de confiança de aproximadamente $95 \%$. Fonte: autor da dissertação.

Devido à proximidade de energia de alguns fotopicos, e também da meia vida dos radionuclídeos de interesse, optou-se por dividir os padrões pipetados em grupos. A combinação é apresentada na Tabela 10, onde a coluna "padrão" expressa a abreviatura dos elementos químicos contido em tal padrão pipetado, que pode ser consultada na coluna ao lado.

\subsection{Irradiação e medição das radiações induzidas}

\subsubsection{Irradiação de curta duração}

Para cada irradiação, utilizou-se um conjunto formado por uma amostra ou MRC e os padrões elementares. Antes da irradiação, o conjunto era empilhado e envolvido em invólucro de polietileno, e posteriormente colocado em dispositivo de polietileno, 
responsável em levar tal conjunto até o reator nuclear por meio do sistema pneumático da Estação 4. O mesmo era irradiado pelo período de $20 \mathrm{~s}$, sob fluxo de nêutrons térmicos de $1,9 \times 10^{12} \mathrm{~cm}^{-2} \mathrm{~s}^{-1}$ no reator nuclear IEA-R1 do IPEN - CNEN/SP. O procedimento de preparo do conjunto irradiado é ilustrado na Figura 3.

Figura 3 - Preparação do conjunto para irradiação de curta duração

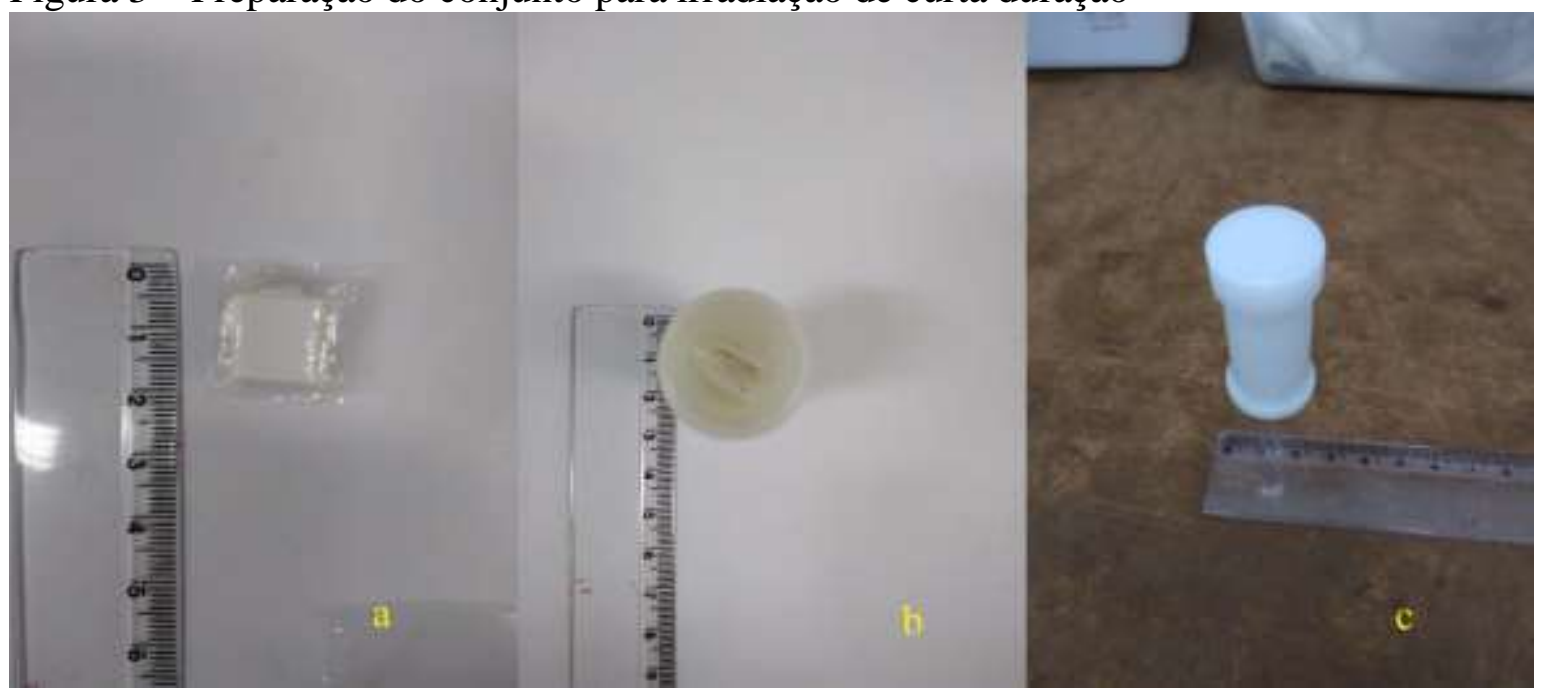

a) as amostras e padrões foram alinhados e colocados em invólucro de polietileno; b) esse invólucro foi colocado em dispositivo também de polietileno; c) dispositivo tampado e pronto para ser irradiado. Fonte: autor da dissertação.

A Tabela 12 apresenta parâmetros dos radionuclídeos identificados nos espectros obtidos nas irradiações de curta duração.

Tabela 12 - Parâmetros dos radionuclídeos utilizados na INAA de curta duração

\begin{tabular}{cccc}
\hline Elemento & Radionuclídeo & Energia $(\mathrm{keV})$ & Meia vida \\
\hline Bromo & ${ }^{80} \mathrm{Br}$ & 616,3 & $17,68 \mathrm{~min}$ \\
Cloro & ${ }^{38} \mathrm{Cl}$ & 1642,7 & $37,24 \mathrm{~min}$ \\
Potássio & ${ }^{42} \mathrm{~K}$ & 1524,6 & $12,360 \mathrm{~h}$ \\
Magnésio & ${ }^{27} \mathrm{Mg}$ & 843,3 & $9,458 \mathrm{~min}$ \\
Manganês & ${ }^{56} \mathrm{Mn}$ & 846,8 & $2,5785 \mathrm{~h}$ \\
Sódio & ${ }^{24} \mathrm{Na}$ & 1368,6 & $14,9590 \mathrm{~h}$ \\
\hline
\end{tabular}

Fonte: CHU et al., 1999.

Após as irradiações curtas realizadas na estação pneumática, a medição dos raios gama característicos provenientes dos radionuclídeos (espectrometria gama) foi realizada por meio do espectrômetro Canberra de germânio de alta pureza (HPGe - GC2018) acoplado a analisador espectral digital (Canberra DSA 1000).

A ordem de medição foi feita levando-se em consideração os tempos de meia vida dos radionuclídeos, sendo realizada da seguinte maneira: amostra e o padrão $\mathrm{Mg}\left({ }^{27} \mathrm{Mg}\right)$ 
por 300 segundos; $\mathrm{CB}\left({ }^{38} \mathrm{Cl}\right.$ e $\left.{ }^{80} \mathrm{Br}\right)$, NKM $\left({ }^{24} \mathrm{Na},{ }^{42} \mathrm{~K}\right.$ e $\left.{ }^{56} \mathrm{Mn}\right)$ por 1800 segundos; seguido da amostra novamente por 3600 segundos. Na primeira medição da amostra, foram determinados os elementos $\mathrm{Br}$ e $\mathrm{Mg}$, e na segunda, $\mathrm{Cl}, \mathrm{K}, \mathrm{Mn}$, $\mathrm{Na}$. Todas as medições foram realizadas na prateleira 0 , ou seja, na mais próxima do detector.

\subsubsection{Irradiação de longa duração}

Cada conjunto irradiado era composto por 3 amostras, um MRC e os padrões elementares preparados. Antes da irradiação, cada subamostra foi envolvida em folha de alumínio. Após todas as subamostras serem embrulhadas, as mesmas foram empilhadas e alinhadas, e uma nova camada de papel alumínio foi utilizada para envolver todo conjunto. Por fim, o conjunto foi colocado em um dispositivo de alumínio, e o mesmo foi selado, para evitar contato da água do reator nuclear durante a irradiação. O procedimento do preparo do conjunto irradiado é apresentado na Figura 4.

Figura 4 - Preparação do conjunto para irradiação de longa duração

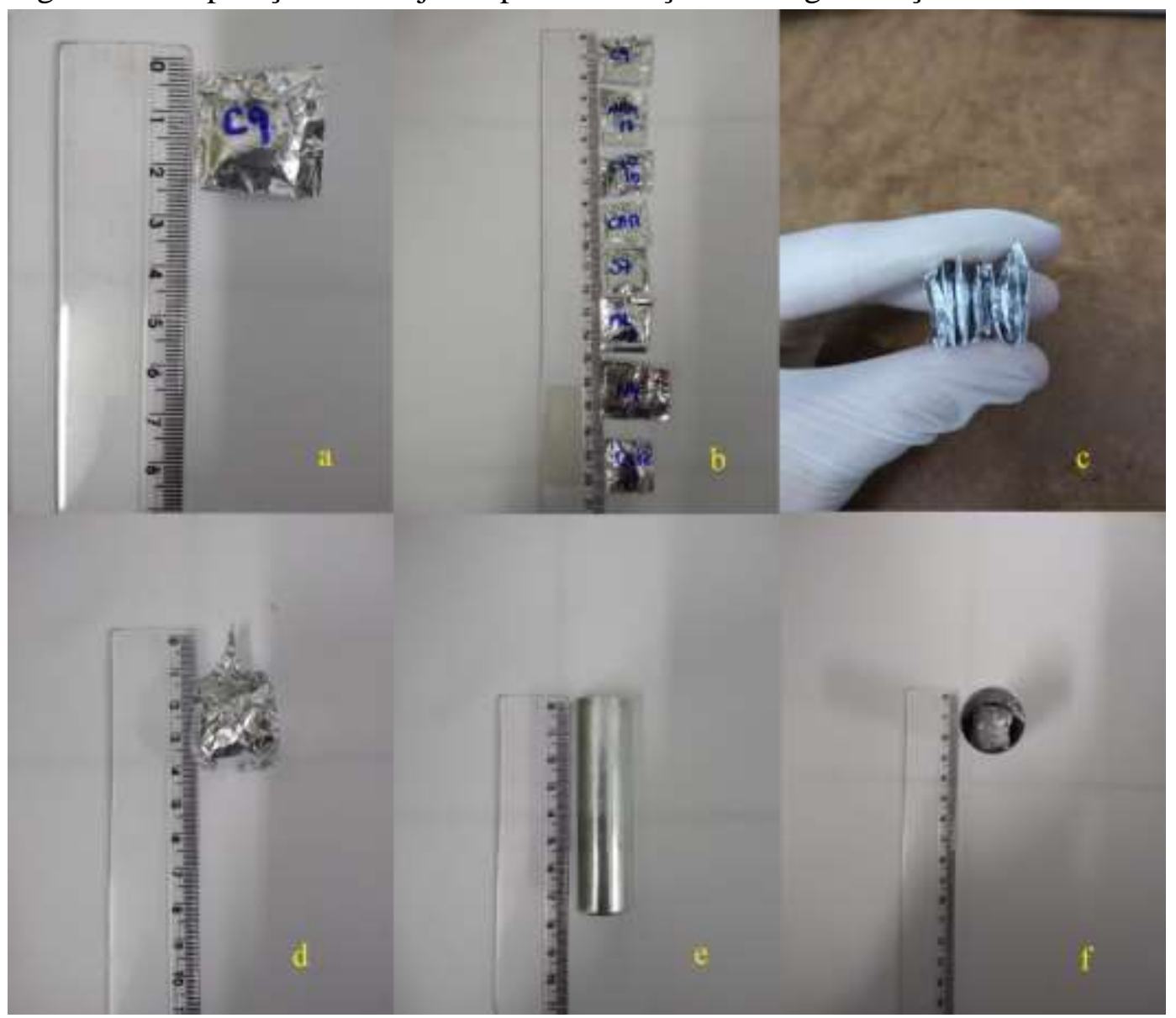

a) cada subamostra foi envolvida em papel alumínio; b) todas as subamostras já envoltas em folha de alumínio; c) as subamostras foram alinhadas e empilhadas; d) essa pilha foi envolvida em uma nova folha de papel alumínio; d) dispositivo onde a pilha de alumínio foi colocada f) conjunto a ser irradiado colocado no dispositivo. 
Esse dispositivo de alumínio selado foi colocado no EIRA (Elemento de Irradiação Refrigerado a Água) pela equipe do Reator Nuclear IEA-R1 do IPEN - CNEN/SP e deixado sob fluxo de nêutrons térmicos de $2-510^{12} \mathrm{~cm}^{-2} \mathrm{~s}^{-1}$ durante um ciclo diário de funcionamento desse reator (aproximadamente oito horas).

A Tabela 13 apresenta parâmetros dos radionuclídeos identificados nos espectros obtidos nas irradiações de longa duração.

Tabela 13 - Parâmetros dos radionuclídeos utilizados na INAA de longa duração

\begin{tabular}{cccc}
\hline Elemento & Radionuclídeo & Energia $(\mathrm{keV})$ & Meia vida \\
\hline Arsênio & ${ }^{76} \mathrm{As}$ & 559,101 & $1,0778 \mathrm{~d}$ \\
Bromo & ${ }^{82} \mathrm{Br}$ & 776,514 & $35,30 \mathrm{~h}$ \\
Cobalto & ${ }^{60} \mathrm{Co}$ & 1173,237 & $5,2714 \mathrm{a}$ \\
Cromo & ${ }^{51} \mathrm{Cr}$ & 320,0824 & $27,7025 \mathrm{~d}$ \\
Césio & ${ }^{134} \mathrm{Cs}$ & 795,864 & $2,0648 \mathrm{a}$ \\
Ferro & ${ }^{59} \mathrm{Fe}$ & 1099,251 & $44,503 \mathrm{~d}$ \\
Potássio & ${ }^{42} \mathrm{~K}$ & 1524,6 & $12,360 \mathrm{~h}$ \\
Sódio & ${ }^{24} \mathrm{Na}$ & 1368,6 & $14,9590 \mathrm{~h}$ \\
Rubídio & ${ }^{86} \mathrm{Rb}$ & 1076,64 & $18,631 \mathrm{~d}$ \\
Antimônio & ${ }^{122} \mathrm{Sb}$ & 564,119 & $2,7238 \mathrm{~d}$ \\
Selênio & ${ }^{75} \mathrm{Se}$ & 264,6576 & $119,779 \mathrm{~d}$ \\
Zinco & ${ }^{65} \mathrm{Zn}$ & 1115,546 & $224,26 \mathrm{~d}$ \\
\hline
\end{tabular}

Fonte: CHU et al., 1999.

Após a irradiação, foram esperados sete dias para abertura dos dispositivos de alumínio, para que os radionuclídeos dos elementos mais abundantes (como sódio e potássio) descaíssem algumas meias vidas, diminuindo o tempo morto das subamostras, o que melhora a exatidão e incerteza de medição. Esse tempo de decaimento também permitia menor taxa de dose recebida pelos envolvidos no processo de abertura da amostra. Posteriormente a esse período, a medição dos raios gamas característicos provenientes dos radionuclídeos (espectrometria gama) foi realizada por meio do espectrômetro Canberra de germânio de alta pureza (HPGe - GC2018) acoplado com analisador espectral digital (Canberra DSA 1000).

Após os sete dias de decaimento (primeira contagem), foram medidos os radionuclídeos ${ }^{76} \mathrm{As},{ }^{82} \mathrm{Br},{ }^{42} \mathrm{~K} \mathrm{e}{ }^{24} \mathrm{Na}$ por $1800 \mathrm{~s}$ nos padrões pipetados, amostras e MRC foram medidos por $5400 \mathrm{~s}$. Após 14 dias da irradiação (segunda contagem), mediram-se os demais radionuclídeos ${ }^{60} \mathrm{Co},{ }^{51} \mathrm{Cr},{ }^{134} \mathrm{Cs},{ }^{59} \mathrm{Fe},{ }^{86} \mathrm{Rb},{ }^{122} \mathrm{Sb},{ }^{75} \mathrm{Se}$ e ${ }^{65} \mathrm{Zn}$ por 3600 s nos padrões pipetados, amostra e CRM por 36000 s. Dessa forma, na primeira contagem foram determinados os elementos $\mathrm{As}, \mathrm{Br}, \mathrm{K}$ e $\mathrm{Na}$, e na segunda contagem $\mathrm{Co}, \mathrm{Cr}, \mathrm{Cs}, \mathrm{Fe}, \mathrm{Rb}, \mathrm{Sb}$, Se e $\mathrm{Zn}$. Todas as medições foram realizadas na prateleira 0 . 


\subsection{Espectrometria de Absorção Atômica (AAS)}

\subsubsection{Digestão das amostras}

Cerca de $350 \mathrm{mg}$ de amostra e $150 \mathrm{mg}$ dos MRC utilizados foram pesados diretamente nos tubos MARSXPress por meio de balança analítica.

O procedimento de digestão consistiu em deixar o material pesado reagindo com $10 \mathrm{~mL}$ de $\mathrm{HNO}_{3}$ P.A (Êxodo) durante a noite no próprio tubo XPress. No dia seguinte, os tubos foram abertos para que o gás de $\mathrm{NO}_{\mathrm{x}}$ já formado na reação com a matéria orgânica fosse desprendido e, posteriormente, os mesmos foram fechados e lacrados. Os tubos foram levados ao Sistema de Digestão por Micro-ondas MARS 6 e o procedimento para tecido animal (CEM, 2018) foi utilizado para realizar a digestão.

Após a digestão, os tubos foram levados para capela para resfriar até temperatura ambiente. Foi observado que as soluções estavam translúcidas, e, portanto, não foi necessário filtrações. A solução do tubo XPress foi transferida quantitativamente e avolumada para $25 \mathrm{~mL}$ com água purificada (Milli-Q), e depois transferida para tubos de polietileno (Falcon), recipientes esses que foram armazenados em freezers até a análise das amostras.

O branco dos reagentes foi feito de forma análoga, ou seja, pipetou-se $10 \mathrm{~mL}$ de $\mathrm{HNO}_{3}$ PA (Êxodo) em tubo XPRESS, que foi deixado em repouso durante a noite, e no dia seguinte levado ao Sistema de Digestão por Micro-ondas MARS-6 no mesmo procedimento de digestão juntamente com as amostras. O branco dos reagentes também foi avolumado com água purificada para $25 \mathrm{~mL}$.

\subsubsection{Espectrometria de Absorção Atômica por Geração de Vapor Frio (CV AAS)}

Para as determinações de $\mathrm{Hg}$ das amostras no espectrômetro FIMS da Perkin Elmer, foi retirado alíquota de $2 \mathrm{~mL}$ da solução de $25 \mathrm{~mL}$ e diluída 1:5 em água purificada. Para realização do branco dos reagentes, procedeu-se de forma análoga. O processo de preparação das soluções para calibração do espectrômetro é apresentado no fluxograma da Figura 5. 
Figura 5 - Fluxograma do procedimento de diluição a partir da solução concentrada para obtenção das soluções da curva de calibração para $\mathrm{Hg}$

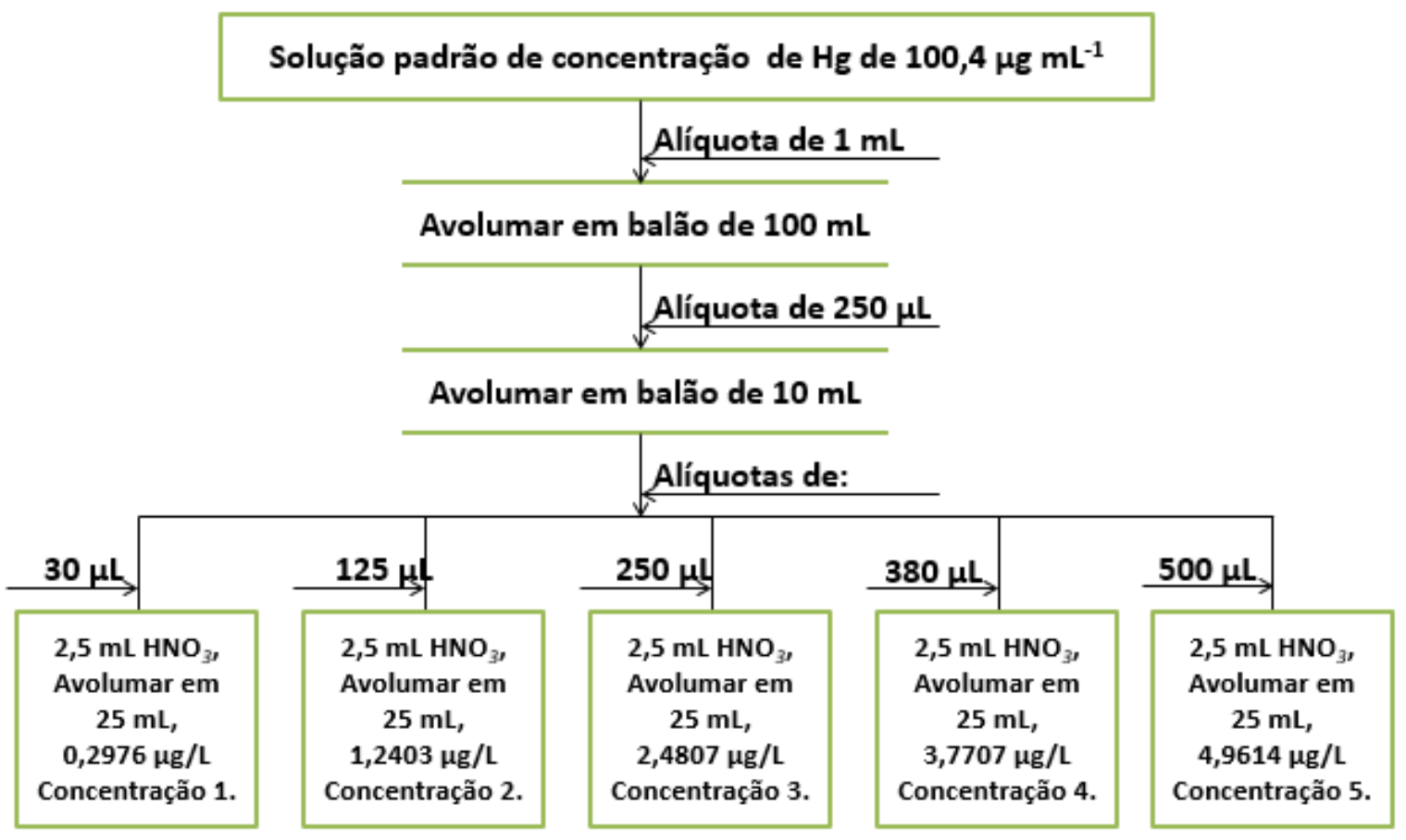

Fonte: autor da dissertação.

Para preparação do branco das curva de calibração, adicionou-se $2,5 \mathrm{~mL}$ de $\mathrm{HNO}_{3}$ P.A em balão de $25 \mathrm{~mL}$ e completou-se o menisco com água Mili-Q. Os parâmetros utilizados na programação do equipamento para a determinação de $\mathrm{Hg}$ são detalhados no trabalho de MOREIRA (2010). Todas as leituras de Hg se deram no mesmo dia em que foi realizada a digestão.

\subsubsection{Espectrometria de Absorção Atômica com Atomização Eletrotérmica (ET AAS)}

Para a determinação dos elementos $\mathrm{Cd}$ e $\mathrm{Pb}$ no espectrômetro AAnalyst 800 da Perkin Elmer, não foi necessário diluição prévia, ou seja, as amostras previamente digeridas foram transferidas diretamente em frascos de $1 \mathrm{~mL}$ do amostrador automático do equipamento.

O processo de preparação das soluções padrão para calibração do equipamento para a medição de $\mathrm{Cd}$ e $\mathrm{Pb}$ são apresentados nos fluxogramas abaixo, Figura 6 e Figura 7. Os parâmetros do programa de aquecimento do forno de micro-ondas utilizados neste estudo foram retirados do trabalho de MOREIRA (2010). 
Figura 6 - Fluxograma do procedimento de diluição a partir da solução concentrada para obtenção das soluções da curva de calibração para $\mathrm{Cd}$

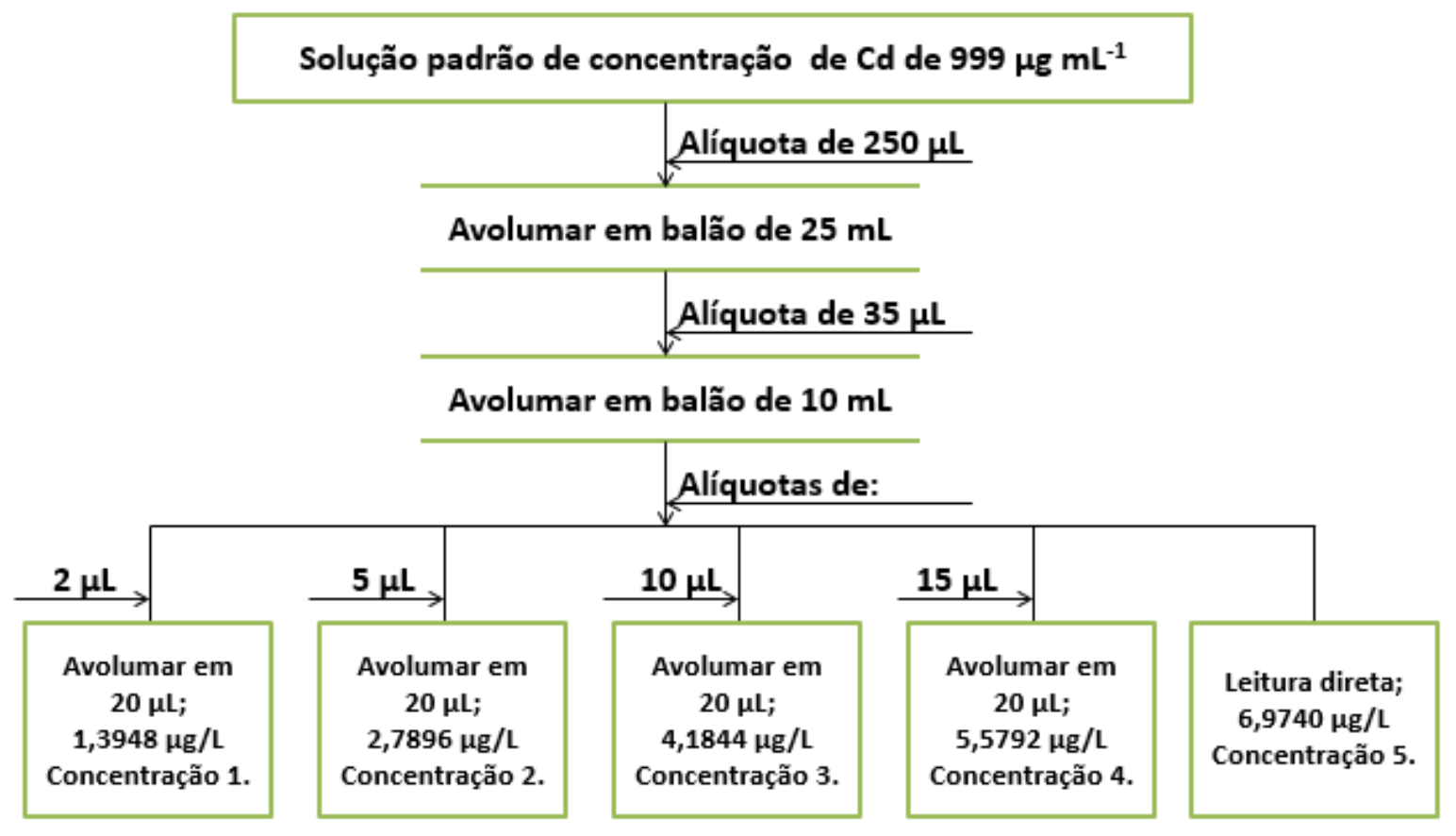

Fonte: autor da dissertação.

Figura 7 - Fluxograma do procedimento de diluição a partir da solução concentrada para obtenção das soluções da curva de calibração para $\mathrm{Pb}$

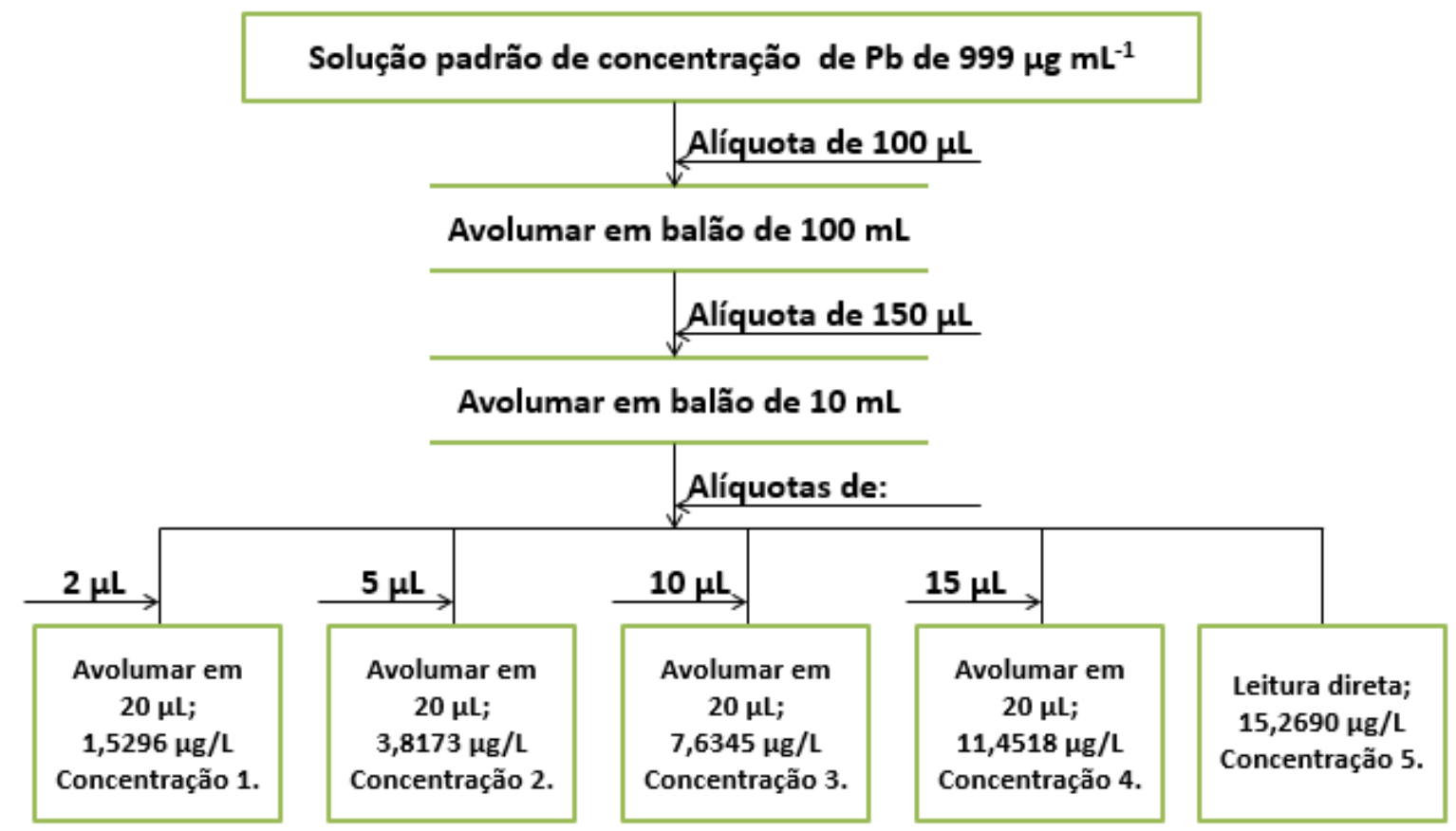

Fonte: autor da dissertação. 


\section{RESULTADOS E DISCUSSÃO}

7.1 Limites de detecção $\left(L_{D}\right)$ e quantificação $\left(L_{Q}\right)$ das técnicas analíticas utilizadas

\subsubsection{Análise por Ativação Neutrônica Instrumental}

Os valores de $L_{D}$ e $L_{Q}$ calculados para as condições de análise utilizadas no presente trabalho são apresentados na Tabela 14 para INAA de curta duração e na Tabela 15 para INAA de longa duração.

Tabela $14-\mathrm{L}_{\mathrm{D}}$ e $\mathrm{L}_{\mathrm{Q}}$ dos pescados analisados na INAA de curta duração (massa da amostra $=200 \mathrm{mg}$, base seca)

\begin{tabular}{ccc}
\hline Elemento & $\mathrm{L}_{\mathrm{D}}\left(\mathrm{mg} \mathrm{kg}^{-1}\right)$ & $\mathrm{LQ}_{\mathrm{Q}}\left(\mathrm{mg} \mathrm{kg}^{-1}\right)$ \\
\hline $\mathrm{Br}$ & 0,84 & 2,6 \\
$\mathrm{Cl}\left(\mathrm{g} \mathrm{kg}^{-1}\right)$ & 0,017 & 0,052 \\
$\mathrm{~K}\left(\mathrm{~g} \mathrm{~kg}^{-1}\right)$ & 0,081 & 0,25 \\
$\mathrm{Mg}\left(\mathrm{g} \mathrm{kg}^{-1}\right)$ & 0,025 & 0,075 \\
$\mathrm{Mn}$ & 0,040 & 0,12 \\
$\mathrm{Na}\left(\mathrm{g} \mathrm{kg}^{-1}\right)$ & 0,0025 & 0,0075 \\
\hline
\end{tabular}

Fonte: autor da dissertação.

Tabela 15 - $\mathrm{L}_{\mathrm{D}}$ e $\mathrm{L}_{\mathrm{Q}}$ dos pescados analisados na INAA de longa duração (massa da amostra $=200 \mathrm{mg}$, base seca)

\begin{tabular}{ccc}
\hline Elemento & $\mathrm{L}_{\mathrm{D}}\left(\mathrm{mg} \mathrm{kg}^{-1}\right)$ & $\mathrm{L}_{\mathrm{Q}}\left(\mathrm{mg} \mathrm{kg}^{-1}\right)$ \\
\hline $\mathrm{As}$ & 0,054 & 0,17 \\
$\mathrm{Br}$ & 0,073 & 0,22 \\
$\mathrm{Co}\left(\mu \mathrm{g} \mathrm{kg}^{-1}\right)$ & 4,5 & 14 \\
$\mathrm{Cr}$ & 0,086 & 0,26 \\
$\mathrm{Cs}\left(\mu \mathrm{g} \mathrm{kg}^{-1}\right)$ & 7,7 & 23 \\
$\mathrm{Fe}$ & 2,2 & 6,6 \\
$\mathrm{~K}\left(\mathrm{~g} \mathrm{~kg}^{-1}\right)$ & 0,29 & 0,90 \\
$\mathrm{Na}\left(\mathrm{g} \mathrm{kg}^{-1}\right)$ & 0,0017 & 0,0053 \\
$\mathrm{Rb}\left(\mu \mathrm{g} \mathrm{kg}^{-1}\right)$ & 112 & 339 \\
$\mathrm{Sb}\left(\mu \mathrm{g} \mathrm{kg}^{-1}\right)$ & 1,4 & 4,1 \\
$\mathrm{Se}$ & 0,11 & 0,34 \\
$\mathrm{Zn}$ & 0,11 & 0,34 \\
\hline
\end{tabular}

Fonte: autor da dissertação. 
Para as amostras analisadas por INAA de curta duração, não foram encontrados nenhum elemento abaixo do $\mathrm{L}_{\mathrm{Q}}$. Para as amostras de INAA de longa duração, houveram espécimes abaixo do LQ para As, Cr, Cs, Fe, Rb e Sb.

\subsubsection{Espectrometria de Absorção Atômica}

Os valores de $\mathrm{L}_{\mathrm{D}}$ e $\mathrm{L}_{\mathrm{Q}}$ obtidos para as modalidades de AAS nas condições utilizadas no presente trabalho estão apresentadas na Tabela 16.

Tabela $16-\mathrm{L}_{\mathrm{D}}$ e $\mathrm{L}_{\mathrm{Q}}$ dos pescados analisados na AAS (massa da amostra $=350 \mathrm{mg}$, volume final da solução $=25 \mathrm{~mL}$, base seca)

\begin{tabular}{cccc}
\hline Elemento & $\mathrm{L}_{\mathrm{D}}\left(\mu \mathrm{g} \mathrm{kg}^{-1}\right)$ & $\mathrm{LQ}_{\mathrm{Q}}\left(\mu \mathrm{g} \mathrm{kg}^{-1}\right)$ & Técnica analítica \\
\hline $\mathrm{Hg}$ & 15 & 41 & CV AAS \\
$\mathrm{Cd}$ & 3,1 & 7,3 & ET AAS \\
$\mathrm{Pb}$ & 208 & 295 & \\
\hline
\end{tabular}

Fonte: autor da dissertação.

Para o elemento $\mathrm{Hg}$, dos 60 espécimes analisados, apenas 10 estavam abaixo do limite de quantificação. Já no caso do $\mathrm{Cd}, 50 \%$ das amostras de todas as espécies estavam abaixo $\mathrm{L}_{\mathrm{Q}}$. Para o $\mathrm{Pb}$, foi possível quantificar o elemento apenas para a pescada, pois todas as demais espécies encontraram-se inferiores do $L_{D}$ da técnica.

\subsection{Cálculo da incerteza de medição}

\subsubsection{Análise por Ativação Neutrônica}

Neste estudo, o mensurando foi definido como as frações mássicas de As, Br, $\mathrm{Cl}, \mathrm{Co}, \mathrm{Cr}, \mathrm{Cs}, \mathrm{Fe}, \mathrm{K}, \mathrm{Mg}, \mathrm{Mn}, \mathrm{Na}, \mathrm{Rb}, \mathrm{Sb}$, Se e $\mathrm{Zn}$ em seis pescados (anchova, robalo, sardinha, tainha, pescada-branca e corvina) a serem determinados pelo método de INAA

A descrição do modelo matemático foi tratada na seção 4.1.1. As principais componentes de incerteza para o método de INAA são apresentadas por meio do Diagrama de Ishikawa, na Figura 8. 
Figura 8 - Diagrama de Ishikawa para o método de INAA

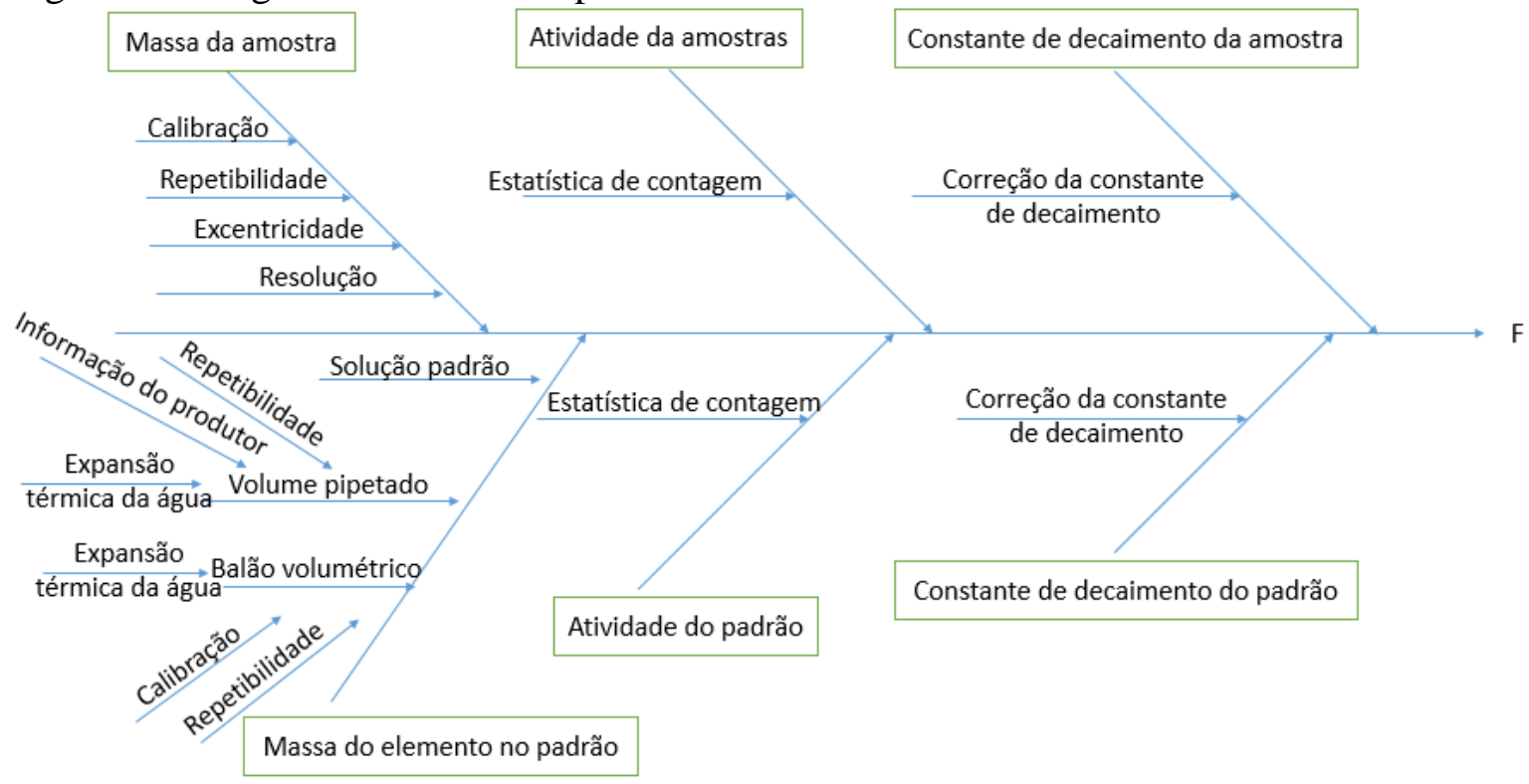

Fonte: autor da dissertação.

Para conversão das incertezas de entrada em incertezas padrão, foi necessário avaliar o tipo de incerteza. A avaliação do tipo A de incerteza de medição é atribuída a partir de distribuições estatísticas de valores provenientes de séries de medições. Avaliação do tipo B de incerteza de medição é estimada a partir de dados da literatura (INMETRO, 2012). Para as incertezas do tipo B deve-se levar em consideração as distribuições de probabilidades no processo de conversão da incerteza de entrada em incerteza padrão (EURACHEM e CITAC, 2012). A conversão das incertezas de entrada utilizadas neste trabalho em incertezas padrão encontra-se na Tabela 17. 
Tabela 17 - Fontes de incertezas utilizadas e sua conversão para forma de incerteza padrão

\begin{tabular}{|c|c|c|c|c|}
\hline \multicolumn{5}{|c|}{ Fontes de incertezas na INAA } \\
\hline \multirow[b]{2}{*}{$\begin{array}{c}\text { Incerteza de } \\
\text { entrada }\end{array}$} & \multirow[b]{2}{*}{$\begin{array}{l}\text { Incerteza } \\
\text { associada }\end{array}$} & \multirow[b]{2}{*}{ Distribuição } & \multicolumn{2}{|c|}{ Quantificação da incerteza padrão } \\
\hline & & & $\begin{array}{c}\text { Fator da } \\
\text { incerteza }\end{array}$ & Tipo (A ou B) \\
\hline \multirow{6}{*}{$\begin{array}{l}\text { Massa do } \\
\text { elemento no } \\
\text { padrão }\end{array}$} & $\begin{array}{c}\text { DP dos } \\
\text { pipetadores } \\
\text { (analista) }\end{array}$ & Normal & $1 /(\operatorname{raiz}(n))$ & A \\
\hline & $\begin{array}{c}\text { DP dos } \\
\text { pipetadores } \\
\text { (fabricante) }\end{array}$ & Retangular & $1 /(\operatorname{raiz}(3))$ & B \\
\hline & $\begin{array}{c}\text { DP do balão } \\
\text { volumétrico } \\
\text { (analista) }\end{array}$ & Normal & $1 /(\operatorname{raiz}(n))$ & A \\
\hline & $\begin{array}{l}\text { DP do balão } \\
\text { volumétrico } \\
\text { (calibração) }\end{array}$ & Retangular & $1 /(\operatorname{raiz}(3))$ & B \\
\hline & $\begin{array}{l}\text { Expansão } \\
\text { térmica da água }\end{array}$ & Retangular & $1 /(\operatorname{raiz}(3))$ & B \\
\hline & $\begin{array}{c}\text { Incerteza } \\
\text { expandida da } \\
\text { solução padrão }\end{array}$ & $k=2$ & $1 / 2$ & B \\
\hline $\begin{array}{l}\text { Atividade do } \\
\text { padrão }\end{array}$ & $\begin{array}{c}\text { Estatística de } \\
\text { contagem }\end{array}$ & $\begin{array}{l}\text { Distribuição de } \\
\text { Poisson }\end{array}$ & - & A \\
\hline $\begin{array}{l}\text { Constante de } \\
\text { decaimento }\end{array}$ & $\begin{array}{l}\text { Correção da } \\
\text { constante de } \\
\text { decaimento }\end{array}$ & Retangular & $1 /(\operatorname{raiz}(3))$ & B \\
\hline $\begin{array}{l}\text { Atividade da } \\
\text { amostra }\end{array}$ & $\begin{array}{c}\text { Estatística de } \\
\text { contagem }\end{array}$ & $\begin{array}{l}\text { Distribuição de } \\
\text { Poisson }\end{array}$ & - & A \\
\hline \multirow{4}{*}{$\begin{array}{l}\text { Massa da } \\
\text { amostra }\end{array}$} & Repetibilidade & Normal & $1 /(\operatorname{raiz}(n))$ & A \\
\hline & Resolução & Retangular & $1 /(\operatorname{raiz}(3))$ & B \\
\hline & Calibração & Normal & $1 /(\operatorname{raiz}(n))$ & $\mathrm{A}$ \\
\hline & Excentricidade & Retangular & $1 /($ raiz (3)) & $\mathrm{B}$ \\
\hline
\end{tabular}

Fonte: autor da dissertação.

As incertezas expandidas das soluções estoques utilizadas foram extraídas de seus respectivos certificados. Por já se tratarem de incertezas expandidas, dividiu-se a mesma por seus respectivos fatores de abrangência $(k)$, a fim de se obter sua incerteza padrão combinada.

As incertezas associadas aos volumes das pipetas foram calculadas por meio de verificação dos volumes e utilizando os valores fornecidos pelo produtor contidos no manual. A verificação dos volumes forneceu informações do desvio padrão. Também havia 
indicação de DP para os volumes utilizados no certificado das pipetas, e esses valores também foram levados em consideração.

Para elementos em que a diluição foi necessária, foram levados em consideração os valores de DP calculado e do manual das pipetas nos volumes utilizados para pipetar as alíquotas no balão, o DP calculado e o do certificado do balão volumétrico, e por fim, o DP calculado e do manual das pipetas nos volumes utilizados para pipetar a solução do balão para o papel de filtro na confecção dos padrões pipetados. Em todos esses procedimentos, levou-se em consideração a expansão térmica da água.

As incertezas associadas ao tempo de meia vida dos radionuclídeos de interesse foram retiradas do mesmo banco de dados (CHU et al., 1999) que contêm os tempos de meia vida. A incerteza da estatística de contagem é a raiz quadrada da atividade, uma vez que essa segue a distribuição de Poisson (MOREIRA et al., 2006).

Das incertezas relacionadas à pesagem, a resolução, excentricidade e calibração da balança foram retiradas do certificado de calibração da balança analítica utilizada, e a repetibilidade foi obtida experimentalmente $(n=10)$.

As incertezas de entrada foram convertidas em incertezas padrão, de acordo com seu tipo e distribuição. Posteriormente, foram calculadas as incertezas padrão combinadas pelo método de planilha de Kragten, indicado pelo guia EURACHEM (EURACHEM e CITAC, 2012) e, por fim, a incerteza expandida, que é o produto da incerteza padrão combinada por um fator de abrangência. $O$ fator de abrangência utilizado foi $k=2$, que fornece nível de confiança de aproximadamente 95\% (INMETRO, 2008).

Na Tabela 18 estão apresentados os valores de incerteza expandida obtidos para a modalidade de irradiação de curta duração.

Tabela 18 - Incerteza expandida obtida para os elementos determinados por irradiação de curta duração

\begin{tabular}{cc}
\hline Elemento & $\mathrm{U}(\%)$ \\
\hline $\mathrm{Br}$ & 9,6 \\
$\mathrm{Cl}$ & 2,8 \\
$\mathrm{~K}$ & 4,4 \\
$\mathrm{Mg}$ & 4,4 \\
$\mathrm{Mn}$ & 1,0 \\
$\mathrm{Na}$ & 1,5 \\
\hline
\end{tabular}

Fonte: autor da dissertação. 
Com base nas informações utilizadas para o cálculo da incerteza expandida para INAA de curta duração, os resultados obtidos foram considerados como satisfatórios.

Na Figura 9, são apresentadas as contribuições de cada incerteza de entrada no cálculo da incerteza expandida para o elemento $\mathrm{Mg}$.

Figura 9 - Contribuições das incertezas padrão na INAA de curta duração

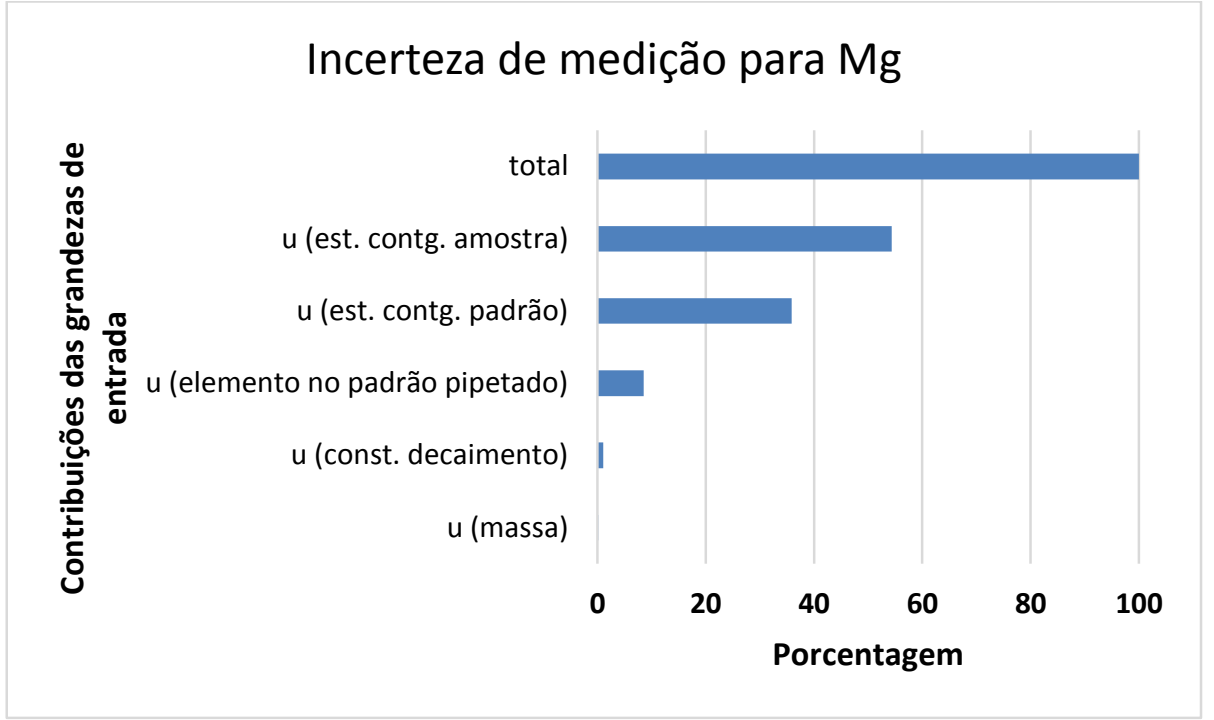

Fonte: autor da dissertação.

O principal componente de incerteza obtido para $\mathrm{Mg}$, mas que se aplica aos demais elementos químicos determinados por INAA de curta duração é a estatística de contagem, tanto da amostra quanto do padrão.

A Tabela 19 contém os valores de incerteza expandida obtidos para a modalidade de irradiação longa.

Tabela 19 - Incerteza expandida obtida para os elementos determinados por irradiação de longa duração

\begin{tabular}{cc}
\hline Elemento & $\mathrm{U}(\%)$ \\
\hline $\mathrm{As}$ & 2,8 \\
$\mathrm{Br}$ & 1,7 \\
$\mathrm{Co}$ & 11 \\
$\mathrm{Cr}$ & 21 \\
$\mathrm{Cs}$ & 8,1 \\
$\mathrm{Fe}$ & 9,9 \\
$\mathrm{~K}$ & 10 \\
$\mathrm{Na}$ & 1,2 \\
$\mathrm{Rb}$ & 3,9 \\
$\mathrm{Sb}$ & 17 \\
$\mathrm{Se}$ & 9,3 \\
$\mathrm{Zn}$ & 3,0 \\
\hline
\end{tabular}

Fonte: autor da dissertação. 
Com bases nas informações utilizadas para o cálculo da incerteza expandida para INAA de longa duração, os resultados obtidos foram considerados satisfatórios.

Na Figura 10, são apresentadas as contribuições de cada incerteza de entrada no cálculo da incerteza expandida para o contaminante As.

Figura 10 - Contribuições das incertezas padrão na INAA de longa duração

\section{Incerteza de medição de As}

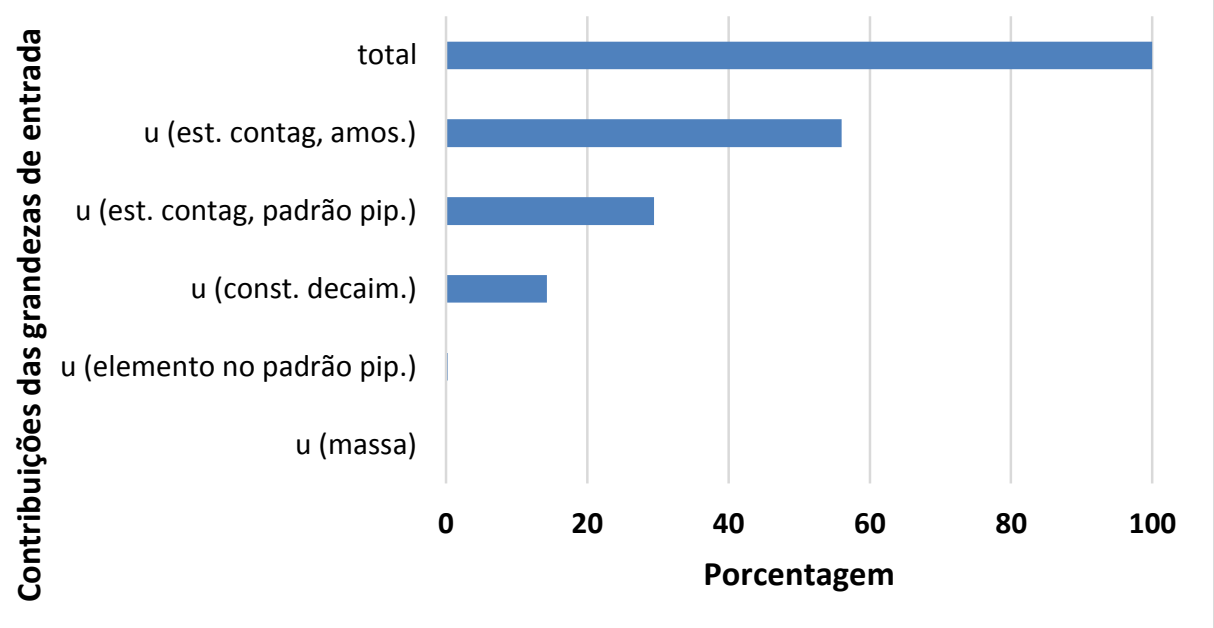

Fonte: autor da dissertação.

Para INAA de longa duração, assim como também obtida para outra modalidade dessa técnica, a maior contribuição para a incerteza expandida foi a estatística de contagem, da amostra e do padrão.

\subsubsection{Espectrometria de absorção Atômica}

Na Espectrometria de Absorção Atômica, o mensurando foi definido como as frações mássicas dos contaminantes $\mathrm{Cd}, \mathrm{Hg}$ e $\mathrm{Pb}$ nos filés dos pescados analisados neste trabalho.

O modelo matemático utilizado para o cálculo da incerteza é definido pela Equação 20:

$$
F=\frac{A-c}{a} x \frac{V}{M}
$$

sendo:

$A$ = absorbância;

$c=$ coeficiente linear da curva analítica; 
$a=$ coeficiente angular da curva analítica;

$V=$ volume final da amostra digerida;

$M=$ massa da amostra digerida.

As fontes de incertezas utilizadas para o cálculo da incerteza expandida em AAS são apresentadas no Diagrama de Ishikawa da Figura 11.

Figura 11 - Diagrama de Ishikawa com as incertezas de entrada usadas para AAS

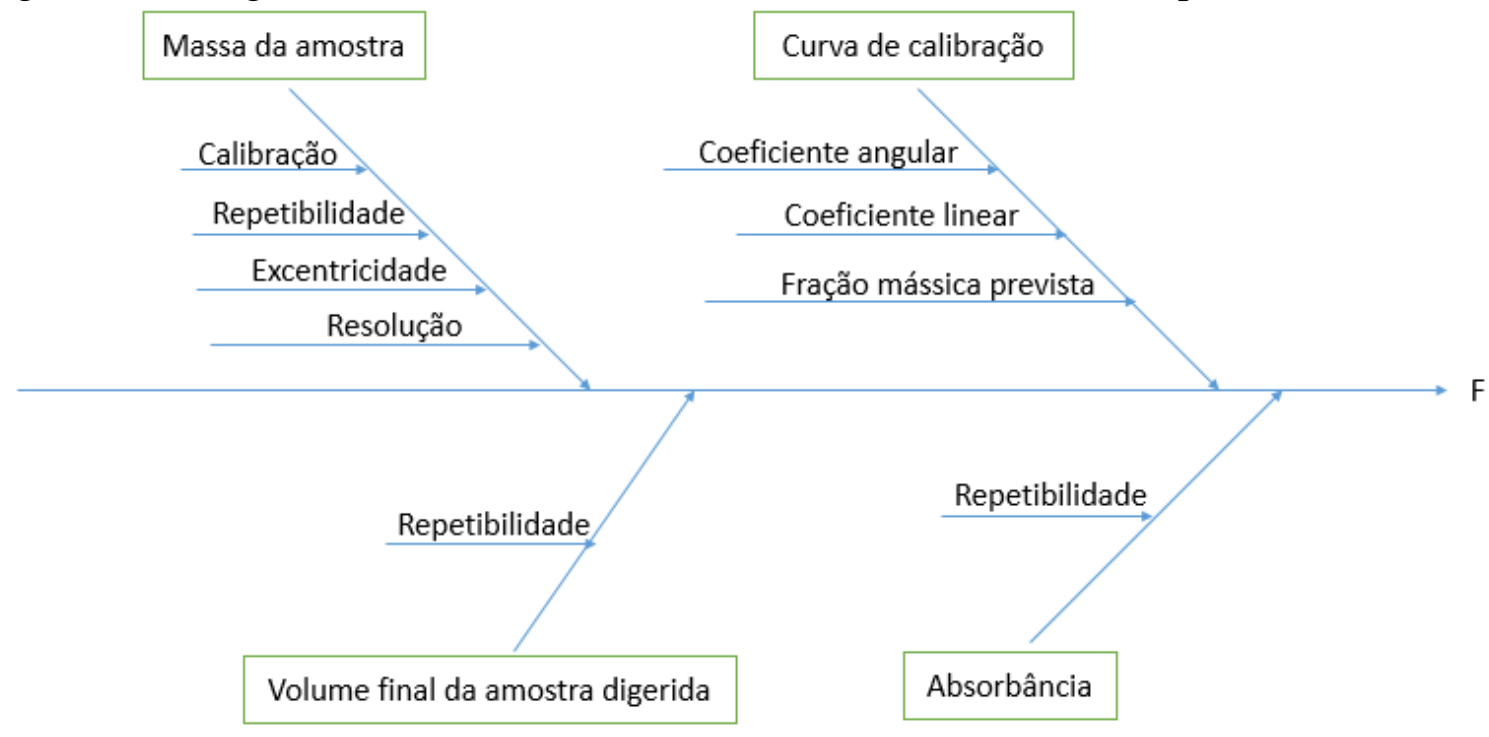

DP = desvio padrão. Fonte: autor da dissertação.

A Tabela 20 traz a conversão das incertezas de entrada em incerteza padrão levando em consideração o tipo de incerteza.

Tabela 20 - Fontes de incertezas utilizadas em AAS e sua conversão em incerteza padrão

\begin{tabular}{ccccc}
\hline \multirow{2}{*}{$\begin{array}{c}\text { Incerteza de } \\
\text { entrada }\end{array}$} & Incerteza associada & Distribuição & $\begin{array}{c}\text { Fator de } \\
\text { incerteza }\end{array}$ & \multirow{2}{*}{ Tipo (A ou B) } \\
\hline \multirow{3}{*}{ Massa da amostra } & Repetibilidade & Normal & $1 /(\operatorname{raiz}(n))$ & $\mathrm{A}$ \\
\cline { 2 - 5 } & Resolução & Retangular & $1 /(\operatorname{raiz}(3))$ & $\mathrm{B}$ \\
\cline { 2 - 5 } & Calibração & Normal & $1 /(\operatorname{raiz}(n))$ & $\mathrm{A}$ \\
\cline { 2 - 5 } & Excentricidade & Retangular & $1 /(\operatorname{raiz}(3))$ & $\mathrm{B}$ \\
\hline Volume final & Repetibilidade & Normal & $1 /(\operatorname{raiz}(n))$ & $\mathrm{A}$ \\
\hline Absorbância & Repetibilidade & Normal & $1 /(\operatorname{raiz}(n))$ & $\mathrm{A}$ \\
\hline \multirow{2}{*}{$\begin{array}{c}\text { Curva de } \\
\text { calibração }\end{array}$} & DP coeficiente angular & Normal & $1 /(\operatorname{raiz}(n))$ & $\mathrm{A}$ \\
\cline { 2 - 5 } & DP coeficiente linear & Normal & $1 /(\operatorname{raiz}(n))$ & $\mathrm{A}$ \\
\cline { 2 - 5 } & Fração mássica estimada & Normal & $1 /(\operatorname{raiz}(n))$ & $\mathrm{A}$ \\
\hline
\end{tabular}

Fonte: autor da dissertação. 
Assim como para INAA, para as incertezas relacionadas à pesagem, a resolução, excentricidade e calibração da balança foram retiradas do certificado de calibração da balança analítica utilizada, e a repetibilidade foi obtida experimentalmente.

A incerteza associada ao volume final se deu por meio da verificação do volume do recipiente utilizado para avolumar as amostras digeridas. A calibração desse volume possibilitou obter o resultado do DP, que foi levado em consideração.

A incerteza associada à absorbância é o desvio padrão entre as medições desta grandeza, realizada pelo software WinLab 32 for AAS, versão 6.2.0079 do espectrômetro de AAS.

Em relação às incertezas associadas à curva de calibração, os desvios padrão dos coeficientes angulares e lineares foram obtidos por meio do software Past 3.

Por fim, para o cálculo do desvio padrão associado ao valor de fração mássica estimada por interporlação $(\hat{x})$, foi utilizado a seguinte fórmula, descrita na Equação 21 (FARRANT, 1997):

$$
D P(\hat{x})=\frac{r s d}{m} \sqrt{\frac{1}{N}+\frac{1}{n}+\frac{\left(\bar{y}_{0}-\bar{y}\right)^{2}}{m^{2}\left(\left(\sum_{i=1}^{n}\left(x_{i} x_{i}\right)-\left(\sum_{i=1}^{n} x i\right)^{2} / n\right)\right)}}
$$

em que:

$m=$ coeficiente angular;

$n=$ número de pontos da curva analítica;

$N$ = número de repetições da leitura de absorbância y;

$\bar{y}_{0}=$ média de absorbância de determinada leitura;

$\bar{y}=$ média da absorbância da curva analítica;

$r s d$, sendo esse termo definido pela Equação 22:

$$
r s d=\sqrt{\frac{\sum_{i=1}^{n}\left(y_{i}-\widehat{y}_{l}\right)^{2}}{n-2}}
$$

em que:

$y_{i}=$ absorbância medida no ponto $i$ da curva analítica; 
$\hat{y}_{i}=$ a absorbância predita no ponto $i$ da curva analítica.

As incertezas de entrada foram convertidas em incertezas padrão e combinadas pelo método de planilha de Kragten (EURACHEM e CITAC, 2012). Para o cálculo da incerteza expandida, a incerteza combinada foi multiplicada pelo fator de abrangência $k=2$, que fornece nível de confiança de aproximadamente 95\% (INMETRO, 2008).

Na Tabela 21 estão contidos os valores de incerteza expandida obtida para as técnicas de CV AAS e ET AAS.

Tabela 21 - Incerteza expandida obtida para elementos determinados por AAS

\begin{tabular}{cc}
\hline Elemento & $\mathrm{U}(\%)$ \\
\hline $\mathrm{Cd}$ & 13 \\
$\mathrm{Hg}$ & 7,9 \\
$\mathrm{~Pb}$ & 6,5 \\
\hline
\end{tabular}

Fonte: autor da dissertação.

Com base nas informações utilizadas para o cálculo da incerteza expandida para AAS, os resultados obtidos para as modalidades CV e ET AAS foram considerados satisfatórios.

Na Figura 12 é possível observar como as incertezas associadas às grandeza de entrada contribuem para a incerteza expandida na técnica de AAS.

Figura 12 - Contribuições das incertezas padrão na AAS

\section{Incerteza de medição para $\mathrm{Pb}$}

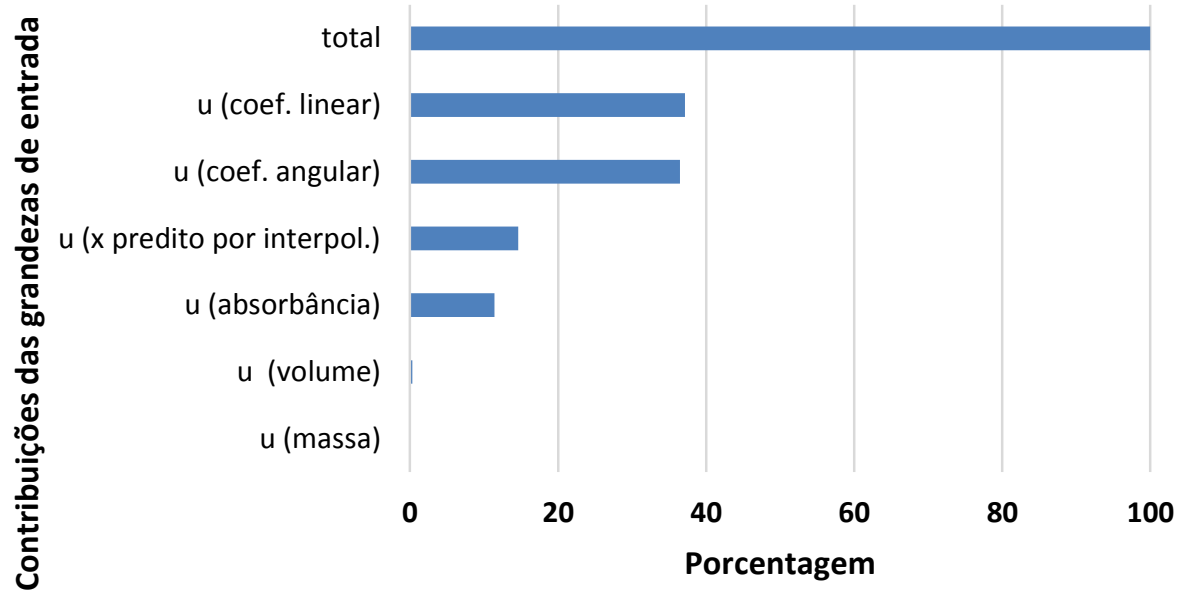

Fonte: autor da dissertação.

As maiores fontes de incertezas foram os desvios padrões associados aos coeficientes lineares e angulares da curva de calibração. 
Mesmo após o cálculo da incerteza expandida das técnicas analíticas utilizadas neste trabalho, optou-se por apresentar os valores de fração mássica dos elementos determinados nos pescados juntamente com o desvio padrão, uma vez que a variação natural de frações mássicas foi, em geral, maior do que a variação analítica do método, refletida na incerteza expandida.

Esta variação de fração mássica dos elementos determinados nos espécimes de pescado, principalmente para os contaminantes é considerada comum, uma vez que a acumulação depende de fatores como teor de gorduras, tamanho, idade, gênero, nível do elemento no ambiente, forma química do contaminante e tempo de exposição (FDA, 2011; CORRALES et al., 2016).

\subsection{Análise dos MRC para o controle da qualidade}

\subsection{1 Índice $z$}

Na irradiação de curta duração, foram irradiados dois MRC: mexilhão Perna Perna e o NIST SRM 1566b - tecido de ostra (Oyster Tissue). Informações sobre os valores obtidos no índice z para irradiação curta encontram-se na Tabela 22 e na Figura 13.

Tabela 22 - Fração mássica obtida por INAA (média \pm incerteza expandida, $k=2$, base seca, $n=4$ ) e os valores certificado dos materiais de referência

\begin{tabular}{|c|c|c|c|c|}
\hline \multirow{3}{*}{ Elemento } & \multicolumn{4}{|c|}{$\mathrm{MRC}$} \\
\hline & \multicolumn{2}{|c|}{ Mexilhão Perna Perna } & \multicolumn{2}{|c|}{$\begin{array}{c}\text { NIST SRM 1566b Oyster } \\
\text { Tissue }\end{array}$} \\
\hline & $\begin{array}{c}\text { Valor obtido } \\
\text { (valor certificado) }\end{array}$ & Índice z & $\begin{array}{c}\text { Valor obtido } \\
\text { (valor certificado) }\end{array}$ & Índice $\mathrm{z}$ \\
\hline $\mathrm{Br}\left(\mathrm{mg} \mathrm{kg}^{-1}\right)$ & $\begin{array}{c}250 \pm 50 \\
(248 \pm 42)^{\mathrm{i}}\end{array}$ & 0,13 & $\begin{array}{c}52,7 \pm 4,8 \\
(\mathrm{SV})\end{array}$ & - \\
\hline $\mathrm{Cl}(\%)$ & $\begin{array}{c}3,763 \pm 0,098 \\
(3,69 \pm 0,57)\end{array}$ & 0,58 & $\begin{array}{c}0,495 \pm 0,013 \\
(0,514 \pm 0,010)\end{array}$ & $-0,83$ \\
\hline $\mathrm{K}(\%)$ & $\begin{array}{c}0,90 \pm 0,14 \\
(0,82 \pm 0,13)\end{array}$ & 2,0 & $\begin{array}{c}0,635 \pm 0,031 \\
(0,652 \pm 0,009)\end{array}$ & $-0,58$ \\
\hline $\operatorname{Mg}(\%)$ & $\begin{array}{c}0,427 \pm 0,038 \\
(0,373 \pm 0,056)\end{array}$ & 2,7 & $\begin{array}{c}0,1118 \pm 0,0088 \\
(0,1085 \pm 0,0023)\end{array}$ & 0,51 \\
\hline $\operatorname{Mn}\left(\mathrm{mg} \mathrm{kg}^{-1}\right)$ & $\begin{array}{c}24,09 \pm 0,26 \\
(22,7 \pm 1,3)\end{array}$ & 0,5 & $\begin{array}{c}17,21 \pm 0,16 \\
(18,5 \pm 0,2)\end{array}$ & $-0,65$ \\
\hline $\mathrm{Na}(\%)$ & $\begin{array}{c}2,350 \pm 0,038 \\
(2,28 \pm 0,36)\end{array}$ & 0,82 & $\begin{array}{c}0,3005 \pm 0,0043 \\
(0,3297 \pm 0,0053)\end{array}$ & $-1,9$ \\
\hline
\end{tabular}

Fonte: autor da dissertação; ${ }^{i}$ valor informativo; SV: sem valor certificado. 
Figura 13 - Valores do índice z em forma gráfica para os MRC utilizados na irradiação de curta duração

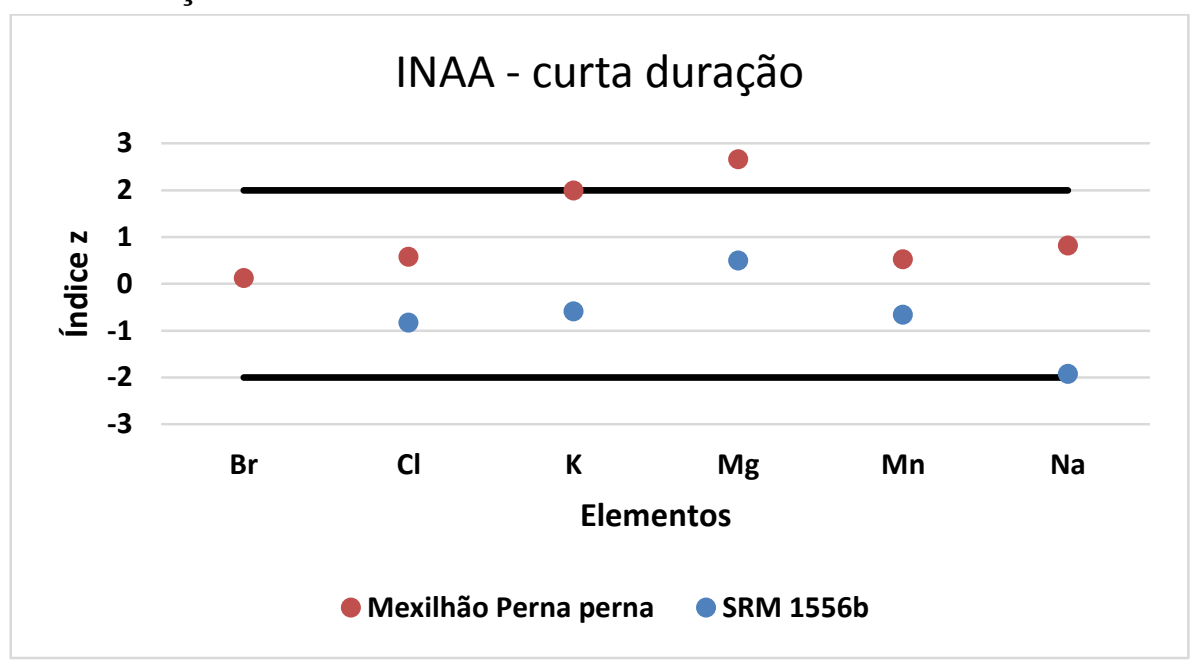

Fonte: autor da dissertação.

A forma gráfica dos dados de índice z permite verificar que, de forma geral, os valores obtidos são de $|z| \leq 2$, indicando resultados satisfatórios e, portanto, exatidão para os MRC analisados sob mesma condições das amostras. Verifica-se também que não há aparente tendência nos valores, que parecem variar de forma aleatória para os dois MRC.

Na irradiação longa, foram irradiados seis MRC: MRC mexilhão Perna Perna, NIST SRM 1566b - tecido de ostra (Oyster Tissue), NRCC DORM-4 - proteína de peixe, MRC tecido de peixe (Micropoginas furnieri), SRM NIST 2976 - tecido de Mexilhão (Mussel Tissue), MRC Modas-3 tecido de peixe (Hering tissue). Informações sobre os valores obtidos no índice z para irradiação longa encontram-se nas Tabela 23 e 24 e na Figura 14. 
Tabela 23 - Fração mássica obtida por INAA (media \pm incerteza expandida; $k=2$; base seca, $n=3$ ) e os valores certificados dos materiais de referência

\begin{tabular}{|c|c|c|c|c|c|c|}
\hline \multirow[b]{3}{*}{ Elemento } & \multicolumn{6}{|c|}{ MRC } \\
\hline & \multicolumn{2}{|c|}{ MRC Mexilhão Perna perna } & \multicolumn{2}{|c|}{ NIST SRM 1566b } & \multicolumn{2}{|c|}{ NRCC DORM-4 } \\
\hline & $\begin{array}{c}\text { Valor obtido } \\
\text { (valor certificado) }\end{array}$ & Índice $\mathrm{z}$ & $\begin{array}{c}\text { Valor obtido } \\
\text { (valor certificado) }\end{array}$ & Índice $\mathrm{z}$ & $\begin{array}{c}\text { Valor obtido } \\
\text { (valor certificado) }\end{array}$ & Índice $\mathrm{z}$ \\
\hline $\begin{array}{c}\mathrm{As} \\
\left(\mathrm{mg} \mathrm{kg}^{-1}\right)\end{array}$ & $\begin{array}{c}15,11 \pm 0,31 \\
(13,6 \pm 1,7)\end{array}$ & 0,85 & $\begin{array}{c}7,42 \pm 0,17 \\
(7,65 \pm 0,65)\end{array}$ & $-0,24$ & $\begin{array}{c}6,39 \pm 0,15 \\
(6,87 \pm 0,44)\end{array}$ & $-0,56$ \\
\hline $\begin{array}{c}\mathrm{Br} \\
\left(\mathrm{mg} \mathrm{kg}^{-1}\right)\end{array}$ & $\begin{array}{l}248,2 \pm 2,9 \\
(248 \pm 42)^{i}\end{array}$ & 0,01 & SV & - & SV & - \\
\hline $\begin{array}{c}\mathrm{Co} \\
\left(\mathrm{mg} \mathrm{kg}^{-1}\right)\end{array}$ & $\begin{array}{c}0,914 \pm 0,018 \\
(0,829 \pm 0,077)\end{array}$ & 0,42 & $\begin{array}{c}0,404 \pm 0,013 \\
(0,371 \pm 0,009)\end{array}$ & 0,37 & $\begin{array}{c}0,294 \pm 0,012 \\
(0,25)^{\mathrm{i}}\end{array}$ & 0,68 \\
\hline $\begin{array}{c}\mathrm{Cr} \\
\left(\mathrm{mg} \mathrm{kg}^{-1}\right)\end{array}$ & $\begin{array}{c}1,19 \pm 0,13 \\
(1,24 \pm 0,28)^{r}\end{array}$ & $-0,22$ & SV & - & $\begin{array}{c}1,82 \pm 0,19 \\
(1,87 \pm 0,18)\end{array}$ & $-0,17$ \\
\hline $\begin{array}{c}\mathrm{Cs} \\
\left(\mathrm{mg} \mathrm{kg}^{-1}\right)\end{array}$ & $\begin{array}{r}0,1091 \pm 0,0089 \\
(0,106 \pm 0,026)^{\mathrm{i}}\end{array}$ & 0,11 & SV & - & SV & - \\
\hline $\begin{array}{c}\mathrm{Fe} \\
\left(\mathrm{mg} \mathrm{kg}^{-1}\right)\end{array}$ & $\begin{array}{c}638 \pm 13 \\
(593 \pm 0,53)^{r}\end{array}$ & 1,1 & $\begin{array}{c}194 \pm 11 \\
(205,8 \pm 6,8)\end{array}$ & $-0,77$ & $\begin{array}{c}334 \pm 11 \\
(343 \pm 20)\end{array}$ & $-0,37$ \\
\hline $\begin{array}{c}\mathrm{K} \\
(\%)\end{array}$ & $\begin{array}{c}0,85 \pm 0,43 \\
(0,82 \pm 0,13)\end{array}$ & 0,76 & $\begin{array}{c}0,69 \pm 0,11 \\
(0,652 \pm 0,009)\end{array}$ & 1,3 & $\begin{array}{c}1,20 \pm 0,15 \\
(1,55 \pm 0,10)\end{array}$ & $-7,2$ \\
\hline $\begin{array}{l}\mathrm{Na} \\
(\%)\end{array}$ & $\begin{array}{c}2,034 \pm 0,020 \\
(2,28 \pm 0,36)\end{array}$ & $-3,3$ & $\begin{array}{c}0,2987 \pm 0,0038 \\
(0,3297 \pm 0,0053)\end{array}$ & $-2,1$ & $\begin{array}{l}1,244 \pm 0,014 \\
(1,40 \pm 0,24)^{\mathrm{r}}\end{array}$ & $-3,1$ \\
\hline $\begin{array}{c}\mathrm{Rb} \\
\left(\mathrm{mg} \mathrm{kg}^{-1}\right)\end{array}$ & $\begin{array}{c}4,86 \pm 0,24 \\
(4,93 \pm 0,92)^{\mathrm{i}}\end{array}$ & $-0,11$ & $\begin{array}{c}2,96 \pm 0,11 \\
(3,26 \pm 0,14)\end{array}$ & $-0,65$ & SV & - \\
\hline $\begin{array}{c}\mathrm{Se} \\
\left(\mathrm{mg} \mathrm{kg}^{-1}\right)\end{array}$ & $\begin{array}{c}4,60 \pm 0,24 \\
(4,42 \pm 0,45)\end{array}$ & 0,28 & $\begin{array}{c}1,94 \pm 0,15 \\
(2,06 \pm 0,15)\end{array}$ & $-0,39$ & $\begin{array}{c}3,35 \pm 0,17 \\
(3,45 \pm 0,40)\end{array}$ & $-0,21$ \\
\hline $\begin{array}{c}\mathrm{Sb} \\
\left(\mathrm{mg} \mathrm{kg}^{-1}\right)\end{array}$ & SV & - & $\begin{array}{c}0,00459 \pm 0,00091 \\
(0,011 \pm 0,002)^{\mathrm{r}}\end{array}$ & $-6,4$ & SV & - \\
\hline $\begin{array}{c}\mathrm{Zn} \\
\left(\mathrm{mg} \mathrm{kg}^{-1}\right)\end{array}$ & $\begin{array}{c}117,9 \pm 2,3 \\
(118,5 \pm 9,5)\end{array}$ & $-0,06$ & $\begin{array}{c}1281 \pm 31 \\
(1424 \pm 46)\end{array}$ & $-1,9$ & $\begin{array}{c}50,3 \pm 1,3 \\
(51,6 \pm 2,8)\end{array}$ & $-0,27$ \\
\hline
\end{tabular}

Fonte: autor da dissertação. SV = sem valor certificado; ${ }^{\mathrm{r}}$ valor de referência; ${ }^{\mathrm{i}}$ valor informativo. 
Tabela 24 - Fração mássica obtida por INAA (media \pm incerteza expandida; $k=2$; base seca, $n=3$ ) e os valores certificados dos materiais de referência

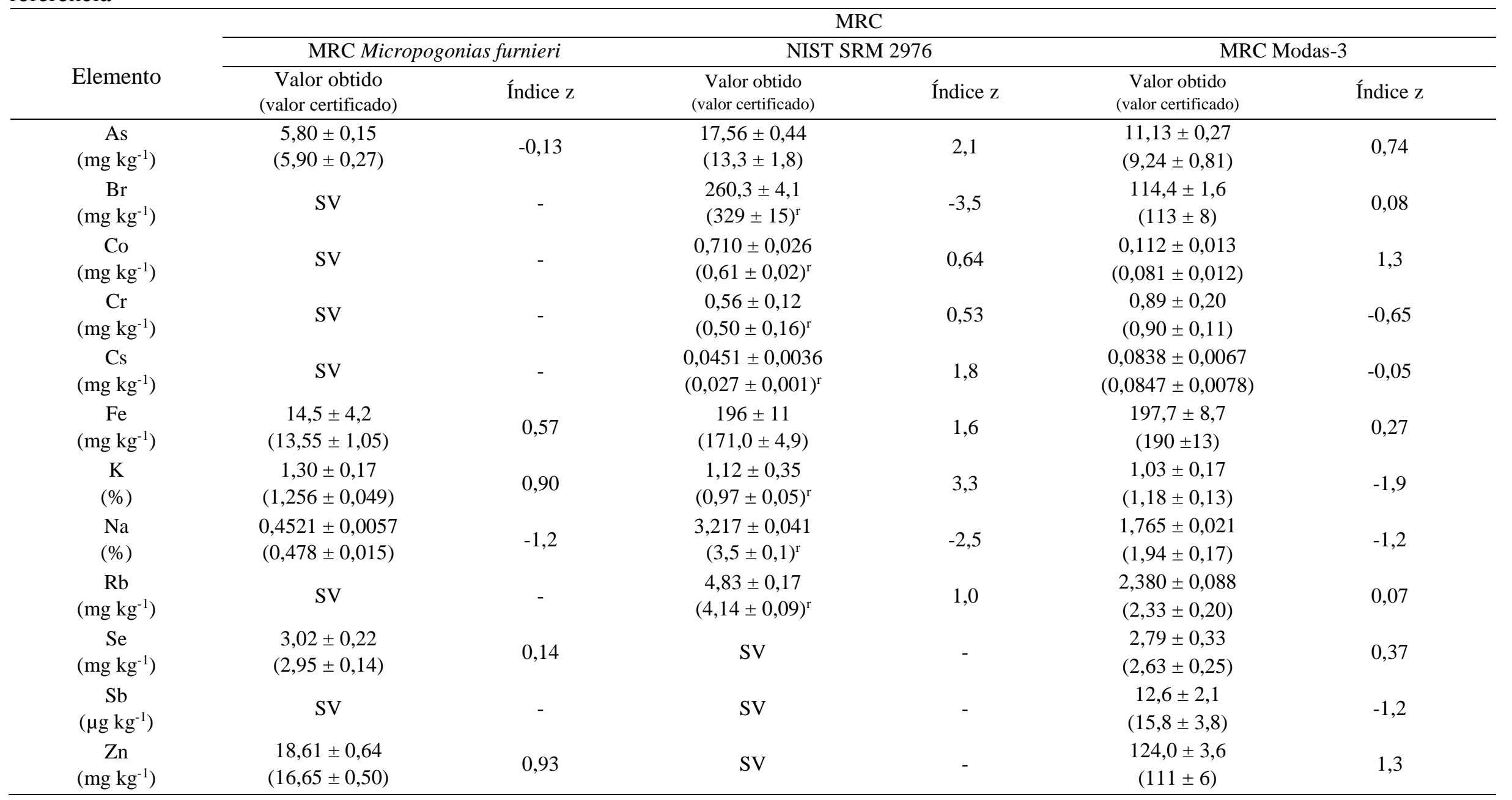

Fonte: autor da dissertação. SV = sem valor certificado; ${ }^{\mathrm{r}}$ valor de referência. 
Figura 14 - Valores do índice z em forma gráfica para os MRC utilizados na irradiação de longa duração

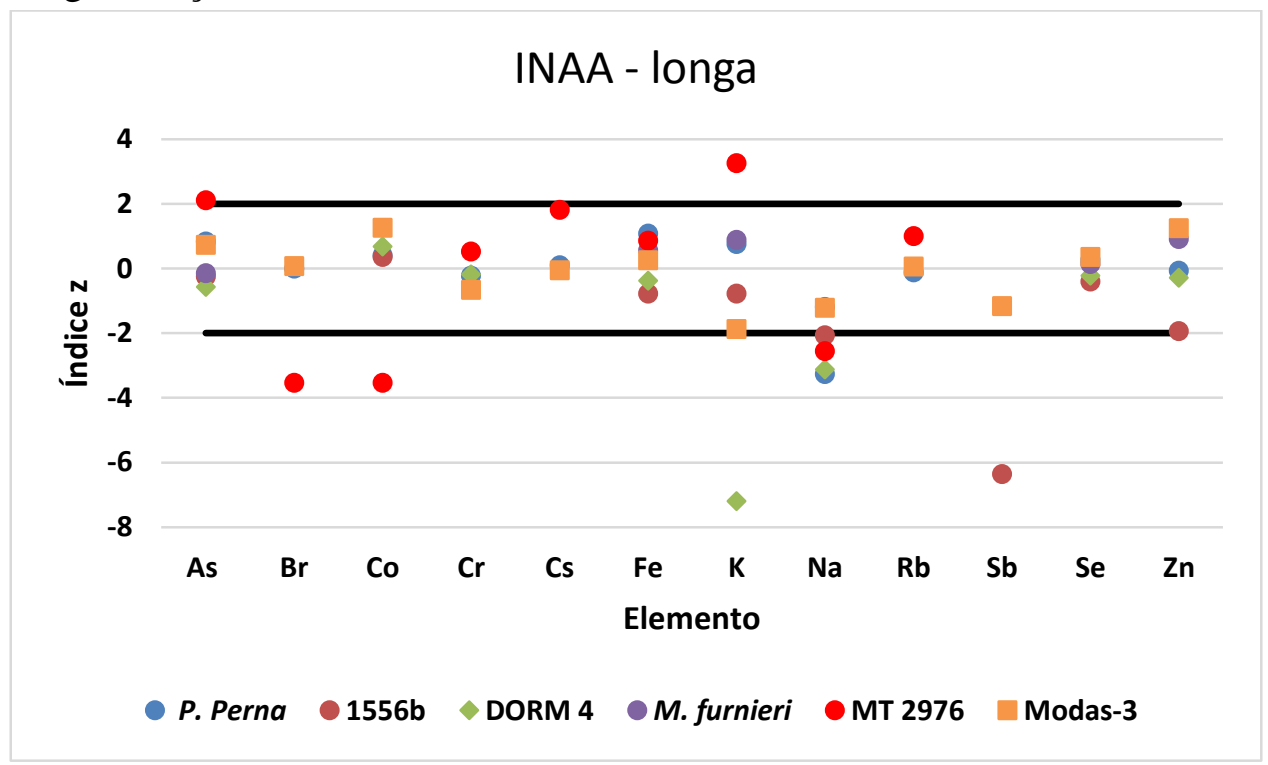

Fonte: autor da dissertação.

A forma gráfica possibilita visualizar que a maioria dos resultados obtidos são $|z| \leq 2$, que indica resultados satisfatórios e, portanto, exatidão para os MRC analisados sob mesma condições das amostras. Torna-se possível também verificar que não há aparente tendência nos dados, que ora são positivos, ora negativos, seja pra um mesmo elemento ou em comparação com os demais elementos, variando de forma aleatória.

Ressalta-se que os 2 MRC de tecido de peixe utilizados (M. furnieri e Modas-3) apresentaram os melhores resultados de índice $\mathrm{z}$, com todos os resultados satisfatórios.

Para os elementos com $|z| \geq 3$, destacam-se os elementos $\mathrm{Br}$ para o NIST SRM 2976, Sb no NIST SRM 1566b e os elementos Na e K de maneira geral.

Os elementos Na e K são quantificáveis na primeira contagem, e como descrito na subseção 6.4.1, foram esperados sete dias para esta medição, tempo que pode ter sido excessivo para elementos de meia vida da ordem de grandeza de horas.

O elemento $\mathrm{Br}$, também de primeira contagem, pode ter tido sua determinação prejudicada pois, o NIST SRM 2976 apresentou elevado tempo morto (mais radiação chegando ao detector do que o mesmo é capaz de quantificar) mesmo após sete dias de decaimento, o que pode ter ocasionado um índice z insatisfatório de valor negativo. 
Por fim, para o elemento Sb que está em outra ordem de grandeza (parte por bilhão), maiores investigações são necessárias para seu índice z insatisfatório de $-6,4$ no NIST SRM 1566b.

Já na Espectrometria de Absorção Atômica, foram analisados quatro MRC: MRC mexilhão Perna Perna, MRC tecido de peixe (Micropogonias furnieri), NRCC DOLT-3 fígado de cação, NIST SRM 2976 tecido de mexilhão (Mussel Tissue). Os valores obtidos de índice z para a técnica de AAS encontram-se na Tabela 25 e em forma gráfica na Figura 15.

Tabela 25 - Fração mássica obtida por AAS (média $\pm \mathrm{U}$; base seca, $n=3, k=2$ ) e os valores certificados dos materiais certificados

\begin{tabular}{ccccc}
\hline \multirow{2}{*}{ Valores } & \multicolumn{3}{c}{ Elemento $\left(\mathrm{mg} \mathrm{kg}^{-1}\right)$} & \multirow{2}{*}{ MRC } \\
\cline { 2 - 4 } & $\mathrm{Cd}$ & $\mathrm{Hg}$ & $\mathrm{Pb}$ & \\
\hline Valor obtido & $0,503 \pm 0,065$ & $0,1510 \pm 0,012$ & $0,728 \pm 0,047$ & \\
(valor certificado) & $(0,58 \pm 0,10)$ & $(0,165 \pm 0,041)^{\mathrm{i}}$ & $(0,56 \pm 0,15)$ & MRC . perna \\
Índice z & $-0,70$ & $-0,38$ & 1,2 & \\
\hline Valor obtido & $0,0233 \pm 0,0030$ & $0,917 \pm 0,072$ & $\mathrm{SV}$ & MRC M. furnieri \\
(valor certificado) & $(0,020 \pm 0,002)$ & $(0,88 \pm 0,12)^{\mathrm{i}}$ & & \\
Índice z & 0,64 & 0,22 & - & \multirow{2}{*}{ NRCC DOLT-3 } \\
Valor obtido & $19,2 \pm 2,5$ & $3,82 \pm 0,30$ & $0,771 \pm 0,050$ & \\
(valor certificado) & $(19,4 \pm 0,6)$ & $(3,37 \pm 0,14)$ & $(0,32 \pm 0,05)$ & \\
Índice z & $-0,10$ & 0,81 & 3,1 & \multirow{2}{*}{ NIST SRM 2976 ${ }^{\mathrm{a}}$} \\
\hline Valor obtido & $0,83 \pm 0,11$ & $0,0864 \pm 0,0068$ & $1,78 \pm 0,12$ & \\
(valor certificado) & $(0,82 \pm 0,16)$ & $(0,0610 \pm 0,0036)$ & $(1,19 \pm 0,18)$ & \\
Índice z & 0,06 & 1,3 & 2,0 &
\end{tabular}

Fonte: autor da dissertação. ${ }^{\mathrm{i}}$ valor informativo; ${ }^{\mathrm{a}} n=2$. 
Figura 15 - Valores de índice z obtidos para os MRC por AAS

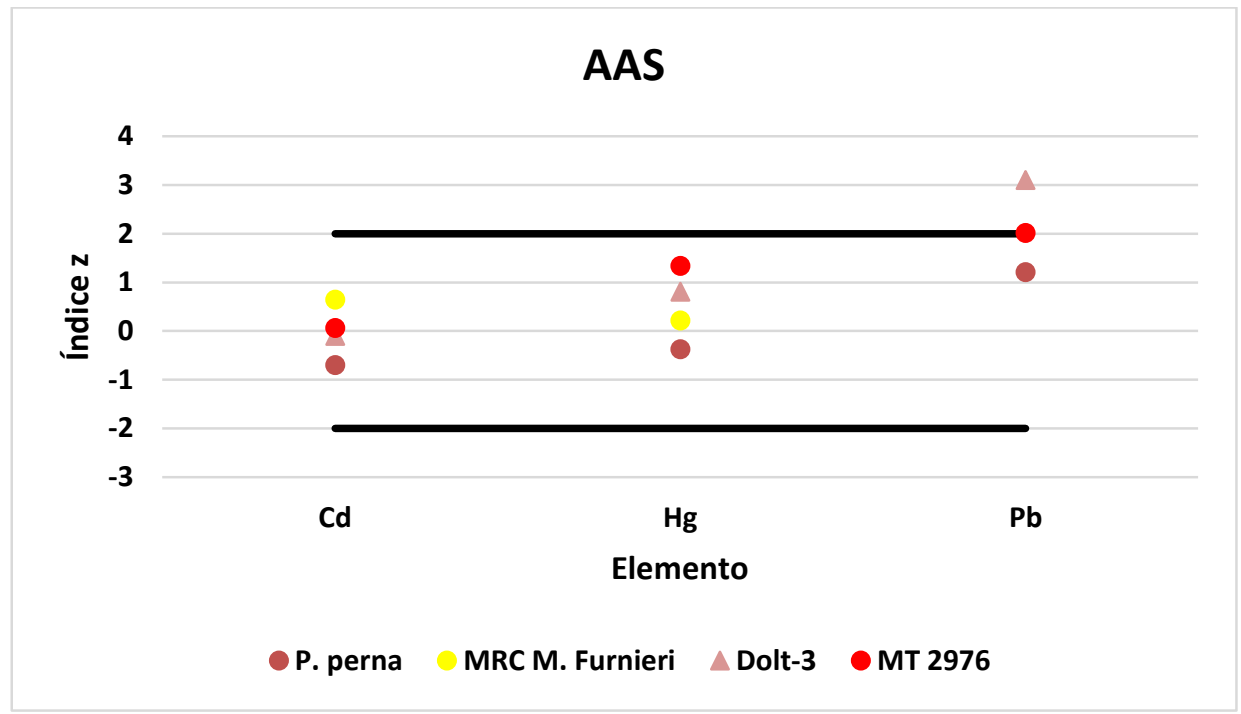

Fonte: autor da dissertação.

Observa-se que, em geral, os resultados obtidos são de $|z| \leq 2$ e, portanto, são considerados satisfatórios, apresentando exatidão adequada para os MRC analisados sob mesma condição das amostras de pescado. Como resultados a serem observados com maior atenção, pode-se destacar o Pb para os MRC P. perna e NIST SRM 2976. Contudo, o elemento $\mathrm{Pb}$ apresenta o $\mathrm{L}_{\mathrm{D}}$ e $\mathrm{L}_{\mathrm{Q}}$ menos sensível em relação aos outros elementos determinados por AAS (em outra ordem de grandeza inclusive), o que indica que tanto as amostras quanto os próprios MRC estavam próximos ao limite de detecção durante as medições, o que pode ter resultado em valor de índice $\mathrm{z}$ insatisfatório.

\subsubsection{Valor de HorRat}

Para os materiais de referência analisados, também se efetuou o cálculo do valor de HorRat. A Tabela 26, assim como a Figura 16, apresentam os valores de HorRat para as irradiações de curta duração.

Tabela 26 - Valores de HorRat para os MRC analisados por irradiação de curta duração

\begin{tabular}{ccc}
\hline \multirow{2}{*}{ Elemento } & \multicolumn{2}{c}{ MRC } \\
\cline { 2 - 3 } & Mexilhão Perna perna & NIST SRM 1566b \\
\cline { 2 - 3 } & Valor de HorRat & Valor de HorRat \\
\hline $\mathrm{Br}$ & 1,7 & - \\
$\mathrm{K}$ & 0,83 & 2,6 \\
$\mathrm{Mg}$ & 1,4 & 1,8 \\
$\mathrm{Mn}$ & 2,1 & 1,1 \\
$\mathrm{Na}$ & 0,91 & 0,40 \\
& 2,2 & 0,91 \\
\hline
\end{tabular}

Fonte: autor da dissertação. 
Figura 16 - Representação gráfica dos valores de HorRat para os MRC analisados por irradiação de curta duração

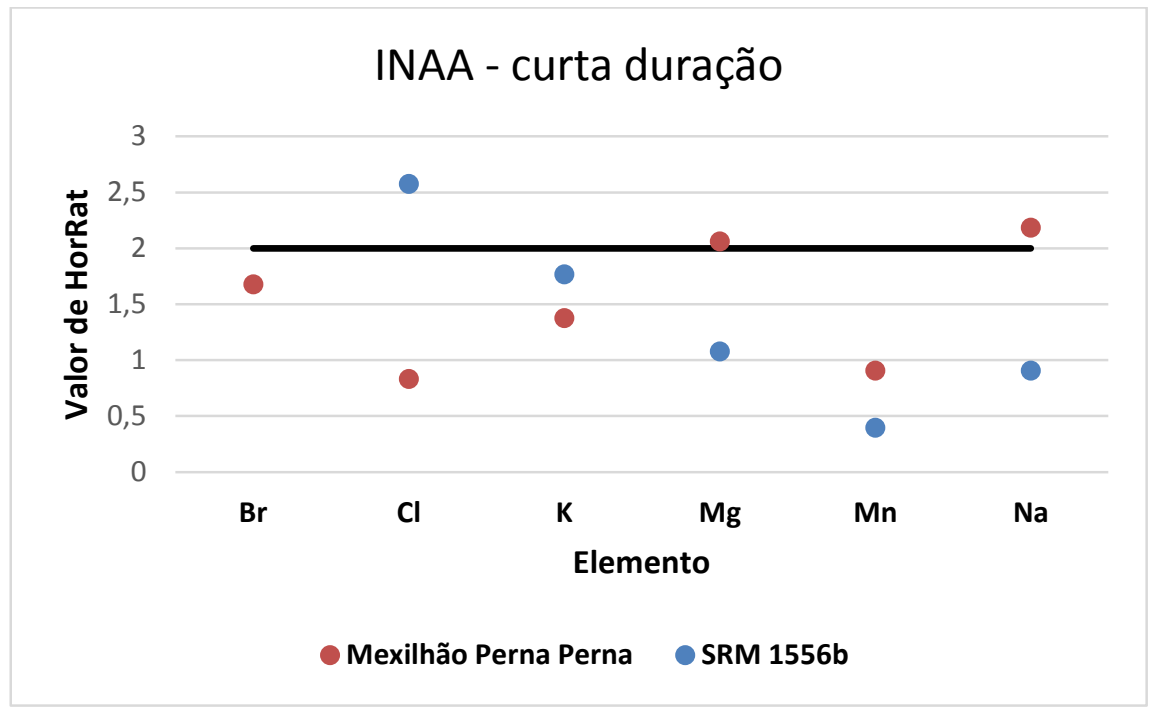

Fonte: autor da dissertação.

Os resultados obtidos foram em geral $\leq 2$ e portanto, foram considerados satisfatórios, o que neste caso indica valores reprodutíveis para os MRC analisados nas mesmas condições das amostras.

Em relação aos MRC utilizados na irradiação de longa duração, o cálculo dos valores de HorRat são apresentados na Tabela 27, enquanto a Figura 17 apresentam os valores na forma gráfica.

Tabela 27 - Valores de HorRat para os MRC analisados por irradiação de longa duração

\begin{tabular}{ccccccc}
\hline & \multicolumn{7}{c}{ MRC } \\
\cline { 2 - 7 } Elemento & P. perna & NIST 1566b & DORM-4 & M. Furnieri & NIST 2976 & MODAS-3 \\
\cline { 2 - 7 } & 0,48 & 0,17 & 1,2 & 0,35 & 1,4 & 0,17 \\
$\mathrm{As}$ & 1,0 & - & - & - & 0,37 & 0,50 \\
$\mathrm{Br}$ & 0,55 & 0,49 & 0,96 & - & 0,07 & 1,4 \\
$\mathrm{Co}$ & 0,23 & - & 1,1 & - & 1,4 & 0,07 \\
$\mathrm{Cr}$ & 0,54 & - & - & - & 0,51 & 0,88 \\
$\mathrm{Cs}$ & 1,1 & 0,96 & 2,6 & 0,76 & 0,42 & 0,88 \\
$\mathrm{Fe}$ & 2,7 & 2,5 & 5,2 & 2,9 & 4,6 & 5,8 \\
$\mathrm{~K}$ & 1,6 & 1,1 & 3,6 & 0,63 & 0,11 & 0,85 \\
$\mathrm{Na}$ & 0,33 & 0,42 & - & - & 0,52 & 0,50 \\
$\mathrm{Rb}$ & 0,22 & 0,33 & 1,4 & 0,23 & - & 0,31 \\
$\mathrm{Se}$ & - & 0,16 & - & - & - & 2,1 \\
$\mathrm{Sb}$ & 0,36 & 0,63 & 2,3 & 0,23 & - & 0,40 \\
$\mathrm{Zn}$ & & 7
\end{tabular}

Fonte: autor da dissertação. 
Figura 17 - Representação gráfica dos valores de HorRat para os MRC analisados na irradiação de longa duração

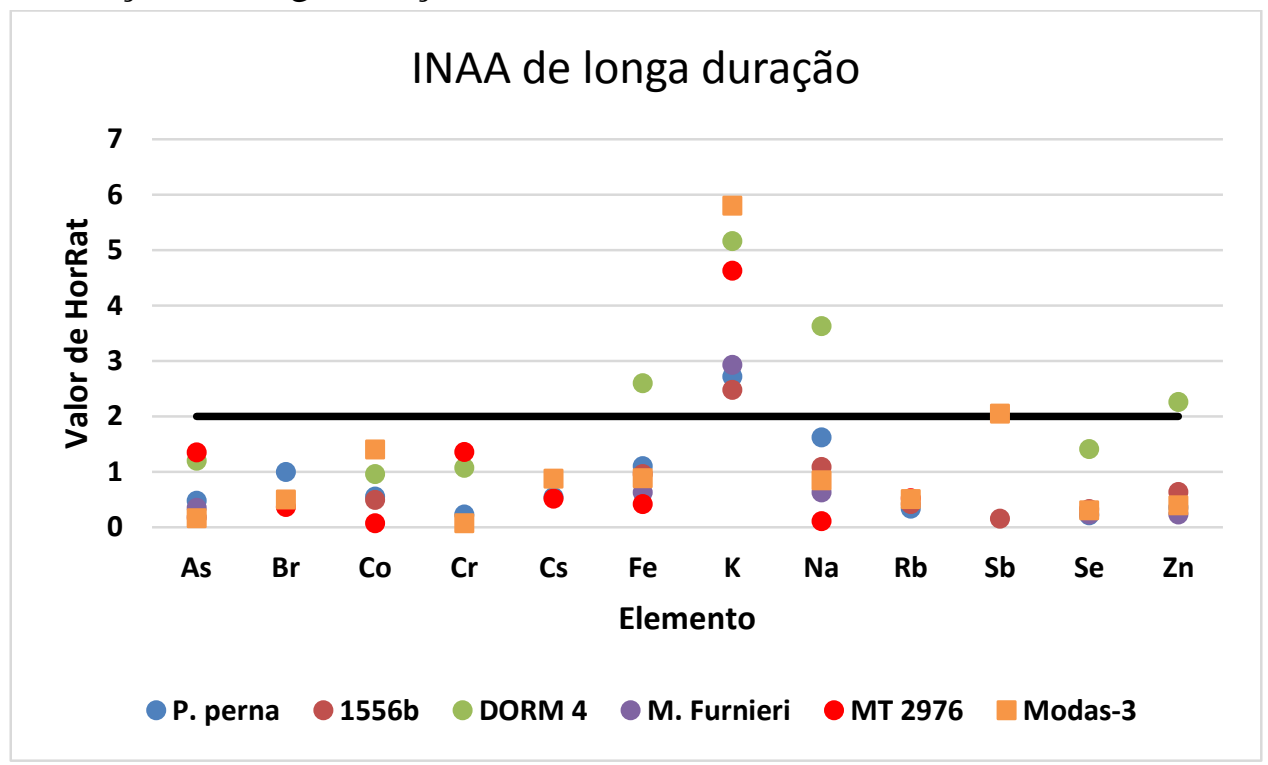

Fonte: autor da dissertação.

Nota-se em análise descritiva dos dados, que na sua grande maioria, os valores observados foram $\leq 2$, considerados satisfatoriamente reprodutíveis.

Destacam-se para os valores $\geq 2$ os elementos $\mathrm{Na}$ e $\mathrm{K}$, que são de primeira medição, e assim como o tempo de sete dias para o início da leitura dos mesmos pode ter afetado a exatidão da determinação, por conta do decaimento, o mesmo pode ser acontecido para a precisão.

Por fim, os resultados de valor de HorRat para os MRC utilizados em ET AAS e CV AAS são apresentados na Tabela 28 e na Figura 18.

Tabela 28 - Valores de HorRat para os MRC analisados em CV e ET AAS

\begin{tabular}{ccccc}
\hline \multirow{2}{*}{ Elemento } & Perna perna & M. Furnieri & NRCC DOLT-3 & NIST SRM 2976 \\
\cline { 2 - 5 } & \multicolumn{5}{c}{ Valor de HorRat } \\
$\mathrm{Cd}$ & 0,26 & 0,58 & 0,42 & 0,13 \\
$\mathrm{Hg}$ & 0,15 & 0,17 & 0,16 & 0,07 \\
$\mathrm{~Pb}$ & 1,24 & & 1,3 & 1,7 \\
\hline
\end{tabular}

Fonte: autor da dissertação. 
Figura 18 - Representação gráfica dos valores de HorRat para os MRC analisados por CV e ET AAS

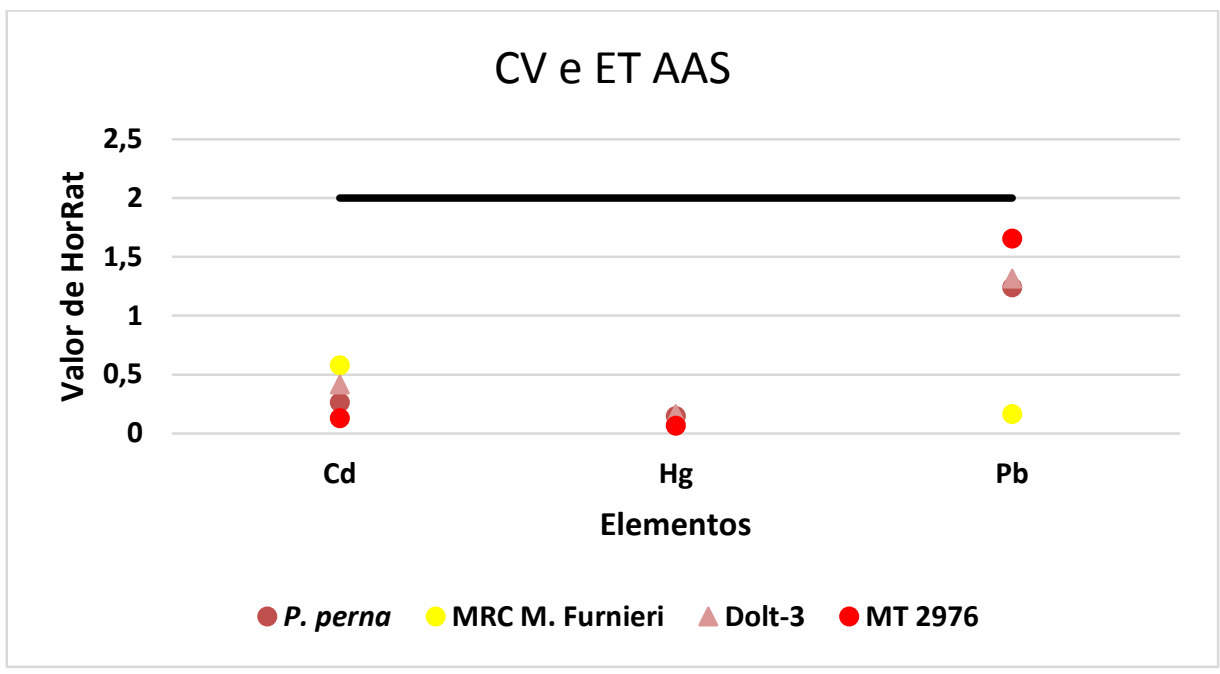

Fonte: autor da dissertação.

Todos os valores de HorRat obtidos para CV e ET AAS para os MRC analisados sob mesma condições de análises foram $\leq 2 \mathrm{e}$, portanto, foram considerados satisfatoriamente reprodutíveis.

\subsection{Análise dos pescados}

\subsubsection{Comparação entre irradiações de curta e longa duração}

Como a determinação dos elementos $\mathrm{Br}$, $\mathrm{Na}$ e $\mathrm{K}$ se deu por ambas as modalidades de irradiação, esta subseção tem como objetivo discutir os resultados obtidos pelas duas técnicas e escolher uma para a apresentação final dos resultados para esses três elementos.

Inicialmente, para verificar se houve diferença significativa nestas análises, se utilizou teste-t de Student com nível de significância $\alpha=5 \%$, observando-se as premissas de normalidade (Shapiro-Wilk) e homocedatiscidade (teste-F). Os resultados obtidos via testet são apresentados na Tabela 29.

Para o teste-t, têm-se a hipótese nula ( $\alpha \geq 5 \%$.) indicando inexistência de diferença entre as modalidades de irradiação, enquanto a hipótese alternativa indica diferença significativa. 
Tabela 29 - Premissas e teste-t de Student entre os elementos Br, Na e K (valor de $p$ )

\begin{tabular}{|c|c|c|c|c|c|c|}
\hline Premissas & \multicolumn{6}{|c|}{ Fração mássica in natura } \\
\hline C. leiarchus & Br curta & Br longa & K curta & K longa & Na curta & $\mathrm{Na}$ longa \\
\hline Normalidade & 0,31 & 0,35 & 0,015 & 0,47 & 0,0079 & 0,45 \\
\hline Homocedasticidade & \multicolumn{2}{|c|}{0,53} & \multicolumn{2}{|c|}{0,44} & \multicolumn{2}{|c|}{0,58} \\
\hline Teste-t & \multicolumn{2}{|c|}{0,78} & \multicolumn{2}{|c|}{$0,97^{\mathrm{a}}$} & \multicolumn{2}{|c|}{$0,79^{\mathrm{a}}$} \\
\hline $\begin{array}{c}\text { Comparação prática } \\
\text { entre os valores }\end{array}$ & \multicolumn{2}{|r|}{ A } & A & $\mathrm{A}$ & A & A \\
\hline C. undecimalis & Br curta & Br longa & K curta & K longa & Na curta & Na longa \\
\hline Normalidade & \multirow{2}{*}{\multicolumn{2}{|c|}{$\begin{array}{ll}0,65 & \\
0,63 & \end{array}$}} & \multicolumn{2}{|l|}{0,35} & 0,68 & 0,63 \\
\hline Homocedasticidade & & & \multicolumn{2}{|c|}{0,55} & \multicolumn{2}{|c|}{0,97} \\
\hline Teste-t & \multicolumn{2}{|c|}{0,24} & \multicolumn{2}{|c|}{0,0067} & \multicolumn{2}{|c|}{0,70} \\
\hline $\begin{array}{l}\text { Comparação prática } \\
\text { entre os valores }\end{array}$ & \multicolumn{2}{|l|}{ A } & \multicolumn{2}{|l|}{$\mathbf{A}$} & $\mathrm{A}$ & A \\
\hline M. Furnieri & Br curta & Br longa & K curta & K longa & Na curta & Na longa \\
\hline Normalidade & \multirow{2}{*}{\multicolumn{2}{|c|}{$0,80 \quad \begin{array}{ll}0,67 \\
\end{array}$}} & \multirow{2}{*}{\multicolumn{2}{|c|}{$0,63 \quad 2^{0,81}$}} & 0,39 & 0,72 \\
\hline Homocedasticidade & & & & & \multicolumn{2}{|c|}{0,11} \\
\hline Teste-t & \multicolumn{2}{|c|}{0,31} & \multicolumn{2}{|c|}{0,54} & \multicolumn{2}{|c|}{0,83} \\
\hline $\begin{array}{l}\text { Comparação prática } \\
\text { entre os valores }\end{array}$ & \multicolumn{2}{|l|}{ A } & \multicolumn{2}{|l|}{ A } & A & $\mathrm{A}$ \\
\hline S. brasiliensis & Br curta & Br longa & K curta & K longa & Na curta & Na longa \\
\hline Normalidade & 0,34 & 0,71 & 0,0061 & 0,50 & 0,63 & 0,27 \\
\hline Homocedasticidade & & & & & & \\
\hline Teste-t & & & & & & \\
\hline $\begin{array}{l}\text { Comparação prática } \\
\text { entre os valores }\end{array}$ & A & A & A & A & $\mathrm{A}$ & A \\
\hline P. Saltatrix & Br curta & Br longa & K curta & K longa & Na curta & Na longa \\
\hline Normalidade & 0,36 & 0,085 & 0,39 & 0,078 & 0,33 & 0,86 \\
\hline Homocedasticidade & & 8 & & & & 0 \\
\hline $\begin{array}{c}\text { Comparação prática } \\
\text { entre os valores }\end{array}$ & $\mathbf{A}$ & B & $\mathrm{A}$ & A & $\mathrm{A}$ & A \\
\hline M. brasiliensis & Br curta & Br longa & K curta & K longa & Na curta & $\mathrm{Na}$ longa \\
\hline Normalidade & 0,28 & 0,39 & 0,26 & 0,89 & 0,61 & 0,41 \\
\hline Homocedasticidade & & & & & & \\
\hline Teste- $\mathrm{t}$ & & & & & & \\
\hline $\begin{array}{l}\text { Comparação prática } \\
\text { entre os valores }\end{array}$ & A & A & $\mathrm{A}$ & A & $\mathrm{A}$ & A \\
\hline
\end{tabular}

aevido a quebra de premissa(s), utilizou-se o teste não paramétrico de Mann-Whitney ao invés do teste-t de Student. Fonte: autor da dissertação.

Como pode ser observado por meio dos resultados, houve diferença significativa em apenas dois dos 18 testes realizados - K para o C. undecimalis e $\mathrm{Br}$ na $P$. saltatrix. Para as demais comparações realizadas, portanto, não há diferença significativa ( $\alpha=5 \%$ ) na apresentação dos resultados de caracterização dos pescados por irradiação de longa ou curta duração. 
Contudo, com o intuito investigar qual dos métodos utilizar, tendo em vista os dois casos em que houve diferença significativa, a análise dos indicadores de qualidade (índice z e valor de HorRat) e outros parâmetros $\left(U, L_{Q}\right)$ serão comparados. Na Tabela 30 está compilado os valores desses parâmetros.

Tabela 30 - Compilação dos indicadores de qualidade, $\mathrm{U}$ e $\mathrm{L}_{\mathrm{Q}}$

\begin{tabular}{cccc|cc|cc}
\hline \multirow{2}{*}{ Parâmetro } & \multirow{2}{*}{ MRC } & \multicolumn{2}{c|}{ Br } & \multicolumn{2}{c|}{$\mathrm{K}$} & \multicolumn{2}{c}{$\mathrm{Na}$} \\
\cline { 2 - 8 } & & Curta & Longa & Curta & Longa & Curta & Longa \\
\hline \multirow{2}{*}{ Índice z } & $P$. perna & 0,13 & 0,01 & 2,0 & 0,76 & 0,82 & $-3,3$ \\
\cline { 2 - 8 } & SRM 1556b & - & - & $-0,58$ & 1,3 & $-1,9$ & $-2,1$ \\
\hline Valor de & P.perna & 1,7 & 1,0 & 1,4 & 2,7 & 2,2 & 1,6 \\
\cline { 2 - 8 } HorRat & SRM 1556b & - & - & 1,8 & 2,5 & 0,91 & 1,1 \\
\hline $\mathrm{L}_{\mathrm{Q}}\left(\mathrm{g} \mathrm{kg}^{-1}\right)$ & - & 2,6 & 0,22 & 0,25 & 0,90 & 0,0075 & 0,0053 \\
\hline $\mathrm{U}(\%)$ & - & 9,6 & 1,7 & 4,4 & 10 & 1,5 & 1,2 \\
\hline
\end{tabular}

Fonte: autor da dissertação.

Para o elemento Br, a irradiação de longa duração possui melhores valores para índice $\mathrm{z}$, valor de HorRat (embora todos sejam consideráveis satisfatório), menores $\mathrm{L}_{\mathrm{Q}} \mathrm{e}$ incerteza expandida, desta forma, será utilizada na caracterização dos pescados.

No caso do K, optou-se por utilizar os resultados obtidos por meio de irradiação de curta duração, pois nessa modalidade, além da incerteza e $\mathrm{L}_{\mathrm{Q}}$ menores, todos os valores de indicadores de índice z e valor de HorRat foram satisfatórios.

Finalmente, para o $\mathrm{Na}$, não houve caso em que os resultados obtidos pelas diferentes modalidades apresentasse diferença significativa. Optou-se por utilizar os resultados obtidos pela modalidade de curta duração, pois essa apresentou, de forma geral, melhores valores de índice $\mathrm{z}$ e valor de HorRat. $\mathrm{O} \mathrm{L}_{\mathrm{Q}}$ da irradiação de curta duração é maior, contudo, a fração mássica nos peixes é muito superior a esse valor, ou seja, esse parâmetro não foi considerado como prioritário nesse caso. A incerteza expandida são próximas e consideradas satisfatórias.

\subsubsection{Caracterização elementar dos tecidos comestíveis dos pescados}

A caracterização multielementar de As, $\mathrm{Br}, \mathrm{Cd}, \mathrm{Cl}, \mathrm{Co}, \mathrm{Cr}, \mathrm{Cs}, \mathrm{Fe}, \mathrm{Hg}, \mathrm{K}, \mathrm{Mg}$, $\mathrm{Mn}, \mathrm{Na}, \mathrm{Pb}, \mathrm{Rb}, \mathrm{Sb}, \mathrm{Se}, \mathrm{Zn}$ determinados nos tecidos comestíveis (filé) de seis pescados dentro os mais consumidos na cidade de São Paulo é apresentada na Tabela 31.

Os resultados de $\mathrm{L}_{\mathrm{Q}}$ apresentados na Tabela foram convertidos a partir do $\mathrm{L}_{\mathrm{Q}}$ da técnica, levando-se em consideração a massa úmida das amostras. 
Tabela 31 - Fração mássica dos elementos determinados na base úmida (média \pm desvio padrão e intervalo entre parênteses)

\begin{tabular}{|c|c|c|c|c|c|c|}
\hline \multirow[b]{2}{*}{ Elemento } & \multicolumn{6}{|c|}{ Espécie do pescado } \\
\hline & Cynoscion leiarchus & $\begin{array}{l}\text { Centropomus } \\
\text { undecimalis }\end{array}$ & $\begin{array}{l}\text { Sardinella } \\
\text { brasiliensis }\end{array}$ & $\begin{array}{l}\text { Micropogonias } \\
\text { furnieri }\end{array}$ & Pomatomus saltatrix & Mugil liza \\
\hline As, $\mathrm{mg} \mathrm{kg}^{-1}$ & $\begin{array}{c}1,13 \pm 0,11 \\
(0,938-1,29)\end{array}$ & $\begin{array}{c}0,19 \pm 0,16 \\
(<0,058-0,58)\end{array}$ & $\begin{array}{c}1,67 \pm 0,49 \\
(0,967-2,37)\end{array}$ & $\begin{array}{c}2,7 \pm 1,0 \\
(0,98-4,11)\end{array}$ & $\begin{array}{c}0,318 \pm 0,066 \\
(0,240-0,431)\end{array}$ & $\begin{array}{c}2,19 \pm 0,91 \\
(1,03-3,67)\end{array}$ \\
\hline $\mathrm{Br}, \mathrm{mg} \mathrm{kg}^{-1}$ & $\begin{array}{r}7,4 \pm 1,6 \\
(5,1-9,5)\end{array}$ & $\begin{array}{r}5,5 \pm 1,0 \\
(3,9-7,5)\end{array}$ & $\begin{array}{l}4,18 \pm 0,49 \\
(3,33-4,99)\end{array}$ & $\begin{array}{l}4,45 \pm 0,60 \\
(3,29-5,18)\end{array}$ & $\begin{array}{c}6,16 \pm 0,76 \\
(5,28-7,53)\end{array}$ & $\begin{array}{c}13,1 \pm 4,8 \\
(7,5-21,8)\end{array}$ \\
\hline $\mathrm{Cd}, \mu \mathrm{g} \mathrm{kg}-1$ & $\begin{array}{c}5,8 \pm 3,4 \\
(2,8-13,3)\end{array}$ & $\begin{array}{l}2,91 \pm 0,28 \\
(<2,6-3,3)\end{array}$ & $\begin{array}{c}12,7 \pm 4,7 \\
(<2,6-19,5)\end{array}$ & $<2,6$ & $<2,6$ & $\begin{array}{c}12,9 \pm 7,9 \\
(<2,6-24,1)\end{array}$ \\
\hline $\mathrm{Cl}, \mathrm{g} \mathrm{kg}^{-1}$ & $\begin{array}{c}1,63 \pm 0,39 \\
(0,956-2,39)\end{array}$ & $\begin{array}{c}0,80 \pm 0,17 \\
(0,59-1,05)\end{array}$ & $\begin{array}{c}0,945 \pm 0,097 \\
(0,82-1,12)\end{array}$ & $\begin{array}{c}0,943 \pm 0,070 \\
(0,83-1,05)\end{array}$ & $\begin{array}{l}0,92 \pm 0,13 \\
(0,67-1,1)\end{array}$ & $\begin{array}{c}2,81 \pm 0,96 \\
(1,7-4,3)\end{array}$ \\
\hline $\mathrm{Co}, \mu \mathrm{g} \mathrm{kg}^{-1}$ & $\begin{array}{c}9,7 \pm 3,4 \\
(4,7-13,4)\end{array}$ & $\begin{array}{c}8,4 \pm 3,1 \\
(4,7-12,5)\end{array}$ & $\begin{array}{c}17,0 \pm 6,1 \\
(9,7-28,2)\end{array}$ & $\begin{array}{c}17,7 \pm 3,8 \\
(11,2-23,1)\end{array}$ & $\begin{array}{c}12,4 \pm 5,0 \\
(7,8-20,7)\end{array}$ & $\begin{array}{c}42 \pm 11 \\
(28-63)\end{array}$ \\
\hline $\mathrm{Cr}, \mathrm{mg} \mathrm{kg}^{-1}$ & ND & $<0,11$ & $\begin{array}{c}0,356 \pm 0,091 \\
(<0,11-0,45)\end{array}$ & $<0,11$ & $<0,11$ & $\begin{array}{c}0,36 \pm 0,18 \\
(<0,11-0,67)\end{array}$ \\
\hline $\mathrm{Cs}, \mu \mathrm{g} \mathrm{kg}^{-1}$ & $\begin{array}{c}11,4 \pm 1,9 \\
(9,5-15,9)\end{array}$ & $\begin{array}{c}10,6 \pm 4,9 \\
(<8,2-20,4)\end{array}$ & $\begin{array}{c}17,6 \pm 5,5 \\
(11,2-26,5)\end{array}$ & $\begin{array}{c}12,0 \pm 2,3 \\
(8,9-16,2)\end{array}$ & $\begin{array}{c}64 \pm 11 \\
(53-88)\end{array}$ & $\begin{array}{c}32,9 \pm 4,1 \\
(26,5-42,0)\end{array}$ \\
\hline $\mathrm{Fe}, \mathrm{mg} \mathrm{kg}^{-1}$ & $\begin{array}{l}3,04 \pm 0,74 \\
(<1,7-4,6)\end{array}$ & $<1,7$ & $\begin{array}{c}16,2 \pm 7,5 \\
(9,7-35,1)\end{array}$ & $\begin{array}{c}2,51 \pm 0,39 \\
(1,97-3,22)\end{array}$ & $\begin{array}{c}8,0 \pm 1,7 \\
(6,4-12,0)\end{array}$ & $\begin{array}{c}22,4 \pm 9,0 \\
(10,7-30,0)\end{array}$ \\
\hline $\mathrm{Hg}, \mu \mathrm{g} \mathrm{kg}^{-1}$ & $\begin{array}{c}28,5 \pm 6,4 \\
(20,1-40,0)\end{array}$ & $\begin{array}{c}89 \pm 64 \\
(24,3-210,3)\end{array}$ & $\begin{array}{c}23,4 \pm 3,9 \\
(<14,5-28,0)\end{array}$ & $\begin{array}{c}65 \pm 37 \\
(29-146)\end{array}$ & $\begin{array}{l}508 \pm 132 \\
(302-720)\end{array}$ & $\begin{array}{c}50 \pm 14 \\
(<14,5-62,3)\end{array}$ \\
\hline $\mathrm{K}, \mathrm{g} \mathrm{kg}^{-1}$ & $\begin{array}{c}3,20 \pm 0,44 \\
(2,62-3,84)\end{array}$ & $\begin{array}{c}3,29 \pm 0,21 \\
(2,87-3,72)\end{array}$ & $\begin{array}{c}4,41 \pm 0,51 \\
(3,61-5,49)\end{array}$ & $\begin{array}{c}3,38 \pm 0,30 \\
(2,86-3,62)\end{array}$ & $\begin{array}{c}5,35 \pm 0,71 \\
(4,60-6,62)\end{array}$ & $\begin{array}{c}11,0 \pm 2,0 \\
(8,3-14,8)\end{array}$ \\
\hline $\mathrm{Mg}, \mathrm{g} \mathrm{kg}^{-1}$ & $\begin{array}{c}0,258 \pm 0,036 \\
(0,207-0,307)\end{array}$ & $\begin{array}{c}0,277 \pm 0,037 \\
(0,191-0,321)\end{array}$ & $\begin{array}{c}0,394 \pm 0,056 \\
(0,296-0,463)\end{array}$ & $\begin{array}{c}0,224 \pm 0,027 \\
(0,181-0,273)\end{array}$ & $\begin{array}{c}0,365 \pm 0,035 \\
(0,314-0,428)\end{array}$ & $\begin{array}{c}0,758 \pm 0,081 \\
(0,66-0,95)\end{array}$ \\
\hline $\mathrm{Mn}, \mathrm{mg} \mathrm{kg}^{-1}$ & $\begin{array}{l}0,096 \pm 0,025 \\
(0,060-0,15)\end{array}$ & $\begin{array}{c}0,065 \pm 0,017 \\
(0,037-0,084)\end{array}$ & $\begin{array}{c}0,67 \pm 0,43 \\
(0,36-1,77)\end{array}$ & $\begin{array}{c}0,100 \pm 0,038 \\
(0,045-0,183)\end{array}$ & $\begin{array}{c}0,102 \pm 0,031 \\
(0,055-0,168)\end{array}$ & $\begin{array}{c}0,26 \pm 0,13 \\
(0,15-0,52)\end{array}$ \\
\hline $\mathrm{Na}, \mathrm{g} \mathrm{kg}^{-1}$ & $\begin{array}{c}1,10 \pm 0,32 \\
(0,82-1,60)\end{array}$ & $\begin{array}{c}0,615 \pm 0,058 \\
(0,504-0,689)\end{array}$ & $\begin{array}{c}0,642 \pm 0,071 \\
(0,549-0,775)\end{array}$ & $\begin{array}{c}0,686 \pm 0,089 \\
(0,58-0,83)\end{array}$ & $\begin{array}{c}0,73 \pm 0,13 \\
(0,58-0,92)\end{array}$ & $\begin{array}{c}1,88 \pm 0,52 \\
(1,20-2,80)\end{array}$ \\
\hline
\end{tabular}

(continua) 
Tabela 30 - Fração mássica dos elementos determinados na base úmida (média \pm desvio padrão e intervalo entre parênteses)

(continuação)

\begin{tabular}{|c|c|c|c|c|c|c|}
\hline Elemento & Cynoscion leiarchus & $\begin{array}{c}\text { Centropomus } \\
\text { undecimalis }\end{array}$ & $\begin{array}{c}\text { Sardinella } \\
\text { brasiliensis }\end{array}$ & $\begin{array}{l}\text { Micropogonias } \\
\quad \text { furnieri }\end{array}$ & Pomatomus saltatrix & Mugil liza \\
\hline $\mathrm{Pb}, \mu \mathrm{g} \mathrm{kg}^{-1}$ & $\begin{array}{c}156 \pm 56 \\
(<86-221)\end{array}$ & $<73^{\mathrm{a}}$ & $<73^{\mathrm{a}}$ & $<73^{\mathrm{a}}$ & $<73^{\mathrm{a}}$ & $<73^{\mathrm{a}}$ \\
\hline $\mathrm{Rb}, \mathrm{mg} \mathrm{kg}^{-1}$ & $\begin{array}{c}0,58 \pm 0,10 \\
(0,45-0,77)\end{array}$ & $\begin{array}{c}0,98 \pm 0,41 \\
(<0,12-1,70)\end{array}$ & $\begin{array}{c}0,91 \pm 0,10 \\
(0,74-1,07)\end{array}$ & $\begin{array}{c}0,628 \pm 0,096 \\
(0,50-0,85)\end{array}$ & $\begin{array}{c}0,92 \pm 0,16 \\
(0,71-1,22)\end{array}$ & $\begin{array}{c}3,17 \pm 1,04 \\
(1,92-4,32)\end{array}$ \\
\hline $\mathrm{Sb}, \mu \mathrm{g} \mathrm{kg} \mathrm{g}^{-1}$ & ND & $<0,92$ & $<0,92$ & $\begin{array}{c}2,15 \pm 1,90 \\
(0,96-7,32)\end{array}$ & $\begin{array}{c}3,7 \pm 1,6 \\
(<0,92-6,1)\end{array}$ & $<0,92$ \\
\hline $\mathrm{Se}, \mathrm{mg} \mathrm{kg}^{-1}$ & $\begin{array}{c}0,43 \pm 0,11 \\
(0,28-0,64)\end{array}$ & $\begin{array}{c}0,28 \pm 0,16 \\
(0,15-0,61)\end{array}$ & $\begin{array}{c}0,63 \pm 0,26 \\
(0,26-0,91)\end{array}$ & $\begin{array}{c}0,77 \pm 0,11 \\
(0,61-0,88)\end{array}$ & $\begin{array}{r}0,730 \pm 0,037 \\
(0,68-0,79)\end{array}$ & $\begin{array}{c}0,62 \pm 0,13 \\
(0,53-0,81)\end{array}$ \\
\hline $\mathrm{Zn}, \mathrm{mg} \mathrm{kg}^{-1}$ & $\begin{array}{c}3,9 \pm 1,1 \\
(2,5-5,8)\end{array}$ & $\begin{array}{c}3,92 \pm 0,62 \\
(3,20-4,52)\end{array}$ & $\begin{array}{c}7,5 \pm 1,0 \\
(6,5-8,9)\end{array}$ & $\begin{array}{c}3,38 \pm 0,43 \\
(2,85-4,28)\end{array}$ & $\begin{array}{c}8,3 \pm 1,3 \\
(5,6-9,9)\end{array}$ & $\begin{array}{c}13,1 \pm 2,9 \\
(8,8-18,5)\end{array}$ \\
\hline
\end{tabular}

Analisados por FABIANO et al (2016) os elementos de INAA de longa duração para: a espécie C. leiarchus, 7 espécimes do C. undecimalis e 6 espécimes da

S. brasiliensis. Para os demais elementos e pescados, fonte: autor da dissertação. ND - elemento não determinado, $<$ N: resultado menor do que $\mathrm{L}_{\mathrm{Q}}{ }^{\mathrm{a}}{ }^{\mathrm{M}} \mathrm{Menor}$ do que $\mathrm{L}_{\mathrm{D}}$. 
A apresentação dos valores dos elementos essenciais, ou seja, aqueles que desempenham diversos papeis biológicos é importante, dado que da mesma forma que a deficiência desses elementos resulta em comprometimento das funções biológicas, quando presentes em excesso, podem ser tóxicos (NORDBERG et al., 2007). Embora o objetivo principal deste trabalho seja a determinação dos contaminantes inorgânicos $\mathrm{As}, \mathrm{Cd}, \mathrm{Hg}$ e $\mathrm{Pb}$, a apresentação dos demais elementos apresentados na tabela acima é relevante, seja pelo citado anteriormente, seja pela potencialidade tóxica desses elementos, e pela possibilidade da criação de bancos de dados da caracterização de micro e macroelementos em pescados, dado o caráter multielementar da técnica analíticas nuclear.

Em relação aos elementos tóxicos, para facilitar a comparação entre os resultados obtidos neste trabalho com os valores da literatura, a Tabela 32 é apresentada.

Tabela 32 - Comparação dos elementos tóxicos em relação aos encontrados na literatura, base úmida, valores apresentados juntamente com desvio padrão

\begin{tabular}{|c|c|c|c|c|c|}
\hline Espécie & As $\mathrm{mg} \mathrm{kg}^{-1}$ & $\mathrm{Cd} \mu \mathrm{g} \mathrm{kg}^{-1}$ & $\mathrm{Hg} \mu \mathrm{g} \mathrm{kg}^{-1}$ & $\mathrm{~Pb} \mu \mathrm{g} \mathrm{kg}^{-1}$ & Referência \\
\hline \multirow[b]{2}{*}{ M. liza } & $2,19 \pm 0,91$ & $12,9 \pm 7,9$ & $50 \pm 14$ & $<73$ & Este trabalho \\
\hline & $0,76 \pm 0,42$ & $9 \pm 4$ & $12 \pm 7$ & $120 \pm 70$ & $\begin{array}{l}\text { MORGANO } \\
\text { et al., } 2011\end{array}$ \\
\hline \multirow[b]{2}{*}{ P. saltatrix } & $0,318 \pm 0,066$ & $<2,6$ & $508 \pm 132$ & $<73$ & Este trabalho \\
\hline & $0,77 \pm 0,06$ & $8 \pm 1$ & $90 \pm 10$ & $30 \pm 10$ & $\begin{array}{l}\text { MAKEDONSKI } \\
\text { et al, } 2017\end{array}$ \\
\hline \multirow[b]{2}{*}{ M. furnieri } & $2,7 \pm 1,0$ & $<2,6$ & $65 \pm 37$ & $<73$ & Este trabalho \\
\hline & $3,98 \pm 2,22$ & $97 \pm 99$ & $42 \pm 51$ & $1120 \pm 1120$ & $\begin{array}{c}\text { MORGANO } \\
\text { et al., } 2011\end{array}$ \\
\hline \multirow[b]{2}{*}{ C. leiarchus ${ }^{e}$} & $1,13 \pm 0,11$ & $5,8 \pm 3,4$ & $28,5 \pm 6,4$ & $156 \pm 56$ & Este trabalho \\
\hline & $0,58 \pm 0,40$ & $7 \pm 6$ & $23 \pm 99$ & $140 \pm 10$ & $\begin{array}{c}\text { MORGANO } \\
\text { et al., } 2011\end{array}$ \\
\hline \multirow[b]{2}{*}{ S. brasiliensis } & $1,67 \pm 0,49$ & $12,7 \pm 4,7$ & $23,4 \pm 3,9$ & $<73$ & Este trabalho \\
\hline & $2,70 \pm 0,58$ & $19 \pm 6$ & $19 \pm 11$ & $111 \pm 111$ & $\begin{array}{c}\text { MORGANO } \\
\text { et al., } 2011\end{array}$ \\
\hline \multirow[b]{2}{*}{ C. undecimalis } & $0,19 \pm 0,16$ & $2,91 \pm 0,28$ & $89 \pm 64$ & $<73$ & Este trabalho \\
\hline & $<0,058$ & $<2,6$ & 86 & 1472 & $\begin{array}{c}\text { RÍOS } \\
\text { et al., } 2018\end{array}$ \\
\hline
\end{tabular}

${ }^{\mathrm{e}}$ Macrodon ancylodon é a espécie de pescada analisada por MORGANO et al., (2011). Fonte: autor da dissertação.

Em relação à $M$. liza, essa apresentou fração mássica de $\mathrm{Cd}$ $\left(12,9 \pm 7,9 \mu \mathrm{g} \mathrm{kg}^{-1}\right)$ parecido com o obtido por MORGANO et al. (2011), de Cd $\left(9 \pm 4 \mu \mathrm{g} \mathrm{kg}^{-1}\right)$. Ainda em comparação com os mesmos autores, os resultados obtidos para As de $\left(2,19 \pm 0,91 \mathrm{mg} \mathrm{kg}^{-1}\right)$ e $\mathrm{Hg}\left(50 \pm 14 \mu \mathrm{g} \mathrm{kg}^{-1}\right)$ são expressivamente diferentes dos 
obtidos por eles, de $\left(0,76 \pm 0,42 \mathrm{mg} \mathrm{kg}^{-1}\right)$ para As e $\left(12 \pm 7 \mu \mathrm{g} \mathrm{kg}^{-1}\right)$ para $\mathrm{Hg}$. MORGANO et al. (2011) apresentaram valores para $\mathrm{Pb}$ de $\left(120 \pm 70 \mu \mathrm{g} \mathrm{kg}^{-1}\right)$, enquanto neste trabalho foi obtido valor inferior ao $L_{D}$ da técnica.

A espécie $P$. saltatrix apresentou maiores frações mássicas para os elementos $\mathrm{Cs}$, Sb e para o contaminante $\mathrm{Hg}$. Os resultados obtidos de As $\left(0,318 \pm 0,066 \mathrm{mg} \mathrm{kg}^{-1}\right)$ e Zn $\left(8,3 \pm 1,3 \mathrm{mg} \mathrm{kg}^{-1}\right)$ são coerentes com o observado no trabalho de MAKEDONSKI et al. (2017) de $\left(0,77 \pm 0,06 \mathrm{mg} \mathrm{kg}^{-1}\right)$ e $\left(10 \pm 1 \mathrm{mg} \mathrm{kg}^{-1}\right)$, respectivamente. Para $\mathrm{Cd} \mathrm{e} \mathrm{Pb}$, as frações mássicas estavam abaixo do $\mathrm{L}_{\mathrm{Q}}$ da técnica, enquanto os autores obtiveram $8 \pm 1 \mu \mathrm{g} \mathrm{kg}^{-1}$ para $\mathrm{Cd}$ e $30 \pm 10 \mu \mathrm{g} \mathrm{kg}^{-1}$ para $\mathrm{Pb}$. Para o contaminante $\mathrm{Hg}$, os resultados variaram de ordem de grandeza, sendo $508 \pm 132 \mu \mathrm{g} \mathrm{kg}^{-1}$ no presente trabalho e $90 \pm 10 \mu \mathrm{g} \mathrm{kg}^{-1}$ na pesquisa de MAKEDONSKI et al. (2017).

A M. furnieri apresentou as frações mássicas mais elevadas para o elemento essencial Se e para o contaminante As. No trabalho de MORGANO et al. (2011), o contaminante As também apresentou o maior teor na corvina $\left(3,98 \pm 2,22 \mathrm{mg} \mathrm{kg}^{-1}\right)$, ante $\left(2,7 \pm 1,0 \mathrm{mg} \mathrm{kg}^{-1}\right)$ do presente trabalho. Houve coerência de resultados também para o contaminante $\mathrm{Hg}\left(65 \pm 37 \mathrm{mg} \mathrm{kg}^{-1}\right)$ neste trabalho e $\left(42 \pm 51 \mathrm{mg} \mathrm{kg}^{-1}\right)$ no dos autores. Não foi possível quantificar $\mathrm{Cd}$ e $\mathrm{Pb}$ na $M$. furnieri, enquanto na pesquisa dos autores foram obtidos $97 \pm 99 \mu \mathrm{g} \mathrm{kg}^{-1}$ e $1120 \pm 1120 \mu \mathrm{g} \mathrm{kg}^{-1}$, respectivamente.

O contaminante $\mathrm{Pb}$ só foi possível de ser quantificado na C. leiarchus. Em comparação com a pescada do trabalho de MORGANO et al. (2011), resultados parecidos foram obtidos para praticamente todos os elementos, de As $\left(1,13 \pm 0,11 \mathrm{mg} \mathrm{kg}^{-1}\right)$, $\mathrm{Cd}\left(5,8 \pm 3,4 \mathrm{mg} \mathrm{kg}^{-1}\right),\left(\mathrm{Hg} 28,5 \pm 6,4 \mathrm{mg} \mathrm{kg}^{-1}\right)$ e $\mathrm{Pb}\left(156 \pm 56 \mathrm{mg} \mathrm{kg}^{-1}\right)$ neste estudo e As $\left(0,58 \pm 0,40 \mathrm{mg} \mathrm{kg} \mathrm{kg}^{-1}\right), \mathrm{Cd}\left(7 \pm 6 \mathrm{mg} \mathrm{kg}{ }^{-1}\right) \mathrm{Hg}\left(23 \pm 99 \mathrm{mg} \mathrm{kg}^{-1}\right)$, $\mathrm{Pb}\left(140 \pm 100 \mathrm{mg} \mathrm{kg}^{-1}\right)$ na pesquisa dos autores.

Para a $S$. brasiliensis, obtiveram-se os seguintes resultados: As $\left(1,67 \pm 0,49 \mathrm{mg} \mathrm{kg}^{-1}\right), \mathrm{Cd}\left(12,7 \pm 4,7 \mu \mathrm{g} \mathrm{kg}^{-1}\right), \mathrm{Hg}\left(23,4 \pm 3,9 \mu \mathrm{g} \mathrm{kg}^{-1}\right)$ similares com os obtidos por MORGANO et al. (2011), de As $\left(2,70 \pm 0,58 \mathrm{mg} \mathrm{kg}^{-1}\right)$, Cd $\left(19 \pm 6 \mu \mathrm{g} \mathrm{kg}^{-1}\right)$, $\mathrm{Hg}\left(19 \pm 11 \mu \mathrm{g} \mathrm{kg}^{-1}\right)$. Neste estudo, o contaminante $\mathrm{Pb}$ ficou abaixo do $\mathrm{L}_{\mathrm{Q}}$ enquanto no trabalho dos pesquisadores foi obtido $111 \pm 111 \mu \mathrm{g} \mathrm{kg}^{-1}$.

A espécie $C$. undecimalis apresentou teores de As $\left(0,19 \pm 0,16 \mathrm{mg} \mathrm{kg}^{-1}\right)$, $\mathrm{Cd}\left(2,91 \pm 0,28 \mu \mathrm{g} \mathrm{kg}^{-1}\right), \mathrm{Hg}\left(89 \pm 64 \mu \mathrm{g} \mathrm{kg}^{-1}\right)$ e $\mathrm{L}_{\mathrm{Q}}$ para $\mathrm{Pb}$. A fração mássica do contaminante $\mathrm{Hg}$, no trabalho de RÍOS et al. (2018) apresentou similaridade com o obtido 
neste trabalho, de $86 \mu \mathrm{g} \mathrm{kg}^{-1}$. Os pesquisadores obtiveram resultados inferiores ao $\mathrm{L}_{\mathrm{D}}$ para As e Cd, e $1472 \mathrm{mg} \mathrm{kg}^{-1}$ para $\mathrm{Pb}$.

Os maiores valores de As foram observados em M. furnieri, Cd em M. liza $\mathrm{Hg}$ em $P$. saltatrix e $\mathrm{Pb}$ só foi quantificado em C. leiarchus.

Os resultados obtidos são condizentes com os obtidos em outros trabalhos. Ressalta-se que resultados são similares ora quando pescados possuem origem semelhante, como no caso do estudo de MORGANO et al. (2011), ora quando as espécimes possuem origens completamente distintas, como nas comparações da espécie $P$. saltratix, amostradas no Mar Negro - Bulgária e na espécie C. undecimalis, amostradas no Golfo de Urabá Caribe colombiano.

\subsection{Comparação dos teores de contaminantes com as legislações}

Após as frações mássicas dos micro, macro e elementos tóxicos serem apresentadas, esta subseção visa analisar se os teores de contaminantes inorgânicos presentes nos filés das espécies estudadas nesta dissertação apresentam risco à segurança alimentar.

Para executar esta avaliação, os contaminantes $\mathrm{As}, \mathrm{Cd}, \mathrm{Hg}$ e $\mathrm{Pb}$ foram plotados em gráficos, agrupados duas espécies por gráfico, para em avaliação descritiva verificar se os resultados são superiores, inferiores ou sem diferença aparente em relação aos valores legais e outros valores técnicos tratados neste trabalho, apresentados na Tabela 3 (página 23). As Figuras 19-21 tratam sobre o contaminante As.

Figura 19 - Comparação dos espécimes de pescada (P) e sardinha (S) com o limite legal de As

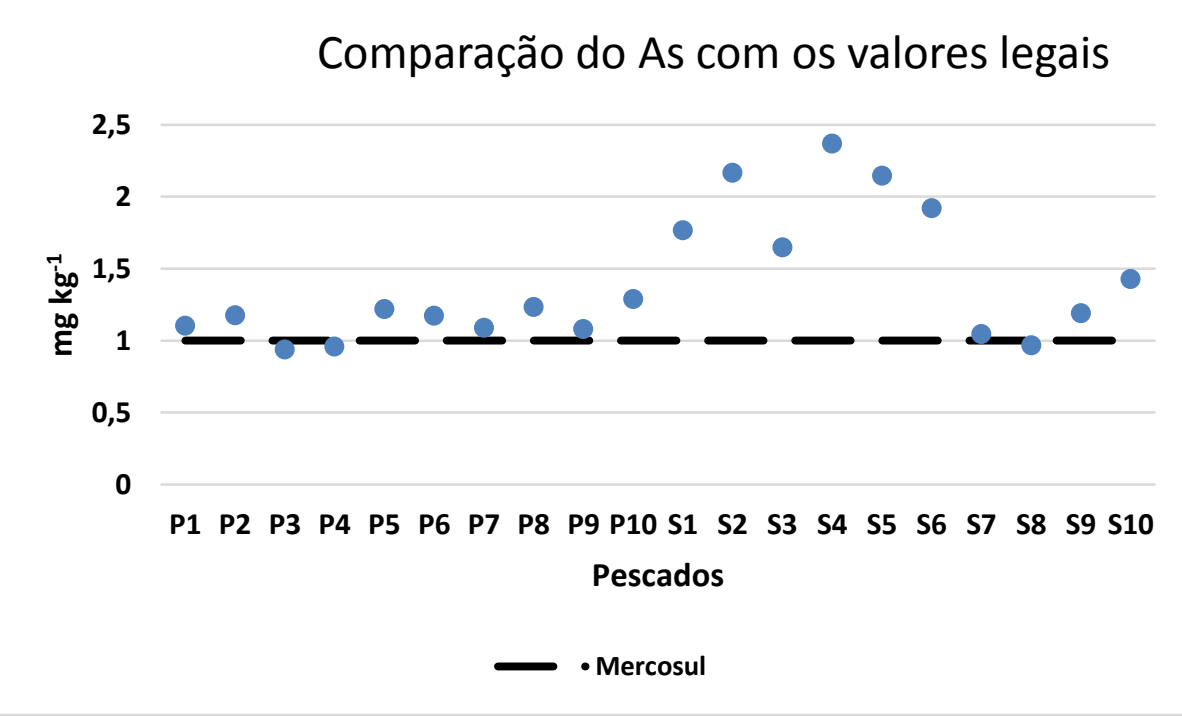

Fonte: autor da dissertação. 
As frações mássicas de As na pescada-branca (C. leiarchus), nos 10 espécimes analisados não apresentaram diferença em relação ao valor legal vigente no Brasil (Resolução RDC No 42, BRASIL, 2013) de $1 \mathrm{mg} \mathrm{kg}^{-1}$.

Ainda em relação à pescada-branca, não houve diferença significativa entre as espécimes de origem de Itajaí (SC - espécimes 1-6) e Rio Grande do Sul (RS - espécimes 7-10), verificadas por meio do teste-t de Student $(p=0,32)$

Os espécimes de sardinha ( $S$. brasiliensis) 1-6 oriundas de Cabo Frio (RJ) apresentaram teores de As superiores aos de Angra dos Reis (RJ) S7-S10. Essa espécie apresentou teor acima do valor legal do Mercosul.

Existe diferença significativa entre frações mássicas de As na sardinha em função do seu local de origem, verificada por meio do teste-t de Student $\left(p=7,510^{-4}\right)$.

Figura 20 - Comparação dos espécimes de robalo (R) e anchova (A) com o limite legal de As

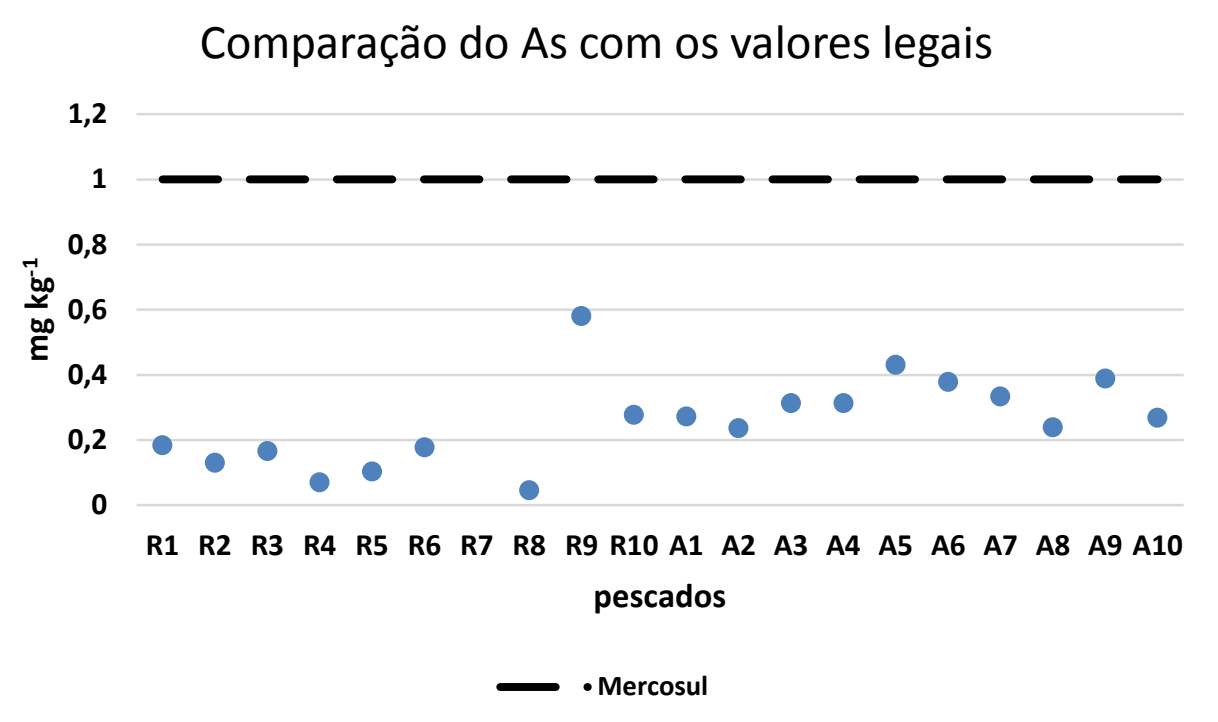

Fonte: autor da dissertação.

A fração mássica das espécies de robalo ( $C$. undecimalis) e anchova ( $P$. saltatrix) ficaram abaixo do valor do MERCOSUL. Além disso, não houve diferença significativa entre as frações mássicas de As em função do local de origem dos espécimes de robalo 1-6 (Natal - RN) e 7-10 (São Luiz - MA) verificada por meio do teste de MannWhitney $(p=0,52)$. 
Figura 21 - Comparação dos espécimes de corvina (C) e tainha (T) com limites legais de As

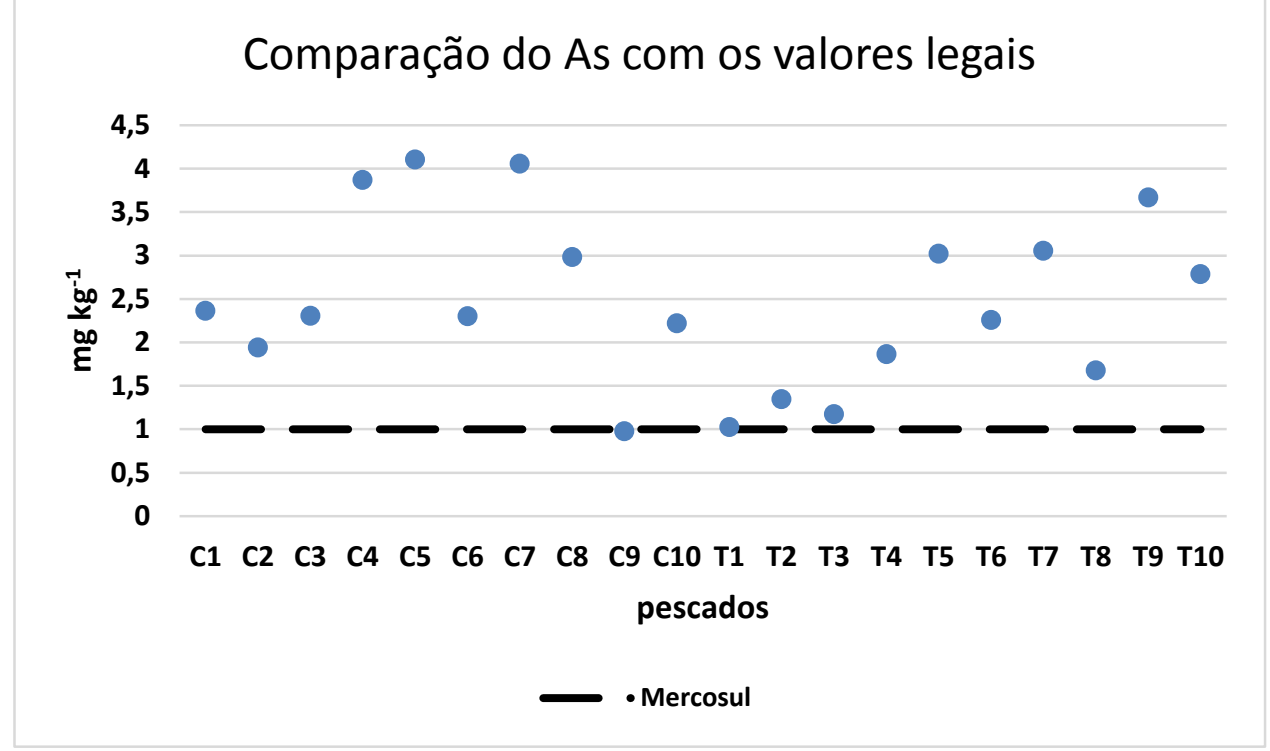

Fonte: autor da dissertação.

As espécies corvina (M. furnieri) e tainha (M. liza) apresentaram teor de As superior à legislação brasileira.

Em relação a diferença de fração mássica em função do local de origem, para tainha houve diferença significativa entre os espécimes 1-4 de Cabo Frio (RJ) e 5-10 de Cananéia (SP), verificada por meio do teste-t $\left(p=6,610^{-3}\right)$.

Em síntese, o contaminante inorgânico As apresentou teores superiores à legislação brasileira nas espécies sardinha (S. brasiliensis), corvina (M. furnieri) e tainha (M. liza). A Resolução da ANVISA que trata sobre os Limites Máximos de Contaminantes Inorgânicos em Alimentos (BRASIL, 2013) diz que os alimentos que não atenderem aos valores legais, não deverão ser utilizados como ingredientes alimentícios.

Entretanto, há de se ponderar que a toxicidade do arsênio está relacionada à sua espécie química, sendo que as espécies inorgânicas $\left(\mathrm{As}^{3+} \mathrm{e} \mathrm{As}^{5+}\right)$ são as mais tóxicas e as orgânicas (arsenocolina e arsenobetaína), essa última a forma mais presente em organismos marinhos inclusive, são relativamente não tóxicas (BARRA et al., 2000).

Por este motivo, B'HYMER et al. (2004) alegam que os requisitos para regulamentações legislativas instituídas hoje devem ser amparados pela identificação de qual espécie química do As está presente. A legislação da Austrália e Nova Zelândia (FSANZ, 2017) segue esse sentido e apresenta valores máximos de As em espécie descriminada (Asinorgânico). 
Por fim, não foi possível afirmar que existe perigo à segurança alimentar no consumo destes pescados relacionado ao contaminante As, por conta da necessidade da realização da especiação química do As, a fim de se verificar a quantidade de As inorgânico presente nos filés dos pescados analisados. Contudo, ressalta-se que no âmbito nacional, como a legislação vigente determina, os pescados com teores acima da legislação MERCOSUL não devem ser utilizados como produtos alimentícios (BRASIL, 2013).

Ainda no âmbito da segurança alimentar, as Figuras 22-24 apresentam comparações gráficas entre os valores obtidos nas análises das seis espécies de pescado e os limites máximos permitidos para $\mathrm{Hg}$.

Figura 22 - Comparação dos espécimes de pescada (P) e corvina (C) com os limites legais de $\mathrm{Hg}$

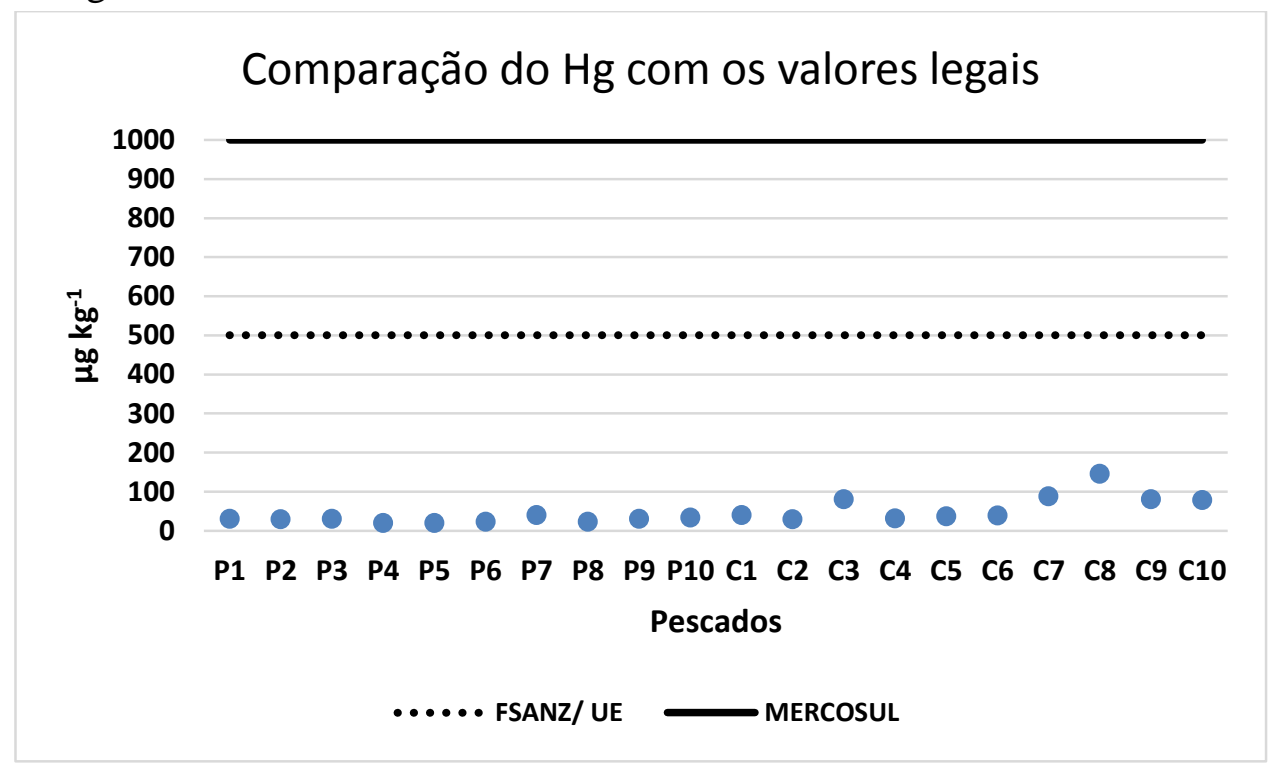

Fonte: autor da dissertação.

Em análise descritiva dos dados, verifica-se que a pescada-branca (C. leiarchus) e a corvina (M. furnieri) apresentaram frações mássicas abaixo de todos os limites máximos tratados neste trabalho para o contaminante $\mathrm{Hg}$, de $500 \mu \mathrm{g} \mathrm{kg}^{-1}$ para FSANZ (2017) e União Europeia (EFSA, 2005) e $1000 \mu \mathrm{g} \mathrm{kg}^{-1}$ para o MERCOSUL.

Ainda em relação à pescada, não foi verificado, por meio do teste-t de Student, diferença significativa em relação à origem das espécimes 1-6 (Itajaí - SC) e 7-10 (Rio Grande do Sul - RS), com valor de $p=0,14$. 
Figura 23 - Comparação dos espécimes da sardinha (S) e tainha (T) com os limites legais de $\mathrm{Hg}$

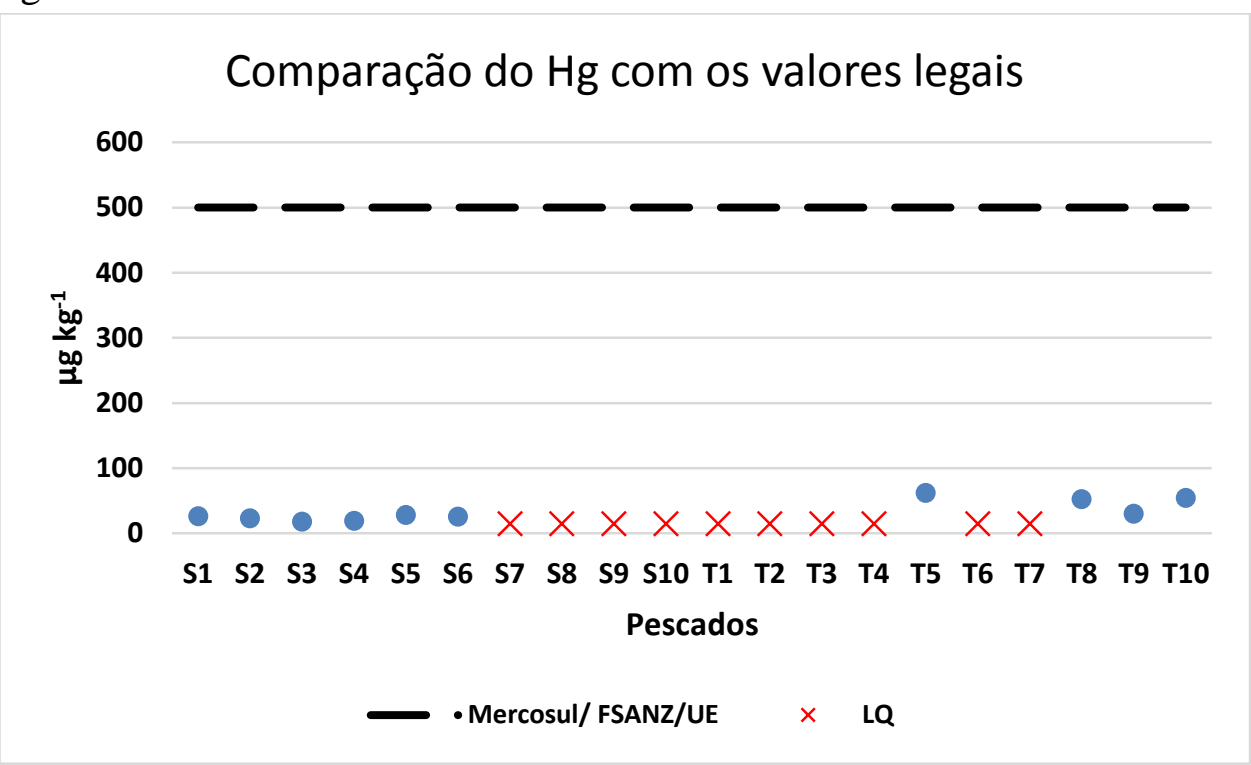

Fonte: autor da dissertação.

Para os pescados sardinha (S. brasiliensis) e tainha (M. liza) os valores de fração mássica obtidos para $\mathrm{Hg}$ ficaram abaixo dos valores de $500 \mu \mathrm{g} \mathrm{kg}^{-1}$ para UE, FSANZ e MERCOSUL. A legislação MERCOSUL é de $500 \mu \mathrm{g} \mathrm{kg}^{-1}$ por se tratarem de espécies não predadoras. Os espécimes da sardinha 7-10 e tainha 1-4, 6 e 7 ficaram abaixo do $\mathrm{L}_{\mathrm{Q}}$.

Não foi possível verificar se há diferença em função do local de origem para a sardinha, pois os espécimes 7-10 oriundos de Angra dos Reis (RJ) ficaram abaixo do LQ da técnica analítica.

Figura 24 - Comparação dos espécimes do robalo (R) e anchova (A) com os limites legais de $\mathrm{Hg}$

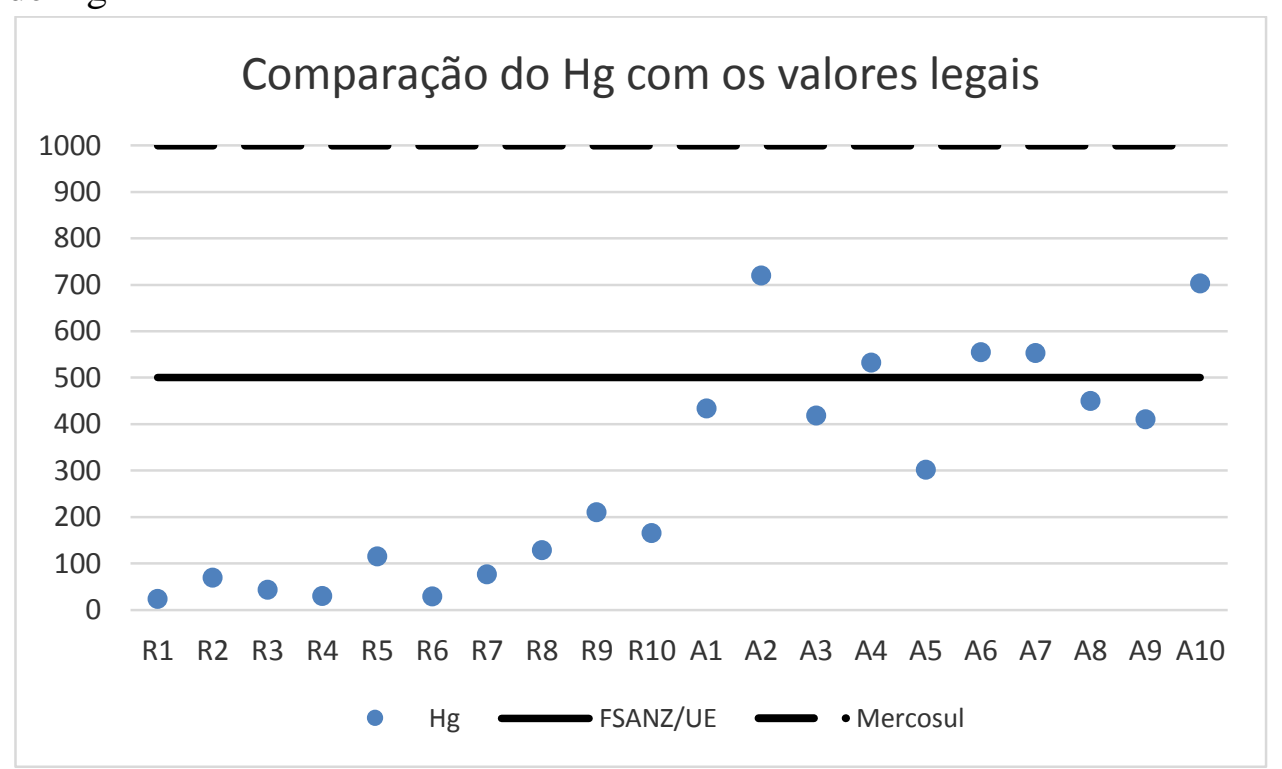

Fonte: autor da dissertação. 
O robalo (C. undecimalis) apresentou teores deste contaminante abaixo de todos os valores limites tratados nesse trabalho. Verificou-se, por meio de teste-t, que existe diferença significativa na fração mássica de $\mathrm{Hg}$ em função da origem dos espécimes R1-R6 de Natal (RN) e R7-R10 de São Luís (MA), com valor de $p$ do teste t de Student de 0,012.

Em relação à anchova ( $P$. saltatrix), animal de maior nível trófico analisado neste trabalho, foi a espécie que apresentou maiores teores de $\mathrm{Hg}$. Foi a única espécie que apresentou alguns espécimes acima dos limites da FSANZ e UE. Por meio de análise descritiva, pode-se inferir que os resultados do contaminante $\mathrm{Hg}$ estão abaixo valor limite do MERCOSUL e sem diferença com os valores da FSANZ e UE.

O resumo do panorama da comparação do contaminante $\mathrm{Hg}$, têm-se que as espécies C. leiarchus, S. brasiliensis, M. liza, M. furnieri e C. undecimalis abaixo de todos os valores tratados neste trabalho, enquanto a espécie $P$. saltatrix (anchova) apresentou os maiores teores desse contaminante, abaixo apenas da legislação MERCOSUL e sem diferença com os valores da FSANZ e UE.

Na avaliação sobre a segurança alimentar deste elemento, analogamente ao contaminante As, é importante discutir sobre as espécies químicas do Hg. Existem praticamente três formas químicas do mercúrio: elementar $\left(\mathrm{Hg}^{0}\right)$, inorgânico $\left(\mathrm{Hg}^{+} \mathrm{e} \mathrm{Hg}^{2+}\right) \mathrm{e}$ orgânico (metilmercúrio MeHg e etilmercúrio EtHg) (POLES, 2016; BERNHOFT, 2011), sendo a forma metilada a mais tóxica (BISINOTI e JARDIM, 2004).

No pescado, cerca de $85 \%$ do $\mathrm{Hg}$ está na forma de $\mathrm{MeHg}$, e a principal forma de exposição do homem à esse contaminante se dá pela dieta, sobretudo pelo consumo do pescado (BISINOTI e JARDIM, 2004). Neste sentido, embora não se conheça com certeza quais as espécies químicas e suas respectivas quantidades presentes nas frações mássicas nos filés analisados, pode-se supor, baseado na literatura, que a maior parte deve ser o $\mathrm{MeHg}$ e, portanto, deve ser realizada uma discussão mais cautelosa.

Portanto, para a segurança alimentar, em relação ao $\mathrm{Hg}$, pode-se afirmar que não há perigo no consumo das espécies C. leiarchus, C. undecimalis, M. liza, M. furnieri e $S$. brasiliensis pois os teores verificados nesses pescados para o contaminante não foram superiores a nenhum limite técnico tratado nesta dissertação.

Não foi possível fazer afirmações sobre riscos associados ao consumo da $P$. saltatrix, tendo em vista que essa espécie não apresentou diferença com os valores 
máximos mais restritivos - da UE e FSANZ. Por fim, pondera-se apenas a complexidade de fazer esta avaliação, tendo em vista a variabilidade dos limites máximos.

Só foi possível analisar potenciais riscos à segurança alimentar para $\mathrm{Pb}$ relacionado à pescada (C. leiarchus), pelo fato que, para as demais espécies tratadas neste trabalho, obtiveram-se valores abaixo do $L_{D}$ da técnica, que foi menor que os teores máximos recomentados e, portanto, pode ser considerado um fato positivo. A Figura 25 faz a comparação entre os teores de $\mathrm{Pb}$ na pescada e os valores máximos tratados neste trabalho.

Figura 25 - Comparação dos espécimes da pescada $(\mathrm{P})$ com os limites técnicos para $\mathrm{Pb}$

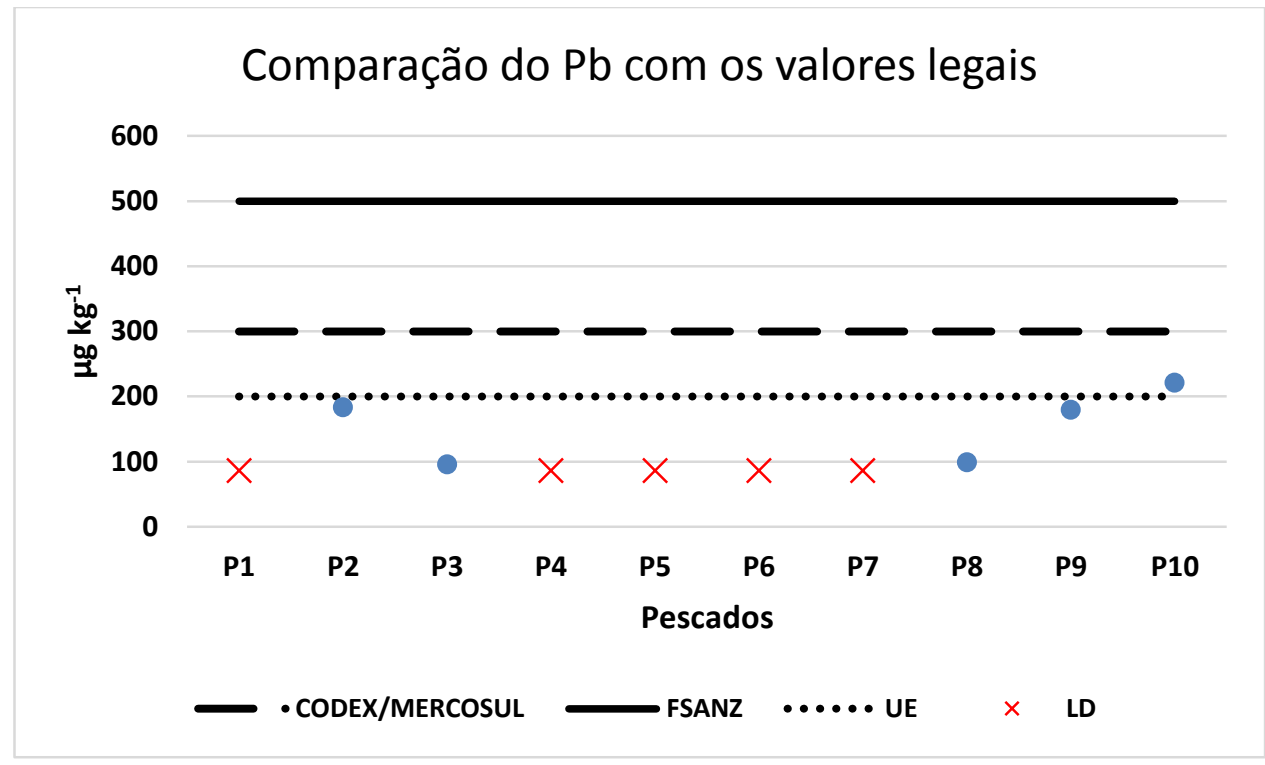

Fonte: autor da dissertação.

$\mathrm{Na}$ determinação da fração mássica de $\mathrm{Pb}$ na pescada, houve apenas um espécime (P10) acima do limite legal mais restritivo (UE) de $200 \mu \mathrm{g} \mathrm{kg} \mathrm{kg}^{-1}$ e outros dois limítrofes (P2 e P9). Contudo, levando-se em consideração os outros 2 espécimes (P3 e P8) que apresentaram teores abaixo da legislação europeia e os 5 espécimes (P1, P4-7) abaixo do $L_{D}$, é possível afirmar que essa espécie apresentou teores abaixo da legislação europeia e também dos demais limites técnicos tratados nesse trabalho.

Se os espécimes analisados estão abaixo dos limites mais rígidos de $200 \mu \mathrm{g} \mathrm{kg}^{-1}$ da legislação europeia, pode-se inferir que as demais amostras das outras 5 espécies que não foram quantificadas devem possuir, portanto, também frações mássicas menores do que todas as legislações, não apresentando risco à segurança alimentar.

A determinação do último contaminante inorgânico no âmbito da segurança alimentar, o Cd, foi feito a partir das Figuras 26 e 27. 
Figura 26 - Comparação dos espécimes de pescada $(\mathrm{P})$ e robalo $(\mathrm{R})$ com os limites legais de $\mathrm{Cd}$

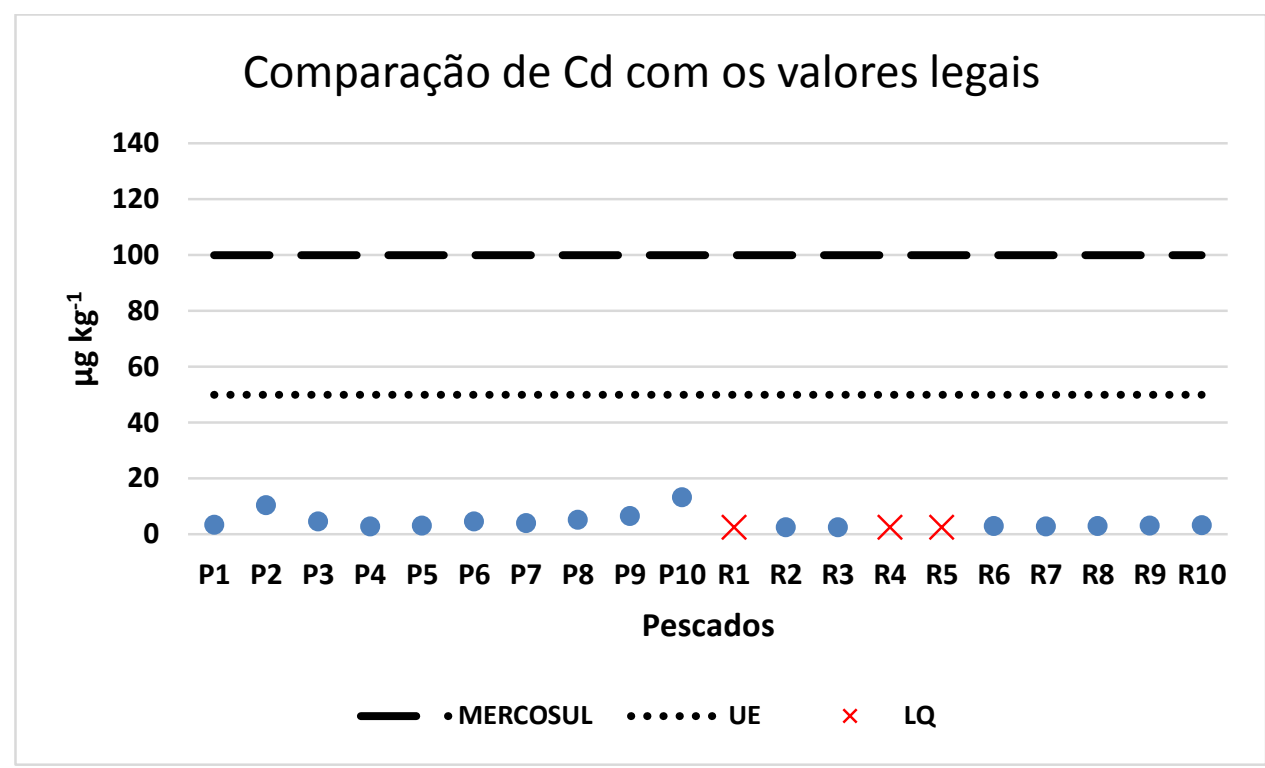

Fonte: autor da dissertação.

Em análise descritiva dos dados, as espécies C. leiarchus (pescada-branca) e C. undecimalis (robalo) apresentaram frações mássicas abaixo de todos os valores legais.

Não foi observado diferença significativa por meio do teste de Mann-Whitney $(p=0,17)$ em função do local de origem para os valores de Cd obtidos entre os espécimes de pescada-branca oriundas de Itajaí (SC, P1-6) e Rio Grande de Sul (RS, P7-10). Não houve diferença significativa, verificada por meio do teste-t, entre os espécimes de robalo de Natal (RN, R1-R6) e São Luiz (MA, R7-R10) com valor de $p=0,32$. Ressalta-se apenas que o número reduzido de amostras com resultado superior ao $\mathrm{L}_{\mathrm{Q}}$ pode prejudicar a qualidade do teste estatístico. 
Figura 27 - Comparação dos espécimes de sardinha (S) e tainha (T) com os limites legais de $\mathrm{Cd}$

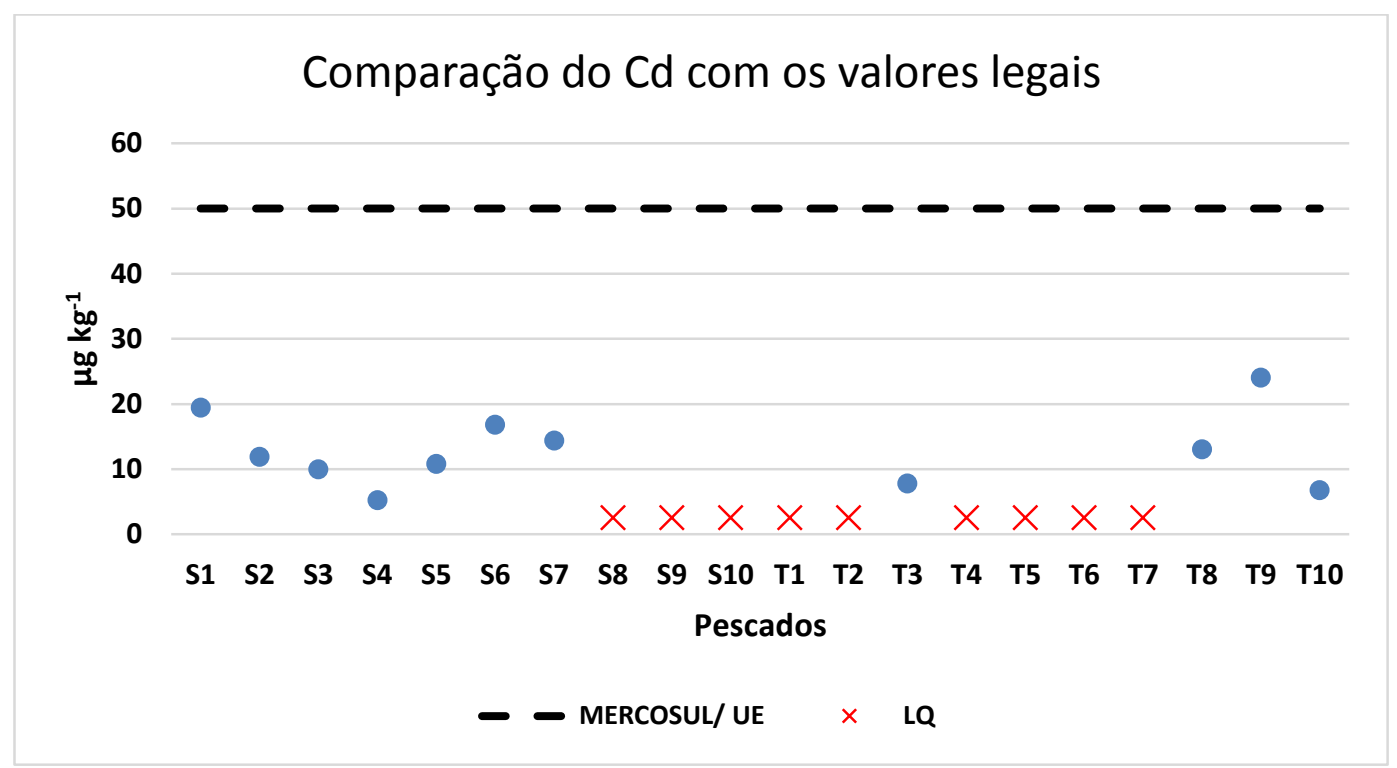

Fonte: autor da dissertação.

As espécies $S$. brasiliensis (sardinha) e $M$. liza (tainha) também apresentaram valores abaixo dos máximos permitidos para o contaminante $\mathrm{Cd}$. Não há possibilidade de verificar se há diferenças nas frações mássicas em função da origem dos espécimes por conta das amostras ficaram abaixo do $\mathrm{L}_{\mathrm{Q}}$.

As outras duas espécies, $P$ saltatrix (anchova) e M. furnieri (corvina), apresentaram fração mássica abaixo do $\mathrm{L}_{\mathrm{Q}}$ da técnica, e por inferência, devem estar abaixo de todos os valores máximos tratados neste trabalho.

Não há riscos para segurança alimentar em função do contaminante $\mathrm{Cd}$, pelo fato de todas as amostras analisadas estarem dentro dos limites técnicos legais de valores máximos estipulados.

Para finalizar a discussão sobre segurança alimentar, a Tabela 33 apresenta resumo de tudo que foi discutido nesta subseção. 
Tabela 33 - Síntese dos resultados para verificação de risco para segurança alimentar

\begin{tabular}{|c|c|c|c|}
\hline Espécie & As & $\mathrm{Hg}$ & $\mathrm{Cd}$ \\
\hline $\begin{array}{l}\text { C. leiarchus } \\
\text { (pescada) }\end{array}$ & $\begin{array}{l}\text { Sem diferença } \\
\text { com } \\
\text { MERCOSUL }\end{array}$ & $\begin{array}{l}\text { Abaixo de todas as } \\
\text { legislações }\end{array}$ & \multirow{6}{*}{$\begin{array}{c}\text { Nenhuma espécie superior } \\
\text { às legislações }\end{array}$} \\
\hline $\begin{array}{l}\text { C. undecimalis } \\
\text { (robalo) }\end{array}$ & $\begin{array}{c}\text { Abaixo do } \\
\text { MERCOSUL }\end{array}$ & $\begin{array}{l}\text { Abaixo de todas as } \\
\text { legislações }\end{array}$ & \\
\hline $\begin{array}{l}\text { S. brasiliensis } \\
\text { (sardinha) }\end{array}$ & $\begin{array}{c}\text { Superior ao } \\
\text { MERCOSUL }\end{array}$ & $\begin{array}{l}\text { Abaixo de todas as } \\
\text { legislações }\end{array}$ & \\
\hline $\begin{array}{l}\text { M. furnieri } \\
\text { (corvina) }\end{array}$ & $\begin{array}{c}\text { Superior ao } \\
\text { MERCOSUL }\end{array}$ & $\begin{array}{l}\text { Abaixo de todas as } \\
\text { legislações }\end{array}$ & \\
\hline $\begin{array}{l}\text { P. saltatrix } \\
\text { (anchova) }\end{array}$ & $\begin{array}{c}\text { Abaixo do } \\
\text { MERCOSUL }\end{array}$ & $\begin{array}{l}\text { Sem diferença com } \\
\text { FSANZ e UE, abaixo } \\
\text { do MERCOSUL }\end{array}$ & \\
\hline $\begin{array}{l}\text { M. liza } \\
\text { (tainha) }\end{array}$ & $\begin{array}{c}\text { Superior ao } \\
\text { MERCOSUL }\end{array}$ & $\begin{array}{c}\text { Abaixo de todas as } \\
\text { legislações }\end{array}$ & \\
\hline
\end{tabular}

Fonte: autor da dissertação.

$\mathrm{Na}$ avaliação final visando verificar se o consumo de determinada espécie apresentaria potencial risco à saúde do consumidor em relação à segurança alimentar, ao observarmos as espécies de pescado em relação ao As, mesmo existindo algumas superiores às legislação MERCOSUL, não se pode afirmar que existe risco, pois neste trabalho foi analisado apenas a fração mássica total desse elemento. É necessário levar em consideração que o arsênio total é constituído de distintas espécies químicas com diferentes níveis de toxicidade, sendo a maior parte do As presente nesta matriz é a arsenobetaína, considerada relativamente não tóxica (BARRA et al., 2000). Futuras análises de especiação de As são necessárias para conclusões mais objetivas.

Todas as espécies analisadas estavam abaixo dos valores legais para $\mathrm{Cd}$ e $\mathrm{Pb}$.

Ante ao anteriormente discutido, para a análise da segurança alimentar, a determinação do contaminante $\mathrm{Hg}$ se mostrou determinante. As espécies S. brasiliensis (sardinha-verdadeira), C. leiarchus (pescada-branca), M. liza (tainha) M. furnieri (corvina) e C. undecimalis (robalo) apresentaram teores abaixo de todos os valores tratados neste trabalho, e portanto, não apresentam risco à segurança alimentar. Por fim, a espécie $P$. saltatrix (anchova) é inconclusiva, pois apresentou teores sem aparente diferença com os valores legais mais restritivos da UE e FSANZ, de $500 \mu \mathrm{g} \mathrm{kg}^{-1}$, ainda que abaixo do teor máximo permitido pelo MERCOSUL. 


\section{CONCLUSÕES}

As técnicas analíticas empregadas neste trabalho - INAA de curta e longa duração, ET AAS e CV AAS, utilizadas para caracterização do filé das seis espécies analisadas: corvina - Micropogonias furnieri (Desmarest, 1823); pescada - Cynoscion leiarchus (Cuvier, 1830); robalo - Centropomus undecimalis (Bloch, 1792); sardinha Sardinella brasiliensis (Steindachner, 1879); anchova - Pomatomus saltatrix (Linnaeus, 1766); e tainha Mugil liza (Valenciennes, 1836) foram satisfatórias ante aos indicadores de qualidade utilizados, de índice $\mathrm{z}$, com resultados em geral $\leq 2$, e de valor de HorRat, em geral $\leq 2$. As técnicas empregadas permitiram a caracterização dos elementos $\mathrm{As}, \mathrm{Br}, \mathrm{Cd}$, $\mathrm{Cl}, \mathrm{Co}, \mathrm{Cr}, \mathrm{Cs}, \mathrm{Fe}, \mathrm{Hg}, \mathrm{K}, \mathrm{Mg}, \mathrm{Mn}, \mathrm{Na}, \mathrm{Pb}, \mathrm{Rb}, \mathrm{Sb}$, Se, Zn nos tecidos comestíveis desses pescados.

Em relação à fração mássica de elementos essenciais e potencialmente tóxicos: $\mathrm{Br}, \mathrm{Cl}, \mathrm{Co}, \mathrm{Cr}, \mathrm{Cs}, \mathrm{Fe}, \mathrm{K}, \mathrm{Mg}, \mathrm{Mn}, \mathrm{Na}, \mathrm{Rb}$, Se e Zn, foi constituído um banco de dados, dado o caráter multielementar da técnica nuclear utilizada, que pode ser útil em futuras discussões no âmbito da segurança alimentar de pescado.

Os elementos $\mathrm{Br}$, $\mathrm{Na}$ e $\mathrm{K}$ foram determinados por ambas as modalidades de INAA, de curta e longa duração. Em comparação dos resultados obtidos pelas técnicas, foi verificada diferença significativa $(\alpha=5 \%)$ apenas em uma comparação para $\mathrm{K}$, no pescado C. undecimalis e um único caso também para $\mathrm{Br}$, no $P$. saltatrix. Para apresentação dos dados de caracterização dos filés dos pescados, optou-se em utilizar os resultados obtidos por irradiação de curta duração para K e Na e de longa duração para Br, pois nestes casos, de forma geral, foram obtidos melhores resultados de índice z, valor de HorRat, incerteza expandida e $\mathrm{L}_{\mathrm{Q}}$.

De maneira geral, pode-se afirmar que os valores obtidos para os contaminantes inorgânicos $\mathrm{As}, \mathrm{Cd}, \mathrm{Hg}$ e $\mathrm{Pb}$ foram coerentes com os valores da literatura abordados. 
$\mathrm{Na}$ avaliação da segurança alimentar, os contaminantes $\mathrm{Cd}$ e $\mathrm{Pb}$ apresentaram teores abaixo de todas as legislações. Para As, o robalo $(C$. undecimalis) e a anchova $(P$. saltatrix) estavam abaixo da legislação, a pescada (C. leiarchus) não apresentou diferença com o MERCOSUL, a sardinha (S. brasiliensis), corvina (M. furnieri) e a tainha (M. liza) ficaram acima da legislação brasileira. Contudo, como neste trabalho foram tratados apenas fração mássica total de As, não foi possível afirmar que existe perigo no consumo dos pescados baseado nesse contaminante.

Do ponto de vista do $\mathrm{Cd}$ e $\mathrm{Pb}$, os pescados não apresentam perigo à saúde do consumidor. Em relação ao contaminante As, só foi determinado sua fração mássica total, portanto, a conclusão sobre a segurança alimentar se deu por meio da determinação do Hg. 
Pelo fato de estarem abaixo de todos os valores legais, conclui-se que não há risco no âmbito da segurança alimentar para as espécies C. leiarchus (pescada), S. brasiliensis (sardinha) e M. liza (tainha), (C. undecimalis) robalo e (M. furnieri) corvina. Para a anchova ( $P$. saltatrix), como apresentou teores sem diferença aparente com os valores máximos mais restritivos, seu caso foi conclusivo.

Para avaliação mais aprofundada sobre o risco dos contaminantes para a saúde humana, sobretudo para os elementos As e $\mathrm{Hg}$, é recomendável a realização de especiação química, para verificar os teores, sobretudo das espécies químicas tóxicas desses elementos. Além disso, a estimativa de ingestão diária para os contaminantes também se faz necessária, e é uma perspectiva de continuidade para este estudo. 


\section{REFERÊNCIAS BIBLIOGRÁFICAS}

AMERICAN HEART ASSOCIATION. Fish and Omega-3 Fatty Acids, 2017. Disponível em: <https://www.heart.org/en/healthy-living/healthy-eating/eat-smart/fats/fish-and-omega-3fatty-acids>. Acesso em 28 maio 2019.

BARRA, C. M., SANTELLI, R. E., ABRÃO, J. J., GUARDIA, M. D. L. Especiação de arsênio - uma revisão. Química Nova, v. 23, n. 1, p. 58-70, 2000.

BERNHOFT, Robin A. Mercury toxicity and treatment: a review of the literature. Journal of Environmental and Public Health, v. 2012, p. 1-10, 2011.

B'HYMER, C.; CARUSO, J. A. Arsenic and its speciation analysis using highperformance liquid chromatography and inductively coupled plasma mass spectrometry. Journal of Chromatography A, v. 1045, n. 1-2, p. 1-13, 2004.

BISINOTI, M. C., JARDIM, W. F. O comportamento do metilmercúrio (metilHg) no ambiente. Química Nova, v.27 n. 4, p.593-600, 2004.

BLOOMINGDALE, A.; GUTHRIE, L. B.; PRICE, S.; WRIGHT, R. O.; PLATEK, D.; HAINES, J.; OKEN, E. A qualitative study of fish consumption during pregnancy. The American Journal of Clinical Nutrition, v. 92, n. 5, p. 1234-1240, 2010.

BODE, P. Instrumental and organizational aspects of a neutron activation analysis laboratory. 1996, 251p. Tese - Delft University of Tecnhology.

BRASIL. Decreto no 9013, de 29 de março de 2017. Dispõe sobre a inspeção industrial e sanitária de produtos de origem animal. Diário Oficial [da] República Federativa do Brasil, Brasília, DF. Disponível em: <http://www.planalto.gov.br/ccivil_03/_ato20152018/2017/decreto/d9013.htm>. Acesso em 21 set. 2018.

BRASIL. Decreto n ${ }^{\circ} 55871$, de 26 de março de 1965. Modifica o decreto no 50.040, referente as normas reguladoras do emprego de aditivos para alimentos. Diário Oficial [da] República Federativa do Brasil, Brasília, DF, 09 abr. 1965. Disponível em: <http://portal.anvisa.gov.br/documents/33916/391619/DECRETO+N\%C2\%BA+55.871\% 2C+DE+26+DE+MAR\%C3\%87O+DE+1965.pdf/59b8704c-52f4-481d-8baaac6edadf6490>. Acesso em: 19 mar. 2016. 
BRASIL. Lei $\mathrm{n}^{\circ}$ 11346, de 15 de setembro de 2006. Cria o sistema nacional de segurança alimentar - Sisan com vistas a assegurar o direito humano à alimentação adequada e dá outras providências. Diário Oficial [da] República Federativa do Brasil, Brasília, DF, 15 set. 2006 Disponível em: <http://www.planalto.gov.br/ccivil_03/_ato20042006/2006/lei/111346.htm> Acesso em: 10 jul. 2016.

BRASIL. Portaria nº 685, de 24 de setembro de 1998. Fixa Limites Máximos de Tolerância de Contaminantes Químicos em Alimentos. Diário Oficial [da] República Federativa do Brasil, Brasília, DF, 27 set. 1998. Disponível em: <http://www.anvisa.gov.br/anvisalegis/portarias/685_98.htm>. Acesso em: 28 set. 2018.

BRASIL. Resolução nº 42, de 29 de agosto de 2013. Dispõe sobre o regulamento técnico Mercosul sobre limites máximos de contaminantes inorgânicos em alimentos. Diário Oficial [da] República Federativa do Brasil, Brasília, DF, 30 ago. 2013. Seção 1. Disponível em: <http://www.agricultura.gov.br/arq_editor/file/CRC/Resolução 42 ANVISA.pdf>. Acesso em: 25 maio 2016.

CEM. Digestion of Animal Tissue (Wet) - MARS6, 2018. Disponível em: <http://cem.com/media/contenttype/media/literature/MetNote_MARS6_Animal_Tissue_W et_.pdf> Acesso em 18 março 2018.

CHU, S. Y. F.; EKSTROM, L. P.; FIRESTONE, R. B. The Lund/LBNL Nuclear Data Search: Table of Radioactive Isotopes. Disponível em <http://nucleardata.nuclear.lu.se/toi/>. Acesso em 19 fev. 2017.

CIENFUEGOS, F.; VAITSMAN, D. Análise Instrumental, 1. ed. Rio de Janeiro: Interciência, 2000.

CLAUZET, M.; RAMIRES, M.; BARRELLA, W. Pesca artesanal e conhecimento local de duas populações caiçaras (Enseada do Mar Virado e Barra do Una) no litoral de São Paulo, Brasil. Multiciência, v. 4, n. 1, p. 1-22, 2005.

CODEX ALIMENTARUS COMMISSION. General standard for contaminants and toxins in food and feed, 2018. Disponível em: <http://www.fao.org/fao-whocodexalimentarius/shproxy/en/?lnk=1\&url=https\%253A\%252F\%252Fworkspace.fao.org\%252Fsites $\% 252 \mathrm{Fcod}$ 
ex\%252FStandards\%252FCODEX\%2BSTAN\%2B193-1995\%252FCXS_193e.pdf> Acesso em: 21 set. 2018.

CORRALES, D.; ACUÑA, A.; SALHI, M.; SAONA, G.; BRUGNOLI, E. Copper, zinc, mercury, and arsenic contente in Micropogonias furnieri and Mugil platanus of the Montevideo coastal zone, Rio de la Plata. Brazilian Journal of Oceanography, v. 64, n. 1, p. 57-65, 2016.

CURRIE, L. A. Detection and quantification limits: origins and historical overview. Analytica Chimica Acta, v. 391, n. 2, p. 127-134, 1999.

DOMINGO, J. L.; BOCIO, A.; FALCÓ, G.; LLOBET, J. M. Benefits and risks of fish consumption: Part I. A quantitative analysis of the intake of omega-3 fatty acids and chemical contaminants. Toxicology, v. 230, n. 2-3, p. 219-226, 2007.

DOMINGO, J. L. Nutrients and chemical pollutants in fish and shellfish. Balancing health benefits and risks of regular fish consumption. Critical Reviews in Food Science and Nutrition, v. 56, n. 6, p. 979-988, 2016.

EFSA, EUROPEAN FOOD SAFETY AUTHORITY. Opinion of the scientific panel on contaminants in the food chain on a request from the European parliament related to the safety assessment of wild and farmed fish. v. 236, p. 1-118, 2005.

EURACHEM e CITAC. Quantifying Uncertainty in Analytical Measurement, 2012. Disponível em:

<https://www.eurachem.org/images/stories/Guides/pdf/QUAM2012_P1.pdf>. Acesso em 15 out. 2018.

EVANGELISTA, J. Alimentos. Um estudo abrangente. São Paulo: Atheneu, 2000.

FABIANO, K. C.; LIMA, A. P S.; VASCONCELLOS; M. B A.., MOREIRA, E. G. Contribution to food safety assurance of fish consumed at São Paulo city by means of trace element determination. Journal of Radioanalytical and Nuclear Chemistry, v. 309, n. 1, p. 383-388, 2016.

FAO, FOOD AND AGRICULTURE ORGANIZATION. Assuring Food Safety and Quality. Roma: FAO, set. 2003. Disponível em < http://www.fao.org/3/a-y8705e.pdf>. Acesso em 19 maio 2016. 
FAO, FOOD AND AGRICULTURE ORGANIZATION. Food security: concepts and measurements. Roma: FAO 2002. Disponível em:

<http://www.fao.org/docrep/005/y4671e/y4671e06.htm>. Acesso em: 13 jul. 2016.

FAO, FOOD AND AGRICULTURE ORGANIZATION. Present and future markets for fish and fish products from small scale fisheries in Latin America. Roma: FAO, 2005.

Disponível em:

<http://www.infopesca.org/sites/default/files/complemento/publilibreacceso/271/art13.pd> Acesso em 21 set 2018.

FAPAS, FOOD ANALYSIS PERFORMANCE ASSESSMENT SCHEME (FAPAS®). Protocol for the organization and analysis of data. Reino Unido: FAPAS, 2002.

Disponível em: <http://sid.gsi.co.jp/csl/fapas/fapas_protocol_6th_ed.pdf> Acesso em 09 jan. 2019.

FARRANT T. Practical statistics for the analytical scientist. A bench guide. Cambridge, UK: LGC, 1997.

FDA, FOOD AND DRUGS ADMISTRATION. Fish and Fishery Products Hazards and Control Guidance, 4 ed. U.S: FDA, 2011. Disponível em:

<https://www.fda.gov/downloads/food/guidanceregulation/ucm251970.pdf> acesso em 26 nov. 2018.

FENG, Y. C.; HUANG, Y C.; MA, X M. The application of Student's t-test in internal quality control of clinical laboratory. Frontiers in Laboratory Medicine, v. 1, n. 3, p. 125 128, 2017.

FONSECA, J. S.; MARTINS, G. A. Curso de estatística, 6. ed. São Paulo: Atlas, 2015.

FROESE, R.; PAULY, D. FishBase, World Wide Web electronic publication. Disponível em: < http://www.fishbase.org/search.php>. Acesso em 15 out. 2018.

FSANZ, FOOD STANDARDS AUSTRALIA NEW ZELAND. Australia and New Zealand Food Standard Code - Schedule 19 - Maximum levels of contaminants and natural toxicants, Australia e Nova Zelândia: FSANZ, 2017. Disponível em: <https://www.legislation.gov.au/Details/F2017C00333 > acesso em 28 set 2018. 
FSANZ, FOOD STANDARDS AUSTRALIA NEW ZELAND. Australia and New Zealand Food Standard Code - Standard 1.4.1 - Contaminants and natural toxicants, Australia e Nova Zelândia: FSANZ, 2016. Disponível em <https://www.legislation.gov.au/Details/F2016C00167>. Acesso em 28 set 2018.

GÖRÜR, F. K.; KESER, R.; AKÇAY, N.; DIZMAN, S Radioactivity and heavy metal concentrations of some commercial fish species consumed in the Black Sea Region of Turkey. Chemosphere, v. 87, n. 4, p. 356-361, 2012.

GREENBERG, R. R.; BODE, P.; FERNANDES, E. A. D. N. Neutron activation analysis: a primary method of measurement. Spectrochimica Acta Part B: Atomic Spectroscopy, v. 66, n. 3-4, p. 193-241, 2011.

GU, Y. G., LIN, Q., WANG, X. H., DU, F. Y., YU, Z. L., HUANG, H. H. Heavy metal concentrations in wild fishes captured from the South China Sea and associated health risks. Marine Pollution Bulletin, v. 96, n. 1-2, p. 508-512, 2015.

HIGSON, S P. J. Química Analítica. 1. ed. São Paulo: McGraw-Hill, 2009.

HORWITZ, W.; ALBERT, R. The Horwitz ratio (HorRat): a useful index of method performance with respect to precision. Journal of AOAC International, v. 89, n. 4, p. 1095-1109, 2006.

IAEA, INTERNATION ATOMIC ENERGY AGENCY. Ensuring seafood safety in Latin America and the Caribbean through a regional programme for the biomonitoring of contaminants in molluscs and fish, Project RLA/5/054 (ARCAL CIII). Technical Cooperation Report for 2012. Viena: IAEA, 2013 Disponível em $<$ https://www.iaea.org/About/Policy/GC/GC57/GC57InfDocuments/English/gc57inf4_en.pdf>. Acesso em 29 set. 2017.

IBAMA, Instituto Brasileiro do Meio Ambiente e Recursos Naturais Renováveis. Plano de gestão para o uso sustentável da sardinha-verdadeira Sardinella brasiliensis no Brasil. Brasilia: IBAMA, 2011. Disponível em:

<https://www.ibama.gov.br/phocadownload/biodiversidade/biodiversidadeaquatica/gestao-pesqueira/publicacoes/2011-livro-plano-gestao-sardinha-verdadeira.pdf> Acesso em 15 out. 2018. 
INMETRO, INSTITUTO NACIONAL DE METROLOGIA, QUALIDADE E TECNOLOGIA. Avaliação de dados de medição - Guia para a expressão de incerteza de medição, 2008. Disponível em:

<http://www.inmetro.gov.br/noticias/conteudo/iso_gum_versao_site.pdf>. Acesso em: 27 mar. 2017.

INMETRO, INSTITUTO NACIONAL DE METROLOGIA, QUALIDADE E TECNOLOGIA. Orientação sobre validação de métodos de ensaios químicos, 2007. Disponível em: <http://www.inmetro.gov.br/Sidoq/Arquivos/CGCRE/DOQ/DOQCGCRE-8_02.pdf>. Acesso em 07 nov. 2018.

INMETRO, INSTITUTO NACIONAL DE METROLOGIA, QUALIDADE E TECNOLOGIA. Orientação sobre validação de métodos analíticos, 2011. Disponível em: <http://www.inmetro.gov.br/Sidoq/Arquivos/Cgcre/DOQ/DOQ-Cgcre-8_04.pdf>. Acesso em 26 nov. 2018.

INMETRO, INSTITUTO NACIONAL DE METROLOGIA, QUALIDADE E TECNOLOGIA. Vocabulário Internacional da Metrologia. Conceitos fundamentais e gerais e termos associados. Rio de Janeiro: INMETRO, 2012. Disponível em: <http://www.inmetro.gov.br/inovacao/publicacoes/vim_2012.pdf>. Acesso em 15 out. 2018.

JIN, S. D.; SEO, S. G.; SHIN, Y. U.; BING, K. C.; KANG, T. H.; PAEK, W. K.; LEE, D. P. Heavy metal accumulations of 4 species of Anseriformes in Korea. Journal of Korean Nature, v. 5, n. 4, p. 345-349, 2012.

LGC. Modas-3 Herring Tissue (M3-HerTis). Disponível em < https://hybris-static-assetsproduction.s3-eu-west-1.amazonaws.com/sysmaster/pdfs/h50/hde/9474346483742/en_ST-WB-CERT-2507849-1-1-1.PDF>. Acesso em 19 mar. 2019.

MAKEDONSKI, L.; PEYCHEVA, K.; STANCHEVA, M. Determination of heavy metals in selected black sea fish species. Food Control, v. 72, p. 313-318, 2017.

MANTOVANI, D. M. B. Contaminantes inorgânicos na cadeia produtiva do pescado. $\boldsymbol{I}$ Simpósio de Controle do Pescado: Qualidade e Sustentabilidade, 17-18 mar. 2005, Santos, SP: Brasil. Disponível em: <http://www.pesca.sp.gov.br/simposio_controle_pescado.pdf>. Acesso em 26 nov. 2018. 
MOREIRA, E. G.; VASCONCELLOS, M. B A.; MAIHARA, V. A.; CATHARINO, M. G. M.; SAIKI, M. Interlaboratory comparison for the characterization of a Brazilian mussel reference material. Journal of Brazilian Chemical Society, v. 29, n. 4, p. 823-830, 2018.

MOREIRA, E., G.; VASCONCELLOS, M. B A, SAIKI, M. Uncertainty assessment in instrumental neutron activation analysis of biological materials. Journal of Radioanalytical and Nuclear Chemistry, v. 269, n. 2, p. 377-382, 2006

MORGANO, M. A.; OLIVEIRA, A. P. F.; RABONATO, L. C.; MILANI, R. F.; VASCONCELlOS, J. P.; MARTINS, C. N.; CITTI, A. L.; TELLES, E. O.; BALIAN, S. C. Avaliação de contaminantes inorgânicos ( $\mathrm{As}, \mathrm{Cd}, \mathrm{Cr}, \mathrm{Hg}$ e $\mathrm{Pb}$ ) em espécies de peixes. Revista do Instituto Adolfo Lutz, v. 70, n. 4, p. 497-506, 2011.

MUNIR, T.; SADDIQUE, M.; REHMAN, H. U.; RAMAZAN, S.; AZEEM, T.; AHMAD, I. Heavy metal analysis in fishes and water of Changhoz dam district Karak, KPK, Pakistan. Journal of Entomology and Zoology Studies, v. 4, n. 2, p. 321-325, 2016.

NEIVA, C. R. P.; TOMITA, R. Y.; CERQUEIRA, M. A. S.; MIURA, M.; FURLAN, E. F.; MACHADO, T. M.; NETO, M. J. L. O mercado do pescado da Região Metropolitana de São Paulo, 2010. Disponível em:

<http://www.infopesca.org/sites/default/files/complemento/publilibreacceso/288/informesan-pablo.pdf>. Acesso em,14 mar. 2017.

NIST, NATIONAL INSTITUTE OF STANDARD AND TECHNOLOGY. Standard Reference Material 1556b. Disponível em :

<https://www-s.nist.gov/srmors/view_cert.cfm?srm=1566B>. Acesso em 19 mar. 2019.

NIST, NATIONAL INSTITUTE OF STANDARD AND TECHNOLOGY. Standard Reference Material 2976. Disponível em:

<https://www-s.nist.gov/srmors/certificates/2976.pdf>. Acesso em 19 mar. 2019.

NORDBERG, G. F.; FOWLER, B. A.; NORBERG, M.; FRIBERG, L. 3. ed. Handbook on the toxicology of metals. USA: Academic Press, 2007.

NRCC, NATIONAL REASEARCH COUNCIL CANADA. Dolt-3 dogfish liver Certified Reference Material for trace metals, 2002. 
NRCC, NATIONAL REASEARCH COUNCIL CANADA. DORM-4: Fish protein certified reference material for trace metals. Disponível em:

$<$ https://www.nrc-cnrc.gc.ca/eng/solutions/advisory/crm/certificates/dorm_4.html>. Acesso em 19 mar. 2019.

PERRY, J. H. Chemical Engineer's Handbook. 2 ed. Nova Iorque: McGraw-Hill Company, 1941.

PERUGINI, M.; VISCIANO, P.; MANERA, M.; ZACCARONI, A.; OLIVEIRI, V.; AMORENA, M. Heavy metal (As, $\mathrm{Cd}, \mathrm{Hg}, \mathrm{Pb}, \mathrm{Cu}, \mathrm{Zn}, \mathrm{Se}$ ) concentrations in muscle and bone of four commercial fish caught in the central Adriatic Sea, Italy. Environmental Monitoring and Assessment, v. 186, n. 4, p. 2205-2213, 2014.

POLES, A. P. S. Desenvolvimento de método analítico para especiação química de mercúrio por HPLC-ICP-MS utilizando microextração em sorvente empacotado (MEPS). 2016. 74p. Dissertação (Mestrado em Toxicologia) Faculdade de Ciências Farmacêuticas de Ribeirão Preto. Disponível em:

<http://www.teses.usp.br/teses/disponiveis/60/60134/tde-17062016-152805/en.php> Acesso em 06 dez. 2018.

PORTAL BRASIL. Consumo do pescado no Brasil aumenta em dois anos, 2013. Disponível em <http://www.brasil.gov.br/economia-e-emprego/2013/10/consumo-depescado-no-brasil-aumenta-23-7-em-dois-anos> Acesso em 17 abril 2016.

RÍOS, S. E. G., RAMÍREZ, C. M., LÓPEZ, B. E., MACÍAS, S. M., LEAL, J., VELÁSQUEZ, C. M. Evaluation of mercury, lead, arsenic, and cadmium in some species of fish in the Atrato River Delta, Gulf of Urabá, Colombian Caribbean. Water, Air, \& Soil Pollution, v. 229, n. 8, p. 275, 2018.

ROCHA, S. Estatística geral e aplicada para cursos de engenharia, 2. ed. São Paulo: Atlas, 2015.SPIEGEL, M. R.; STEPHENS L. J. Estatística, 4. ed. Porto Alegre: Bookman, 2009.

SUBOTIĆ, S.; SPASIĆ, S.; JEFTIĆ, Z. V.; HEGEDIŠ, A.; ĆETKOVIĆM J. K.; MIĆKOVIĆ, B.; SKORIĆ, S.; LENHARDT, M. Heavy metal and trace element bioaccumulation in target tissues of four edible fish species from the Danube River (Serbia). Ecotoxicology and Environmental Safety, v. 98, p. 196-202, 2013. 
TALAMINI, E.; PEDROZO, E. A.; SILVA, A. L. D. Gestão da cadeia de suprimentos e a segurança do alimento: uma pesquisa exploratória na cadeia exportadora de carne suína. Gestão e Produção, v. 12, n. 1, p. 107-120, 2005.

TERRA, B. F.; ARAÚJO, F. G.; CALZA, C. F.; LOPES, R. T.; TEIXEIRA, T. P. Heavy metals in tissues of three fish species from different trophic levels in a tropical Brazilian river. Water, Air, and Soil Pollution, v. 187, n. 1-4, p. 275-284, 2008.

THOMPSON, M. Recent trends in inter-laboratory precision at ppb and sub-ppb concentrations in relation to fitness for purpose criteria in proficiency testing. Analyst, v. 125 , n. 3 , p. $385-386,2000$.

TÜRKMEN, A.; TEPE, Y.; TÜRKMEN, M.; MUTLU, E. Heavy metal contaminants in tissues of the Garfish, Belone belone L., 1761, and the Bluefish, Pomatomus saltatrix L., 1766, from Turkey waters. Bulletin of Environmental Contamination and Toxicology, v. 82, n. 1, p. 70-74, 2009.

WELZ, B.; SPERLING, M. Atomic Absorption Spectrometry. 3. ed. Weinheim: WILEYVCH, 1999.

WOOD, R. How to validate analytical methods Trends in Analytical Chemistry, v. 18, n. 9-10, p. 624-632, 1999.

YI, Y.; TANG, C.; YI, T.; YANG, Z.; ZHANG, S. Health risk assessment of heavy metals in fish and accumulation patterns in food web in the upper Yangtze River, China. Ecotoxicology and Environmental Safety, v. 145, p. 295-302, 2017.

YILDIRIM, Y.; GONULALAN, Z.; NARIN, I.; SOYLAK, M. Evaluation of trace heavy metal levels of some fish species sold at retail in Kayseri, Turkey. Environmental Monitoring and Assessment, v. 149, n. 1-4, p. 223-228, 2009.

ZAHN, G. S.; TICIANELLI, R. B.; LANGE, C. N.; FÁVARO, D. I. T.; FIGUEIREDO, A. M. G. Uncertainty analysis in comparative NAA applied to geological and biological matrices. International Nuclear Atlantic Conference, 4-9 out. 2015, São Paulo, SP: Brasil Disponível em:

<http://repositorio.ipen.br/bitstream/handle/123456789/25171/21161.pdf?sequence=1\&isA llowed=y>. Acesso em 27 nov. 2018. 
ZMOZINSKI, A. V.; MIRANDES, T. L.; DAMIN, I. C. F.; SÁNCHEZ, J. F. L.; VALE, M. G. R.; WELZ, B.; SILVA, M. M. Direct solid sample analysis with graphite furnace atomic absorption spectrometry - A fast and reliable screening procedure for determination of inorganic arsenic in fish and seafood. Talanta. v.134. p.224-231, 2015. 
APÊNDICE A - Informações sobre a amostragem dos pescados

Tabela 34 - Informações sobre o pescado sardinha

\begin{tabular}{ccclc}
\hline Nome popular & Peso total $(\mathrm{g})$ & Tamanho $(\mathrm{cm})$ & Local da pesca & Data de coleta \\
\hline Sardinha 1 & 61 & 18 & Cabo Frio - RJ & $22 / 10 / 2009$ \\
Sardinha 2 & 72 & 18 & Cabo Frio - RJ & $22 / 10 / 2009$ \\
Sardinha 3 & 61 & 17 & Cabo Frio - RJ & $22 / 10 / 2009$ \\
Sardinha 4 & 75 & 19 & Cabo Frio - RJ & $22 / 10 / 2009$ \\
Sardinha 5 & 88 & 19 & Cabo Frio - RJ & $22 / 10 / 2009$ \\
Sardinha 6 & 61 & 17 & Cabo Frio - RJ & $22 / 10 / 2009$ \\
Sardinha 7 & 118 & 19 & Angra dos Reis - RJ & $30 / 10 / 2009$ \\
Sardinha 8 & 108 & 19 & Angra dos Reis - RJ & $30 / 10 / 2009$ \\
Sardinha 9 & 105 & 20 & Angra dos Reis - RJ & $30 / 10 / 2009$ \\
Sardinha 10 & 97 & 18 & Angra dos Reis - RJ & $30 / 10 / 2009$ \\
\hline
\end{tabular}

Fonte: autor da dissertação.

Tabela 35 - Informações sobre o pescado corvina

\begin{tabular}{ccccc}
\hline Nome popular & Peso total $(\mathrm{g})$ & Tamanho $(\mathrm{cm})$ & Local da pesca & Data de coleta \\
\hline Corvina 1 & 761 & 42 & Itajaí-SC & $22 / 10 / 2009$ \\
Corvina 2 & 707 & 41 & Itajaí-SC & $22 / 10 / 2009$ \\
Corvina 3 & 661 & 39 & Itajaí-SC & $22 / 10 / 2009$ \\
Corvina 4 & 871 & 42 & Itajaí-SC & $22 / 10 / 2009$ \\
Corvina 5 & 764 & 40 & Itajaí-SC & $22 / 10 / 2009$ \\
Corvina 6 & 761 & 42 & Itajaí-SC & $22 / 10 / 2009$ \\
Corvina 7 & 1380 & 47 & Itajaí-SC & $30 / 10 / 2009$ \\
Corvina 8 & 1413 & 50 & Itajaí-SC & $30 / 10 / 2009$ \\
Corvina 9 & 1194 & 48 & Itajaí-SC & $30 / 10 / 2009$ \\
Corvina 10 & 1542 & 52 & Itajaí-SC & $30 / 10 / 2009$ \\
\hline
\end{tabular}

Fonte: autor da dissertação.

Tabela 36 - Informações sobre o pescado robalo

\begin{tabular}{ccccc}
\hline Nome popular & Peso total $(\mathrm{g})$ & Tamanho $(\mathrm{cm})$ & Local da pesca & Data de coleta \\
\hline Robalo 1 & 441 & 38 & Natal - RN & $22 / 10 / 2009$ \\
Robalo 2 & 533 & 40 & Natal - RN & $22 / 10 / 2009$ \\
Robalo 3 & 468 & 37 & Natal - RN & $22 / 10 / 2009$ \\
Robalo 4 & 353 & 36 & Natal - RN & $22 / 10 / 2009$ \\
Robalo 5 & 373 & 37 & Natal - RN & $22 / 10 / 2009$ \\
Robalo 6 & 379 & 35 & Natal - RN & $22 / 10 / 2009$ \\
Robalo 7 & 1537 & 48 & São Luiz - MA & $30 / 10 / 2009$ \\
Robalo 8 & 1629 & 66 & São Luiz - MA & $30 / 10 / 2009$ \\
Robalo 9 & 1893 & 61 & São Luiz - MA & $30 / 10 / 2009$ \\
Robalo 10 & 2139 & 65 & São Luiz - MA & $30 / 10 / 2009$ \\
\hline
\end{tabular}

Fonte: autor da dissertação. 
Tabela 37 - Informações sobre o pescado anchova

\begin{tabular}{ccccc}
\hline Nome popular & Peso total $(\mathrm{g})$ & Tamanho $(\mathrm{cm})$ & Local da pesca & Data de coleta \\
\hline Anchova 1 & 977 & 47 & Vitória - ES & $30 / 10 / 2009$ \\
Anchova 2 & 816 & 47 & Vitória - ES & $30 / 10 / 2009$ \\
Anchova 3 & 1021 & 49 & Vitória - ES & $30 / 10 / 2009$ \\
Anchova 4 & 886 & 47 & Vitória - ES & $30 / 10 / 2009$ \\
Anchova 5 & 1206 & 51 & Vitória - ES & $30 / 10 / 2009$ \\
Anchova 6 & 1054 & 49 & Vitória - ES & $30 / 10 / 2009$ \\
Anchova 7 & 1054 & 49 & Vitória - ES & $30 / 10 / 2009$ \\
Anchova 8 & 1018 & 46 & Vitória - ES & $30 / 10 / 2009$ \\
Anchova 9 & 897 & 48 & Vitória - ES & $30 / 10 / 2009$ \\
Anchova 10 & 932 & 48 & Vitória - ES & $30 / 10 / 2009$ \\
\hline
\end{tabular}

Fonte: autor da dissertação.

Tabela 38 - Informações sobre o pescado tainha

\begin{tabular}{ccccc}
\hline Nome popular & Peso total $(\mathrm{g})$ & Tamanho $(\mathrm{cm})$ & Local da pesca & Data de coleta \\
\hline Tainha 1 & 4472 & 73 & Cabo Frio - RJ & $30 / 10 / 2009$ \\
Tainha 2 & 4299 & 75 & Cabo Frio - RJ & $30 / 10 / 2009$ \\
Tainha 3 & 4400 & 72 & Cabo Frio - RJ & $30 / 10 / 2009$ \\
Tainha 4 & 4324 & 78 & Cabo Frio - RJ & $30 / 10 / 2009$ \\
Tainha 5 & 1099 & 50 & Cananéia - SP & $22 / 10 / 2009$ \\
Tainha 6 & 890 & 47 & Cananéia - SP & $22 / 10 / 2009$ \\
Tainha 7 & 938 & 45 & Cananéia - SP & $22 / 10 / 2009$ \\
Tainha 8 & 928 & 47 & Cananéia - SP & $22 / 10 / 2009$ \\
Tainha 9 & 937 & 51 & Cananéia - SP & $22 / 10 / 2009$ \\
Tainha 10 & 918 & 49 & Cananéia - SP & $22 / 10 / 2009$ \\
\hline
\end{tabular}

Fonte: autor da dissertação. 
APÊNDICE B - Teores de umidade das amostras e MRC.

Tabela 39 - Determinação do teor de umidade residual da tainha

\begin{tabular}{ccccc}
\hline Massa úmida $(\mathrm{g})$ & Massa seca $(\mathrm{g})$ & Umidade $(\%)$ & Balança & Amostra \\
\hline 0,61659 & 0,57767 & 6,31 & AUW220D & tainha-1 \\
0,44542 & 0,40922 & 8,13 & AUW220D & tainha-2 \\
0,67575 & 0,63193 & 6,48 & AUW220D & tainha-3 \\
0,58515 & 0,54371 & 7,08 & AUW220D & tainha-4 \\
0,47537 & 0,43353 & 8,80 & AUW220D & tainha-5 \\
0,48673 & 0,43196 & 11,25 & AUW220D & tainha-6 \\
0,66249 & 0,61485 & 7,19 & AUW220D & tainha-7 \\
0,74543 & 0,69709 & 6,48 & AUW220D & tainha-8 \\
0,50972 & 0,47751 & 6,32 & AEL-40SM & tainha-9 \\
0,38324 & 0,35043 & 8,56 & AUW220D & tainha-10 \\
\hline
\end{tabular}

Fonte: autor da dissertação.

Tabela 40 - Determinação do teor de umidade residual do robalo

\begin{tabular}{ccccc}
\hline Massa úmida $(\mathrm{g})$ & Massa seca $(\mathrm{g})$ & Umidade $(\%)$ & Balança & Amostra \\
\hline 0,52349 & 0,46937 & 10,34 & AUW220D & robalo-1 \\
0,4901 & 0,45365 & 7,44 & AUW220D & robalo-2 \\
0,57464 & 0,53373 & 7,12 & AUW220D & robalo-3 \\
0,65900 & 0,55635 & 15,58 & AUW220D & robalo-4 \\
0,58283 & 0,53931 & 7,47 & AUW220D & robalo-5 \\
0,64799 & 0,59791 & 7,73 & AUW220D & robalo-6 \\
0,85508 & 0,78914 & 7,71 & AUW220D & robalo-7 \\
0,62181 & 0,57545 & 7,46 & AUW220D & robalo-8 \\
0,70822 & 0,66244 & 6,46 & AUW220D & robalo-9 \\
0,74058 & 0,70856 & 4,32 & AUW220D & robalo-10 \\
\hline
\end{tabular}

Fonte: autor da dissertação.

Tabela 41 - Determinação do teor de umidade da anchova

\begin{tabular}{ccccc}
\hline Massa úmida $(\mathrm{g})$ & Massa seca $(\mathrm{g})$ & Umidade $(\%)$ & Balança & Amostra \\
\hline 0,74826 & 0,69511 & 7,10 & AUW220D & anchova-1 \\
0,64259 & 0,59468 & 7,46 & AUW220D & anchova-2 \\
0,56623 & 0,53088 & 6,24 & AUW220D & anchova-3 \\
0,55403 & 0,51844 & 6,42 & AUW220D & anchova-4 \\
0,61048 & 0,57043 & 6,56 & AUW220D & anchova-5 \\
0,57795 & 0,53924 & 6,70 & AUW220D & anchova-6 \\
0,64676 & 0,60348 & 6,69 & AUW220D & anchova-7 \\
0,46494 & 0,43268 & 6,94 & AUW220D & anchova-8 \\
0,56092 & 0,52572 & 6,28 & AUW220D & anchova-9 \\
0,44314 & 0,41100 & 7,25 & AUW220D & anchova-10 \\
\hline
\end{tabular}

Fonte: autor da dissertação. 
Tabela 42 - Determinação do teor de umidade da pescada-branca

\begin{tabular}{ccccc}
\hline Massa úmida $(\mathrm{g})$ & Massa seca $(\mathrm{g})$ & Umidade $(\%)$ & Balança & Amostra \\
\hline 0,46793 & 0,42628 & 8,90 & AUW220D & pescada-1 \\
0,58534 & 0,53105 & 9,27 & AUW220D & pescada-2 \\
0,53656 & 0,48132 & 10,30 & AUW220D & pescada-3 \\
0,63367 & 0,56992 & 10,06 & AUW220D & pescada-4 \\
0,57503 & 0,52717 & 8,32 & AUW220D & pescada-5 \\
0,56648 & 0,51685 & 8,76 & AUW220D & pescada-6 \\
0,64964 & 0,59204 & 8,87 & AUW220D & pescada-7 \\
0,41139 & 0,37563 & 8,69 & AUW220D & pescada-8 \\
0,51079 & 0,45846 & 10,24 & AUW220D & pescada-9 \\
0,65496 & 0,59879 & 8,58 & AUW220D & pescada-10 \\
\hline
\end{tabular}

Fonte: autor da dissertação.

Tabela 43 - Determinação do teor de umidade da sardinha

\begin{tabular}{ccccc}
\hline Massa úmida $(\mathrm{g})$ & Massa seca $(\mathrm{g})$ & Umidade $(\%)$ & Balança & Amostra \\
\hline- & - & $10,28^{*}$ & AUW220D & sardinha-1 \\
0,52856 & 0,47332 & 10,45 & AUW220D & sardinha-2 \\
0,52548 & 0,46741 & 11,05 & AUW220D & sardinha-3 \\
0,52471 & 0,46240 & 11,88 & AUW220D & sardinha-4 \\
0,61353 & 0,55126 & 10,15 & AUW220D & sardinha-5 \\
0,46105 & 0,41054 & 10,96 & AUW220D & sardinha-6 \\
0,65475 & 0,58846 & 10,12 & AUW220D & sardinha-7 \\
0,82502 & 0,74710 & 9,44 & AUW220D & sardinha-8 \\
0,68956 & 0,62495 & 9,37 & AUW220D & sardinha-9 \\
0,90005 & 0,8178 & 9,14 & AUW220D & sardinha-10 \\
\hline
\end{tabular}

Fonte: autor da dissertação. "utilizado a média das outras sardinhas como teor de umidade. Medida tomada pela pequena massa de amostra disponível e levando-se em consideração que haviam outras análises a serem feitas (INAA/AAS).

Tabela 44 - Determinação do teor de umidade da corvina

\begin{tabular}{ccccc}
\hline Massa úmida $(\mathrm{g})$ & Massa seca $(\mathrm{g})$ & Umidade $(\%)$ & Balança & Amostra \\
\hline 0,69266 & 0,65609 & 5,28 & AUW220D & corvina-1 \\
0,54221 & 0,50366 & 7,11 & AUW220D & corvina-2 \\
0,62321 & 0,58004 & 6,93 & AUW220D & corvina-3 \\
0,69188 & 0,64175 & 7,25 & AUW220D & corvina-4 \\
0,57595 & 0,53637 & 6,87 & AUW220D & corvina-5 \\
0,85928 & 0,80684 & 6,10 & AUW220D & corvina-6 \\
0,62819 & 0,58506 & 6,87 & AUW220D & corvina-7 \\
0,50174 & 0,46926 & 6,47 & AUW220D & corvina-8 \\
0,61273 & 0,56433 & 7,90 & AUW220D & corvina-9 \\
0,6148 & 0,57671 & 6,20 & AUW220D & corvina-10 \\
\hline
\end{tabular}

Fonte: autor da dissertação. 
Tabela 45 - Determinação do teor de umidade dos MRC

\begin{tabular}{ccccc}
\hline Massa úmida $(\mathrm{g})$ & Massa seca $(\mathrm{g})$ & Umidade $(\%)$ & Balança & MRC \\
\hline 0,60304 & 0,50794 & 15,77 & AUW220D & NRCC DOLT-3 \\
0,54475 & 0,48977 & 10,09 & AUW220D & NRCC Dorm-4 \\
0,50508 & 0,47048 & 6,85 & AUW220D & MRC MODAS-3 \\
0,62414 & 0,58701 & 5,95 & AUW220D & MRC M. Furnieri \\
0,51637 & 0,46993 & 8,99 & AUW220D & NIST SRM 2976 \\
\hline
\end{tabular}

Fonte: autor da dissertação. 
INSTITUTO DE PESQUISAS ENERGÉTICAS E NUCLEARES

Diretoria de Pesquisa, Desenvolvimento e Ensino

Av. Prof. Lineu Prestes, 2242 - Cidade Universitária CEP: 05508-000

Fone/Fax(0XX11) 3133-8908

SÃO PAULO - São Paulo - Brasil

http://www.ipen.br

O IPEN é uma Autaquia vinculada à Secretaria de Desenvolvimento, associada à Universiade de São Paulo e gerida técnica e administrativamente pela Comissão Nacional de Energia Nuclear, órgão do Ministério da Ciência, Tecnologia e Inovação. 